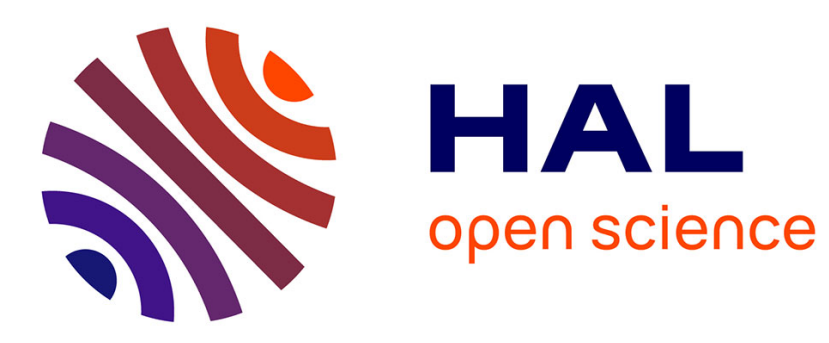

\title{
Comet 67P/CG Nucleus Composition and Comparison to Other Comets
}

\author{
Gianrico Filacchione, Olivier Groussin, Clémence Herny, David Kappel, \\ Stefano Mottola, Nilda Oklay, Antoine Pommerol, Ian Wright, Zurine Yoldi, \\ Mauro Ciarniello, et al.
}

\section{To cite this version:}

Gianrico Filacchione, Olivier Groussin, Clémence Herny, David Kappel, Stefano Mottola, et al.. Comet 67P/CG Nucleus Composition and Comparison to Other Comets. Space Science Reviews, 2019, 215 (1), 10.1007/s11214-019-0580-3 . hal-02496584

\section{HAL Id: hal-02496584 https://hal.science/hal-02496584}

Submitted on 3 Mar 2020

HAL is a multi-disciplinary open access archive for the deposit and dissemination of scientific research documents, whether they are published or not. The documents may come from teaching and research institutions in France or abroad, or from public or private research centers.
L'archive ouverte pluridisciplinaire HAL, est destinée au dépôt et à la diffusion de documents scientifiques de niveau recherche, publiés ou non, émanant des établissements d'enseignement et de recherche français ou étrangers, des laboratoires publics ou privés. 
my journal manuscript No.

(will be inserted by the editor)

\title{
Comet 67P/CG nucleus composition and comparison to other comets
}

\author{
Gianrico Filacchione, Olivier Groussin, \\ Clémence Herny, David Kappel, Stefano \\ Mottola, Nilda Oklay, Antoine Pommerol, \\ Ian Wright, Zurine Yoldi, Mauro \\ Ciarniello, Lyuba Moroz, Andrea Raponi
}

Received: date / Accepted: date

\author{
Abstract We review our current knowledge of comet $67 \mathrm{P} /$ Churyumov-Gerasimenko \\ nucleus composition as inferred from measurements made by remote sensing \\ and in-situ instruments aboard Rosetta orbiter and Philae lander. Spectropho- \\ tometric properties (albedos, color indexes and Hapke parameters) of $67 \mathrm{P} / \mathrm{CG}$ \\ derived by Rosetta are discussed in the context of other comets previously ex- \\ plored by space missions. Composed of an assemblage made of ices, organic \\ materials and minerals, cometary nuclei exhibit very dark and red surfaces \\ which can be described by means of spectrophotometric quantities and re- \\ produced with laboratory measurements. The presence of surface water and \\ carbon dioxide ices was found by Rosetta to occur at localized sites where \\ the the activity driven by solar input, gaseous condensation or exposure of \\ G. Filacchione \\ INAF-IAPS, Institute for Space Astrophysics and Planetology, via del Fosso del Cavaliere, \\ 100, 00133 Rome - IT \\ Tel.: +39-06-45488454 \\ E-mail: gianrico.filacchione@iaps.inaf.it \\ O. Groussin \\ Aix Marseille Université, CNRS, LAM Laboratoire d'Astrophysique de Marseille \\ C. Herny, A. Pommerol, Z. Yoldi \\ Physikalisches Institut, University of Bern, Bern, Switzerland \\ D. Kappel, S. Mottola, N. Oklay \\ German Aerospace Center (DLR), Institute of Planetary Research, Berlin, Germany \\ L. Moroz \\ Institute of Earth and Environmental Sciences, University of Potsdam, Potsdam, Germany; \\ German Aerospace Center (DLR), Institute of Planetary Research, Berlin, Germany \\ I. Wright \\ Department of Physical Sciences, The Open University, Walton Hall, Milton Keynes, UK \\ M. Ciarniello, A. Raponi \\ INAF-IAPS, Institute for Space Astrophysics and Planetology, via del Fosso del Cavaliere, \\ 100, 00133 Rome - IT
}


pristine inner layers can maintain these species on the surface. Apart from these specific areas, 67P/CG's surface appears remarkably uniform in composition with a predominance of organic materials and minerals. The organic compounds contain abundant hydroxyl group and a refractory macromolecular material bearing aliphatic and aromatic hydrocarbons. The mineral components are compatible with a mixture of silicates and fine-grained opaques, including Fe-sulfides, like troilite and pyrrhotite, and ammoniated salts. In the vicinity of the perihelion several active phenomena, including the erosion of surface layers, the localized activity in cliffs, fractures and pits, the collapse of overhangs and walls, the transfer and redeposition of dust, cause the evolution of the different regions of the nucleus by inducing color, composition and texture changes.

Keywords Comets · Composition · Ices · Organic Matter · Minerals

\section{Introduction}

At the dawn of our solar system, $\approx 4.5$ billion years ago, in the cold outer regions of the solar nebula, the first anhydrous dust grains started to aggregate with volatile ices and organics. Driven by accretion, these grains formed comets and planetesimals (Skorov and Blum 2012), the building blocks of the solid bodies of our solar system. Although processed by impacts, comets have not experienced a significant heating and alteration of their solid materials (de Niem et al. 2018). Differently from asteroids and larger bodies, on comets the imprint of pre-solar materials has been preserved (Mumma and Charnley 2011). The study of cometary nuclei is therefore the one of the best way to assess the synthesis of volatiles and organic materials. There is convincing evidence that comets played a key role in the evolution of the planets, because cometary impacts are known to have been much more common in the early solar system than today (Gomes et al. 2005). Comet flux is supposed to be one of the major sources of the water present in Earth's oceans and to have provided the organic material necessary for the life evolution on Earth (Delsemme 1984; Mayo Greenberg and Mendoza-Gómez 1992). So far, before Rosetta only few cometary missions were able to reach the proximity of comets and to infer locally their composition: Giotto at comet 1P/Halley (Reinhard 1982), Stardust at $81 \mathrm{P} /$ Wild 2 (Brownlee et al. 2003), Deep Space 1 at 19P/Borrelly (Nelson et al. 2004), Deep Impact at 9P/Tempel 1 and then EPOXI at 103P/Hartley 2 (A'Hearn et al. 2005a).

In this review we mainly focus on summarizing the current knowledge of the 67P/Churyumov-Gerasimenko (hereafter 67P/CG) nucleus composition which was one the major scientific objectives of ESA's Rosetta mission (Glassmeier et al. 2007) in the context of the results returned by previous space missions at others comets.

By orbiting around comet 67P/CG from August 2014 to September 2016, the Rosetta mission has provided unprecedented spatial, spectral and temporal 
coverage of the changes occurring on a cometary surface and surrounding inner coma before, during and after perihelion passage (Taylor et al. 2017). The remote sensing instruments aboard the orbiter have returned a comprehensive dataset about the nucleus composition while the in-situ payloads have analyzed the gas and dust environment in the surrounding coma. This wealth of information allows to constrain the nucleus composition from different prospectives: OSIRIS, the Optical, Spectroscopic, and Infrared Remote Imaging System (Keller et al. 2007) Wide and Narrow Angle Cameras have imaged the comet's nucleus through different UV, visible and near infrared color filters aiming to determine its volume, shape, bulk density, surface properties, morphology and activity. Three spectrometers operating at different wavelengths, ALICE, the Ultraviolet Imaging Spectrometer (Stern et al. 2007), VIRTIS, the Visible, InfraRed and Thermal Imaging Spectrometer (Coradini et al. 2007) and MIRO, the Microwave Instrument for the Rosetta Orbiter (Gulkis et al. 2007) have mapped the composition and temperature of the nucleus, analyzed the gases in the near-nucleus region, measured and monitored the comet's production rates of water, carbon dioxide and other gaseous species. Additional clues are given by the composition instruments aboard the Philae lander (Bibring et al. 2007) which were designed to infer elemental, isotopic, molecular and mineralogical composition. Unfortunately, due to the non-nominal landing of Philae, only gas chromatography and time-of-flight mass-spectrometry by COSAC (Goesmann et al. 2007) and PTOLEMY (Wright et al. 2007) have provided useful data on those fields. The coma environment, including dust particles and gaseous species, has been analyzed by the in-situ and remote sensing instruments aboard Rosetta. These species are naturally linked to the composition of the surface and subsurface layers from which they are released by active processes. A review of the compositional properties of cometary nuclei, and in particular for $67 \mathrm{P} / \mathrm{CG}$, as inferred from remote sensing and surface instruments, is given in Section 2. The surface composition appears dominated by three endmembers groups, including volatile species condensed as ices, organic material and minerals (Section 3). Moving along the orbit of the comet around the Sun, the surface composition of $67 \mathrm{P} / \mathrm{CG}$ shows temporal changes caused by diurnal and seasonal effects which are discussed in Section

4. Conclusions are discussed in Section 5.

\section{Comets nuclei properties}

\subsection{VIS-IR albedo and photometry}

Cometary nuclei are characterized by very low geometric albedo $\left(A_{\text {geo }}\right)$ at visible wavelengths: average value of $A_{\text {geo }}=0.04$ was measured on $1 \mathrm{P} /$ Halley (Keller 1987), 81P/Wild 2 (Brownlee et al. 2003) and 9P/Tempel 1 (A'Hearn et al. 2005b). At $A_{g e o}=0.03$ (Soderblom et al. 2002; Buratti et al. 2004) the surface of 19P/Borrelly appears darker while 103P/Hartley 2 at $A_{\text {geo }}=0.046(\mathrm{Li}$ et al. 2013) is a little more brighter. On 67P/CG both OSIRIS (Fornasier et al. 
2015) and VIRTIS (Ciarniello et al. 2015) have measured a geometric albedo of $A_{g e o}=0.06$ making this comet the brightest among the ones explored so far by spacecraft. Photometrically-corrected images and maps of the nucleus are shown in Fig. 1 where the illumination and viewing effects have been removed to better study the surface's physical properties and composition. VIRTIS measurements of the surface show a significant phase reddening (the surface becomes redder when the solar phase increases) at both VIS $(0.44 \% / \mathrm{deg})$ and IR $(0.73 \% / \mathrm{deg})$ wavelengths (Ciarniello et al. 2015). A similar reddening effect $(0.95 \% / \mathrm{deg})$ has been reported by OSIRIS on visible images (Fornasier et al. 2015). Once the phase-dependence has been corrected, the surface spectral slope can be determined: VIRTIS has measured a spectral slope of $0.20 / \mathrm{k} \AA$ between $0.55-0.8 \mu \mathrm{m}$ and $0.033 / \mathrm{k} \AA$ between $1-2 \mu \mathrm{m}$. The surface albedo increases in presence of water ice. In fact, the active areas in the Hapi and Seth regions appear brighter on both photometric-corrected OSIRIS images (Fornasier et al. 2015) and on VIRTIS albedo map (Filacchione et al. 2016b) shown in Figure 1. These results were obtained during the inbound orbit at heliocentric distance of about 3.6 AU.

For this low-albedo surface where multiple scattering has a small contribution relative to single-scattering, the phase reddening is interpreted to be caused by a wavelength-dependent single-scattering phase function that might be related to the roughness of the regolith particle surfaces (Schröder et al. 2014; Ciarniello et al. 2015). A summary of the Hapke model (Hapke 1993) photometric parameters of $67 \mathrm{P} / \mathrm{CG}$ compared with others comets is given in Table 1. Following Longobardo et al. (2017), the Phase Curve Slope (PCS) and the $\mathrm{I} / \mathrm{F}$ at $0.75 \mu \mathrm{m}$ retrieved at $30^{\circ}$ phase angle (R30) parameters are given in Table 2 for $67 \mathrm{P} / \mathrm{CG}$ and compared with values for other comets in Table 3.

Reddening in the visible is characterizing $67 \mathrm{P} / \mathrm{CG}$ surface also at local scales and in many studies the color changes have been correlated with surface composition inhomogeneities and activity sources. Local water ice enrichments show higher albedo and a flat to blue spectral response in contrast to the more dark and red reflectance of the anhydrous terrains. Following these properties, water ice-rich areas have been recognized and studied on OSIRIS images by mapping the albedo and the bluening of the VIS slope (Oklay et al. 2016b) or by using multivariate analysis methods (Perna et al. 2017). By adopting this method the spatial inhomogeneities and temporal variations occurring on very different landforms of the nucleus have been traced, including: the grained deposits and outcrops of more consolidated materials on cuestas and steep walls in the Agilkia landing site (La Forgia et al. 2015); the water ice patches in the Khonsu (Deshapriya et al. 2016) and Anhur-Bes regions (Fornasier et al. 2016) in the south hemisphere; the fresh icy material visible on the exposed wall formed after the collapse of the Aswan cliff (Pajola et al. 2017), on Abydos (Lucchetti et al. 2016) and on the circular niches located in the Seth region (Lucchetti et al. 2017); the large water ice-rich clusters (BAP1 and BAP2 in Filacchione et al. (2016a)) and isolated water ice features on Imhotep (Oklay et al. 2017), Hapi and its surrounding (Oklay et al. 2016b). 
During few dedicated Rosetta's flybys designed to fly on the nucleus at low phase angles it has been possible to observe the opposition surge while swiping across the Imhotep region of 67P/CG (Hasselmann et al. 2017). A broad nonlinear phase curve has been measured at low phases resulting in the lack of a sharp opposition peak which is typically associated with the coherentbackscattering mechanism. A similar photometric behavior can be caused by the low albedo of the surface which is dominated by opaque, dehydrated and larger-than-wavelength irregular grains. The similarity between the $67 \mathrm{P} / \mathrm{CG}$ surface phase function with carbon soot samples observed at extremely small angles has been recognized by Masoumzadeh et al. (2017) who reported that the areas placed on the boundary of the Imhotep-Ash regions are made by a very dark and fluffy layer.
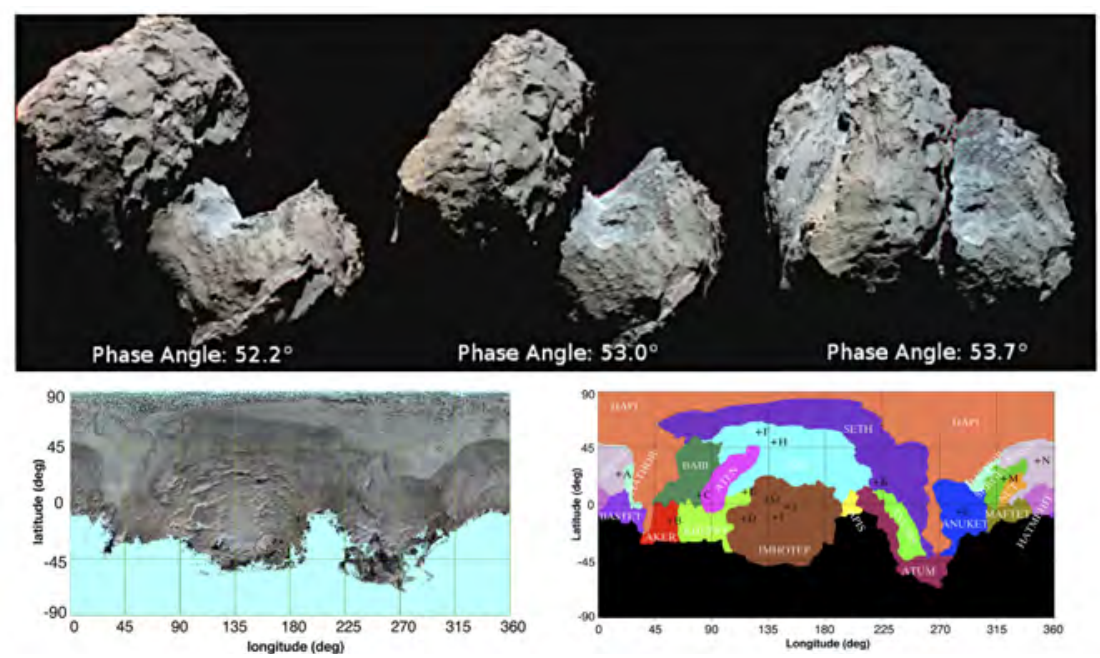

Fig. 1 Photometrically corrected albedo images of $67 \mathrm{P} / \mathrm{CG}$ 's nucleus from AugustSeptember 2014 observations. Top panel: OSIRIS color images (filters B: 480 nm, G: 649 $\mathrm{nm}, \mathrm{R}: 882 \mathrm{~nm}$ ). Spatial resolution is about $2.5 \mathrm{~m} / \mathrm{px}$. From Fornasier et al. (2015). Bottom left panel: cylindrical map of single scattering albedo by VIRTIS (channels B: $440 \mathrm{~nm}, \mathrm{G}$ : $550 \mathrm{~nm}, \mathrm{R}$ : $700 \mathrm{~nm}$ ). Spatial resolution is about $15 \mathrm{~m} /$ bin. From Filacchione et al. (2016c). Bottom right panel: boundaries of $67 \mathrm{P} / \mathrm{CG}$ 's nineteen geomorphological regions in cylindrical projection. From El-Maarry et al. (2015), Thomas et al. (2015). Missing data (light blue bottom left and black bottom right panels) represents the un-illuminated southern hemisphere at the given epochs.

\subsection{VIS-IR spectroscopy from remote sensing}

During Rosetta's initial observations taken during the pre-perihelion period, 67P/CG surface composition appeared quite homogeneous across the different regions illuminated by the Sun. A notable feature of the majority of the spectra is the absence of water-ice absorption bands (at 1.5, $2.0 \mu \mathrm{m}$ ). This indicates 


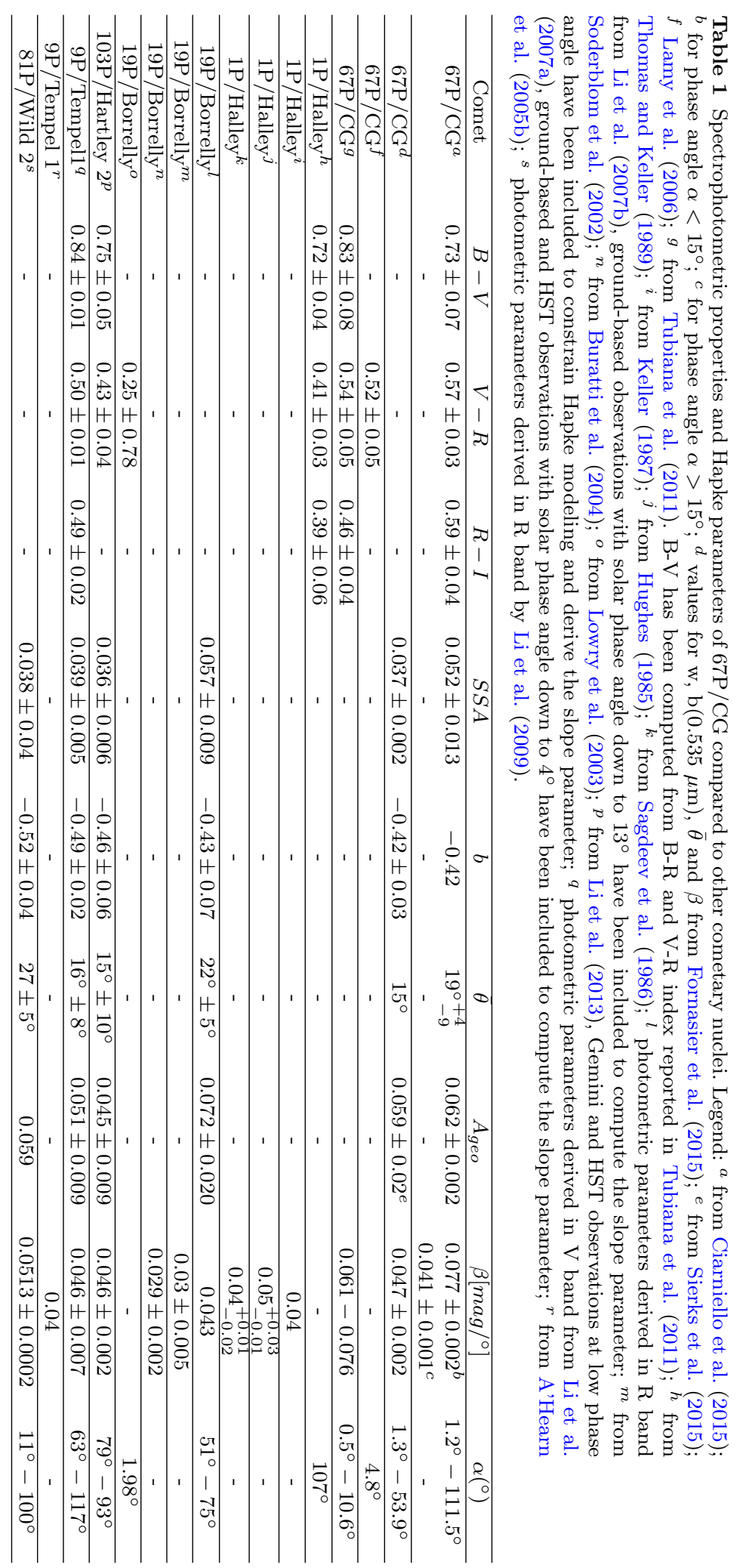


Table 2 Spectrophotometric parameters of $67 \mathrm{P} / \mathrm{CG}$ at visible and near infrared wavelengths. The Phase Curve Slope (PCS) is defined as 1-R60/R20, where R60 and R20 are the reflectances $(\mathrm{I} / \mathrm{F})$ at $60^{\circ}$ and $20^{\circ}$ phase angles, respectively. The R30 (I/F at phase $30^{\circ}$ ) error is 0.001 up to $1.2 \mu \mathrm{m}$ and 0.002 from $1.7 \mu \mathrm{m}$. An absolute error of $5 \%$ is affecting the PCS data. From Longobardo et al. (2017).

\begin{tabular}{cccccccc}
\hline$\lambda(\mu \mathrm{m})$ & 0.55 & 0.75 & 1.2 & 1.7 & 2.0 & 2.8 & 4.0 \\
\hline R30 & 0.013 & 0.017 & 0.031 & 0.035 & 0.036 & 0.041 & 0.041 \\
PCS & 0.61 & 0.60 & 0.61 & 0.60 & 0.60 & 0.57 & 0.55 \\
\hline
\end{tabular}

Table 3 Spectrophotometric parameters R30 and PCS for 67P/CG compared to other comets.

\begin{tabular}{ccccc}
\hline Comet & $\lambda(\mu \mathrm{m})$ & R30 & PCS & Reference \\
\hline 19P/Borrelly & 0.66 & 0.018 & 0.65 & Li et al. (2007b) \\
103P/Hartley 2 & 0.62 & 0.013 & 0.67 & Li et al. (2013) \\
9P/Tempel 1 & 0.67 & 0.015 & 0.71 & Li et al. (2007a) \\
81P/Wild 2 & 0.7 & 0.014 & 0.78 & Li et al. (2009) \\
67P/CG & 0.75 & 0.017 & 0.60 & Longobardo et al. (2017) \\
\hline
\end{tabular}

that water ice-rich patches are absent across the nucleus surface, at a scale larger than $\approx 10 \mathrm{~m}$ with an upper limit on the water-ice abundance of $\approx 1 \%$ (Capaccioni et al. 2015). Moreover, reflectance spectra acquired on different regions of the surface (Fig. 2, top panel) show very low visible albedo, equal to 0.06 at $0.55 \mu \mathrm{m}$ (Fornasier et al. 2015; Ciarniello et al. 2015), a steep red color at visible wavelengths with a slope change around $1.0 \mu \mathrm{m}$ and continuing more gently up to $2.7 \mu \mathrm{m}$ Filacchione et al. (2016c), a broad absorption band in the range between 2.9 to $3.6 \mu \mathrm{m}$ encompassing smaller structures compatible with aromatic and aliphatic signatures (Fig. 2, bottom panel), a wide thermal emission starting from 3.5 to $5.0 \mu \mathrm{m}$. After modelling the thermal emission on the radiance data (add reference to Groussin chapter), a surface temperature in the range between 180 and $230 \mathrm{~K}$ during daytime (August-September 2014, heliocentric distance 3.6 AU, inbound orbit) is derived (Capaccioni et al. 2015).

After having derived and applied a photometric correction (Ciarniello et al. 2015), surface properties have been studied by means of Cometary Spectral Indicators (CSI) suitable to trace color and compositional units across the nucleus (Filacchione et al. 2016c). The more active areas in Hapi, appear brighter and bluer on maps of both $0.5-0.8 \mu \mathrm{m}$ visible and $1.0-2.5 \mu \mathrm{m}$ infrared spectral slopes than the rest of the surface (Fig. 3, top row panels).

The wide $3.2 \mu \mathrm{m}$ absorption band observed by VIRTIS is compatible with a broad class of organic materials, detailed later in Section 3. In presence of water ice, the short-wavelength-wing of the band is affected by the strong fundamental symmetric and anti-symmetric stretching modes which causes a broadening of the band and a spectral shift towards shorter wavelengths. Thermal emission influences the long-wavelength-wing of the band with a contribution increasing with the surface temperature and emissivity. The $3.2 \mu \mathrm{m}$ 

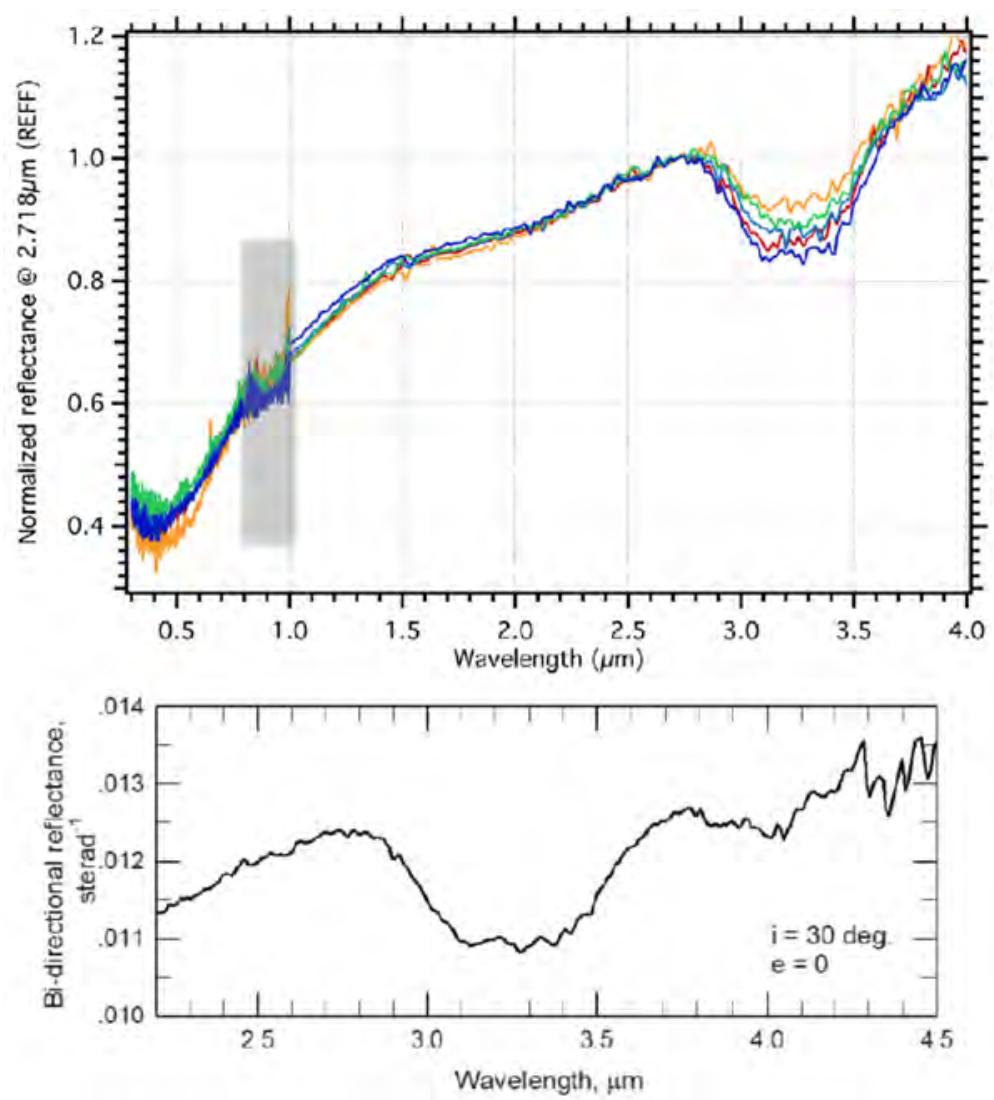

Fig. 2 Top panel: Average visible and infrared reflectance spectra of $67 \mathrm{P} / \mathrm{CG}$ from VIRTIS taken from different macroregions. Gray box indicates calibration residuals. Bottom panel: Bidirectional reflectance of the average dark terrain in the 2.2-4.5 $\mu \mathrm{m}$ spectral range. Within the wide $3.2 \mu \mathrm{m}$ band are visible fainter bands associated to aromatic and aliphatic organic materials discussed in Section 3. Features at $4.4 \mu \mathrm{m}$ are calibration artifacts. Thermal emission is removed from reflectance data. From Ciarniello et al. (2015); Quirico et al. (2016).

absorption band appears ubiquitous across the entire 67P/CG surface (Capaccioni et al. 2015) and has been extensively mapped during the pre-perihelion 

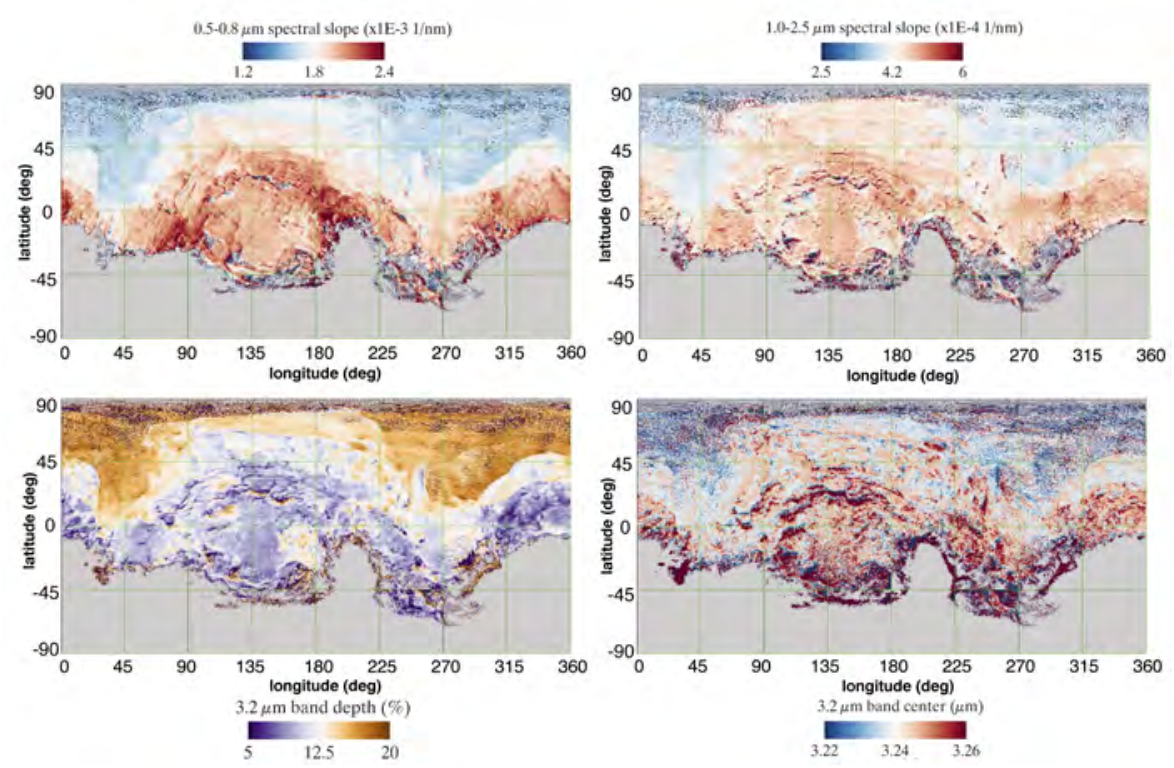

Fig. 3 Cometary Spectral Indicators for the north and equatorial regions of $67 \mathrm{P} / \mathrm{CG}$ surface measured by VIRTIS in August-September 2014. Top left panel: 0.5-0.8 $\mu \mathrm{m}$ visible spectral slope. Top right: 1.0-2.5 $\mu \mathrm{m}$ infrared spectral slope. Bottom left: $3.2 \mu \mathrm{m}$ band depth. Bottom right: $3.2 \mu \mathrm{m}$ band center. Adapted from Filacchione et al. (2016c).

phases (Filacchione et al. 2016c; Ciarniello et al. 2016). As shown in Fig. 3bottom left panel, the band is deeper in the Hapi region and some parts of Imhotep (see Fig. 1 for the locations of these named regions). These areas correspond to surface regions that have been shown to exhibit water ice, i.e. in Imhotep the bright area patches (Filacchione et al. 2016a) and roundish features (Auger et al. 2015), or that have been inferred from the deeper band to contain water ice (de Sanctis et al. 2015). The presence of water ice on these areas is confirmed by the corresponding shift of the band center towards shorter wavelengths (Fig. 3-bottom right map).

\subsection{Surface composition from Philae}

One of the major achievements of the Rosetta mission has been the first landing on a cometary nucleus performed by the Philae lander. The landing occurred on 12th November 2014 when $67 \mathrm{P} / \mathrm{CG}$ was at heliocentric distance of 2.99 AU. While the descent of the lander was nominal allowing to reach the planned touchdown site (called Agilkia), the successive part of the mission has not followed the planned schedule (Biele et al. 2015). This was caused by the failure of the cold gas thruster and harpoon systems necessary to anchor the lander on the nucleus' surface. Images returned by the lander's camera ROLIS have shown that the Agilkia site is characterized by grains and blocks 
with size distribution ranging between centimeters to 5 meters (Mottola et al. 2015). The presence of aeolian-like features, similar to wind-tails, suggests the mobilization of the regolith grains and erosion of the surface. The analysis of Agilkia data indicates a soft granular surface, with a compressive strength estimated of the order of $1 \mathrm{kPa}$, with a thickness of the order of $20 \mathrm{~cm}$ displaced above a more rigid layer (Biele et al. 2015). The failure of Philae's landing subsystem has caused three successive rebounds of the lander which finally stopped on the rim of the large Hatmehit depression. The final landing site, called Abydos, shows an exposed and hard surface (Biele et al. 2015) with the presence of fractured boulders, elongated cliffs and terrain composed by a texture of small agglomerates of dark granular material and bright (up to $10 \%$ reflectance) pebbles of larger dimensions (Bibring et al. 2015). A review of the major results based on measurements recorded by Philae is given in Boehnhardt et al. (2017). Here we focus on the measurements performed by the two gas analyzers on board the lander. COSAC, the Cometary Sampling and Composition experiment (Goesmann et al. 2007) and PTOLEMY, the gas chromatograph and mass spectrometer (Wright et al. 2007), have both operated during the landing phases according to the nominal schedule and therefore their results must be interpreted considering the real lander's trajectory and timing. COSAC has detected the presence of 16 organic compounds, including nitrogen-bearing species but no sulfur-bearing molecules. Among the organic materials, a total of four compounds (methyl isocyanate, acetone, propionaldehyde, and acetamide) never reported on other comets, have been identified (Goesmann et al. 2015). However, isocyanomethane, 2-hydroxyethanal, and propanal could not be confirmed on ROSINA data (Altwegg et al. 2017). A list of compounds observed by COSAC and their possible formation pathways are shown in Fig. 4.

PTOLEMY has reported a wealth of additional information about the nucleus composition (Wright et al. 2015), including: the presence of compounds with $-\mathrm{CH}_{2}$ - and -O- groups having a mass/charge ratios equal to 14 and 16 , respectively; the possible presence of polyoxymethylene chains, a radiationformed polymer, which, however, has not been confirmed by ROSINA (Altwegg et al. 2017); the depletion of aromatic compounds (like benzene) and of sulfurbearing species; the aromatic molecule toluene found in both PTOLEMY and ROSINA-DFMS spectra; very low concentrations of nitrogenous material. Philae lander was successful in detecting volatile species, including water, carbon monoxide and carbon dioxide measured directly at the surface of the comet (Wright et al. 2017). Thanks to the un-nominal Philae's operation it was possible to measure the ratios of the volatiles species sniffed by PTOLEMY on the two landing sites (Agilkia and Abydos). From this analysis results that the two sites have very different ratios which seems to indicate heterogeneity in nucleus composition (albeit measurements could be biased by the different surface morphology of the landing sites and different local times and illumination conditions occurring during Philae operations). Temporal evolution of the mass spectra have been analyzed by Krüger et al. (2017) who has reported that COSAC and PTOLEMY counts decay over time. The first spectra with 


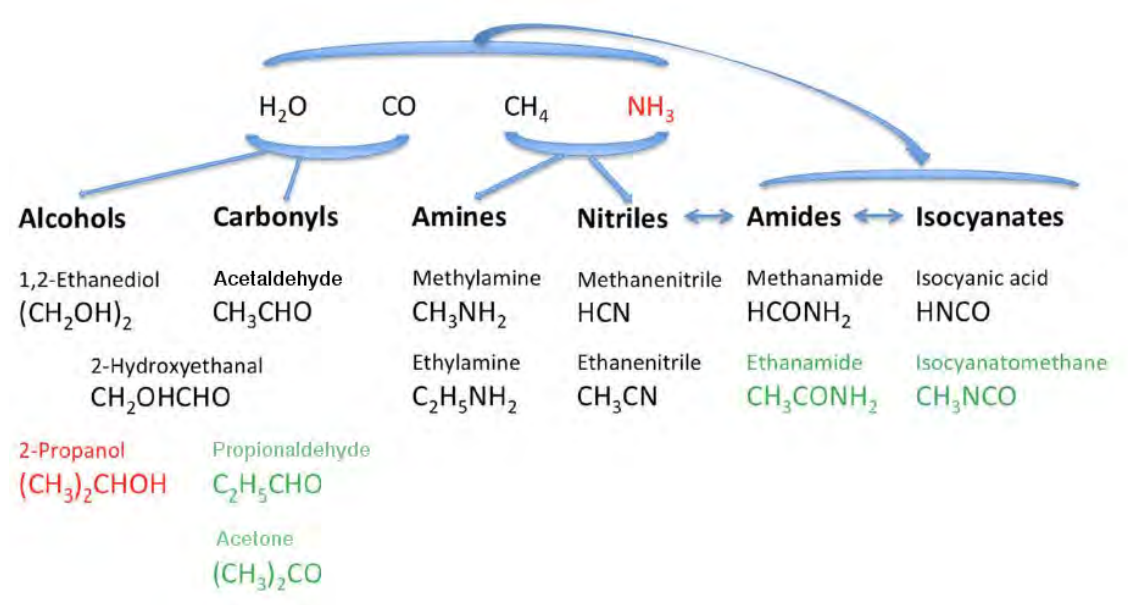

Fig. 4 Organic compounds detected by COSAC and possible formation pathways. Species marked in red are not confidently identified; species in green were observed for the first time in comets by COSAC. Modified from Goesmann et al. (2015).

the highest intensities were recorded by both instruments about 20-30 min after Philae's first touchdown at Agilkia. On the six consecutive measurements taken at Abydos the counts decay. Due to the instruments' designs and vent tubes configurations, the two experiments were preferentially sniffing in two different directions with COSAC collecting regolith samples from the surface while PTOLEMY measured gas species from the ambient coma. As a consequence of this configuration, the diagnostic m/z peak at 44 measured by both instruments has a different origin: for COSAC it is the signature of organic material embedded in surface regolith grains while for PTOLEMY it corresponds to gaseous $\mathrm{CO}_{2}$ in the coma.

\subsection{Coma as a pathway to constrain surface composition}

As they have spent long time far from the Sun, comets are expected to have preserved their initial composition and be one of the most primitive object of the Solar System (Mumma and Charnley 2011). Therefore determining the composition of the nucleus provides precious information on the prevalent thermo-chemical and physical properties of the nebula in which comets have formed. One possibility to determine the composition of the nucleus is the direct sampling of cometary material. For the first time, the Rosetta mission has succeeded to reach the surface of a comet by landing Philae at the surface of $67 \mathrm{P} / \mathrm{CG}$. Initial plan was to drill the upper centimeters of the comet and to analyze the samples with the mass spectrometer PTOLEMY but unfortunately these steps could not be performed (Wright et al. 2015). 
Another way to get information on the composition of the volatile species in the nucleus is to study the gaseous species and their outgassing evolution in the coma. Indeed, as the nucleus orbits around the Sun it experiences sublimation and gas release. Thus by measuring the composition in the coma we indirectly sample the nucleus composition. However, relationships between the coma and nucleus composition are complex (de Almeida et al. 1996; Huebner and Benkhoff 1999) because volatiles can be present as condensed and/or gaseous phase in the nucleus. Among volatiles, pure ices have their own thermodynamical properties and will sublimate at different temperature, pressure and depth (Huebner et al. 2006; Fray and Schmitt 2009; Marboeuf and Schmitt 2014). In addition, the structure of ices, i.e. amorphous, crystalline and clathrate hydrate, influence the outgassing pattern according to the way volatiles are trapped (Espinasse et al. 1991; de Sanctis et al. 2005; Huebner et al. 2006; Marboeuf and Schmitt 2014). Also the presence of a dust mantle at the surface of the nucleus will affect the intensity of the outgassing (Marboeuf and Schmitt 2014). Finally, gas release is strongly dependent on orbital parameters such as heliocentric distance, obliquity of the object, period of rotation and shape of the nucleus (Huebner and Benkhoff 1999; Fulle et al. 2016b). As a result of the combined effects of all these parameters, the mixing ratio measured in the coma often do not reflect directly the abundances of volatiles in the nucleus (Espinasse et al. 1991; Benkhoff 1995; de Almeida et al. 1996; Huebner 2008; Marboeuf and Schmitt 2014), and interpretation of the outgassing data should be done very carefully. For example, the fact that coma composition presents heterogeneities does not necessary imply similar compositional heterogeneities in the nucleus (Huebner and Benkhoff 1999; Hässig et al. 2015). Studies based on coma composition either interpreted it as a result of a homogeneous or either heterogeneous nucleus composition. Analyses of a fragment of the comet $73 \mathrm{P} / \mathrm{Schwassmann}$-Wachmann 3 revealed that the composition was rather homogeneous (Dello Russo et al. 2007). In contrast, observations of freshly exposed material of comet 9P/Tempel 1 during the Deep Impact mission rather suggest a heterogeneous composition (Feaga et al. 2007). Comet 103P/Hartley 2, which presents a bi-lobate shape comparable to the one of $67 \mathrm{P} / \mathrm{CG}$, exhibited a heterogeneous coma which has been interpreted to reflect variations of composition within the nucleus (A'Hearn et al. 2011). However, so far most of the observations of explored comets were sparse and cannot provide an insightful comprehension of the nuclei compositions and properties.

For the first time the Rosetta mission has extensively investigated the coma evolution of a comet during a long period spanning around the perihelion passage with a comprehensive set of instruments. Abundances of molecules in the coma of $67 \mathrm{P} / \mathrm{CG}$ have been measured in detail by the ROSINA instrument (Balsiger et al. 2007) revealing a $\mathrm{CO}$ - and $\mathrm{CO}_{2}$-rich nucleus (compared to other Jupiter Family Comets), the presence of highly volatile molecules and organic molecules (Le Roy et al. 2015). The coma monitoring at different heliocentric distances and above different latitudes on the surface of the nucleus (see Fig. 5) has revealed large fluctuations in the outgassing pattern (Hässig et al. 2015; 

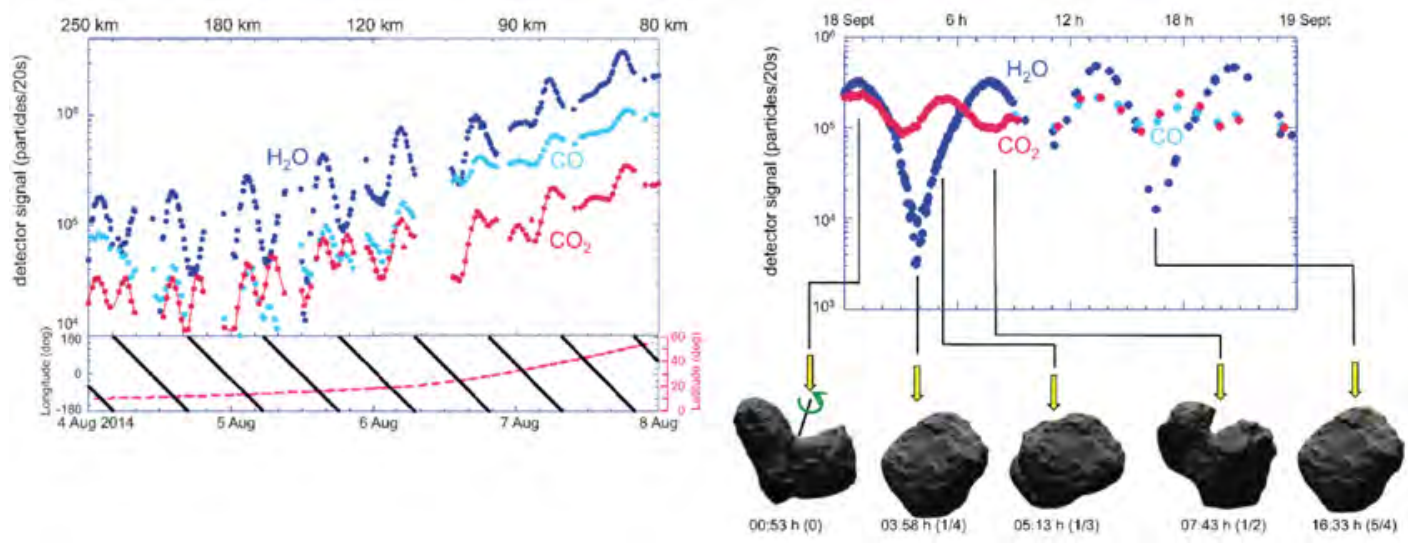

Fig. 5 Left panel: $\mathrm{H}_{2} \mathrm{O}, \mathrm{CO}$ and $\mathrm{CO}_{2}$ molecular densities from in-situ measurements by ROSINA/DFM within the coma of 67P/CG (upper panel) on August 4th-8th 2014. The spacecraft explored different longitude and latitude ranges during that time (lower panel). Right panel: ROSINA/DFMS molecules density measurements of $\mathrm{H}_{2} \mathrm{O}, \mathrm{CO}$ and $\mathrm{CO}_{2}$ in-situ in the coma of $67 \mathrm{P} / \mathrm{CG}$ for September 18 th 2014 correlated to the spacecraft view of the nucleus. From Hässig et al. (2015).

Luspay-Kuti et al. 2015). The major species detected, $\mathrm{H}_{2} \mathrm{O}, \mathrm{CO}$ and $\mathrm{CO}_{2}$ do not always evolve with the same periodicity and intensity. Conversely, minor species seem to follow either the $\mathrm{H}_{2} \mathrm{O}$ or the $\mathrm{CO}_{2}$ emissions (Luspay-Kuti et al. 2015). Apart from in situ measurements, the spatial and temporal distributions of gaseous species in the $67 \mathrm{P} / \mathrm{CG}$ coma have been measured also by remote sensing payloads, e.g. in the infrared by VIRTIS (Coradini et al. 2007) and at microwaves by MIRO (Gulkis et al. 2007). The fluorescences of water vapor (at $2.67 \mu \mathrm{m}$ ) and $\mathrm{CO}_{2}$ (at $4.27 \mu \mathrm{m}$ ) measured by VIRTIS between November 2014 and January 2015 when the heliocentric distance was decreasing from 2.91 to 2.47 AU were analyzed by Bockelée-Morvan et al. (2015). This study has shown a constant water production rate during this period of time, with higher column abundance detected above the active areas in Hapi. A similar distribution has been observed in the sub-mm domain by MIRO (Biver et al. 2015; Lee et al. 2015). While the water emission is correlated with solar illumination, $\mathrm{CO}_{2}$ appears not to be influenced by this as it was observed on both illuminated and non-illuminated areas, including on the south hemisphere (Fink et al. 2016). The derived $\mathrm{CO}_{2} / \mathrm{H}_{2} \mathrm{O}$ column density ratio varies from $2 \%$ (on illuminated areas) to $60 \%$. The study of the fluorescence emissions of $\mathrm{H}_{2} \mathrm{O}, \mathrm{CO}_{2}, \mathrm{CH}_{4}$ and OCS species in the coma around the perihelion passage indicates an abrupt increase of the water production about six days after perihelion while the abundances of $\mathrm{CO}_{2}, \mathrm{CH}_{4}$ and OCS relative to $\mathrm{H}_{2} \mathrm{O}$ increase by a factor 2 (Bockelée-Morvan et al. 2016). This behavior can be explained by the erosion of the dust layer on the surface occurring at perihelion which exposes subsurface volatile-rich layers.

The heterogeneity of the gaseous species observed in the $67 \mathrm{P} / \mathrm{CG}$ coma has been interpreted in terms of: 
1. Homogeneous nucleus composition. The fluctuation of gas density in the coma shows strong correlation to the rotation period and the latitude of observation which suggests that the outgassing is mainly solar insolationdriven (Hässig et al. 2015). Variations of composition in the coma are enhanced by seasonal and diurnal effects due to the combination of the large spin obliquity and the complex shape of the nucleus (Preusker et al. 2015). Therefore, if $67 \mathrm{P} / \mathrm{CG}$ nucleus is homogeneous in composition, the heterogeneities observed in the coma must be controlled by the illumination (Hässig et al. 2015; Bieler et al. 2015; Fougere et al. 2016; Fulle et al. 2016b; Hoang et al. 2017).

2. Heterogeneous nucleus composition. The lack of correlation suggests that $\mathrm{CO}$ and $\mathrm{CO}_{2}$ are not embedded by $\mathrm{H}_{2} \mathrm{O}$ (Hässig et al. 2015). Therefore, $\mathrm{H}_{2} \mathrm{O}$ can be present at the surface while $\mathrm{CO}$ and $\mathrm{CO}_{2}$, which are more volatile, will sublimate from deeper layers. Variation of composition will be generated in the sub-surface of the comet as the nucleus orbits around the Sun and receives different amount of solar energy. The complex shape of the nucleus will strongly enhance the variation of illumination and therefore sub-surface heterogeneities from one area to another (Hässig et al. 2015; Luspay-Kuti et al. 2015; Fink et al. 2016; Hoang et al. 2017). Some asymmetries detected in the $\mathrm{H}_{2} \mathrm{O}$ and $\mathrm{CO}_{2}$ outgassing between the northern and southern regions could be attributed to different characteristics of the nucleus (Hässig et al. 2015; Le Roy et al. 2015; Luspay-Kuti et al. 2015). They can result from heterogeneities in the nucleus with somehow more $\mathrm{CO}_{2}$ compared to $\mathrm{H}_{2} \mathrm{O}$ in the southern plains (Luspay-Kuti et al. 2015). An alternative hypothesis is that these variations are induced by local heterogeneities of the surface properties such as ice sintering or dust coverage due to local morphology (Keller et al. 2015; Luspay-Kuti et al. 2015; Hoang et al. 2017). The presence of a dust mantle in the northern plains of $67 \mathrm{P} / \mathrm{CG}$ was observed by Thomas et al. (2015). Potential presence of condensed $\mathrm{H}_{2} \mathrm{O}$ in this layer (de Almeida et al. 1996; Rubin et al. 2014) can enhance the $\mathrm{H}_{2} \mathrm{O}$ outgassing while it inhibits the $\mathrm{CO}_{2}$ release (Hoang et al. 2017). The presence of a dust mantle could influence the outgassing pattern by shifting the maximum of gas release in dependence on local time related to the mantle thickness (Marboeuf and Schmitt 2014). Another evidence of heterogeneities in the coma is the singular behavior of $\mathrm{CH}_{4}$ which shows a poor correlation with other species (Luspay-Kuti et al. 2015). Numerical simulations suggest that $\mathrm{CH}_{4}$, and possibly $\mathrm{C}_{2} \mathrm{H}_{6}$, can potentially be trapped in clathrates at shallow depths (Mousis et al. 2015; Luspay-Kuti et al. 2016). However, observations and numerical simulations seem to preclude the presence of amorphous phase (Luspay-Kuti et al. 2016) as it has been proposed by Vincent et al. (2015) and Mousis et al. (2015).

A consensus seems to emerge from different studies that the $67 \mathrm{P} / \mathrm{CG}$ outgassing pattern is driven mainly by illumination. Heterogeneities detected in the coma are, at global scale, induced by the combination of the tilt of the 
rotation axis and the complex shape of the nucleus. The strong variation of illumination between different areas of the nucleus's surface is thought to produce heterogeneities in the sub-surface composition. However, insolation variations do not succeed to explain completely the behavior of the species' outgassing. Heterogeneities of the surface-subsurface properties of the nucleus such as the presence of a dust mantle or of clathrates could explain some of the gas behavior. A more detailed discussion about gas properties in the coma is given in Gas composition chapter (Mumma)-add reference.

While gaseous emissions in the coma trace the volatile/ice species on the nucleus from which they have been released, dust grains maintain the minerals and organic materials present on the surface. Dust grains were measured by a dedicated suite of in-situ instruments onboard Rosetta: GIADA, the Grain Impact Analyser and Dust Accumulator (Colangeli et al. 2007), has measured the dust flux from grains larger than $100 \mu \mathrm{m}$ and has inferred a dust-towater ice mass ratio of six from a heliocentric distance of 3.6 AU to perihelion (Rotundi et al. 2015; Fulle et al. 2016a). The same authors state that the mass of dust particles is mainly contained within compact grains having a density of about $2000 \mathrm{~kg} \mathrm{~m}^{-3}$ and sizes larger than $1 \mathrm{~mm}$. As reported by Della Corte et al. (2015), coma dust grains appear in two distinct families: compact particles and fluffy porous aggregates having masses from $10^{-10}$ to $10^{-7} \mathrm{~kg}$. COSIMA, the Cometary Secondary Ion Mass Analyser (Kissel et al. 2007) is a time-of-flight secondary-ion mass spectrometer (TOF-SIMS) instrument able to resolve particles with sizes from tens of microns to millimeters and to capture microscopic images of the grains after their impact on exposed targets (Langevin et al. 2016). By means of secondary ion mass spectroscopy, Bardyn et al. (2017) have modeled grains composition with organic matter for $45 \%$ of the mass and anhydrous mineral phases for the remaining $55 \%$ (see Fig. 6). The loss of volatiles in the dust is a consequence of the heating of the grains in the coma. The average atomic composition of the grains is modeled with $\mathrm{H}(30 \%), \mathrm{C}(30 \%), \mathrm{O}(30 \%)$ with $\mathrm{Si}, \mathrm{Fe}, \mathrm{Mg}$ and other species accounting for the remaining $10 \%$. All these results were derived with certain assumptions on the $\mathrm{H} / \mathrm{C}$ and $\mathrm{O} / \mathrm{C}$ ratios which cannot be measured by the instrument. Noteworthily, within the dust size range (from 50 to $1000 \mu \mathrm{m}$ ) investigated by COSIMA, any particle that would consist of a single mineral or pure organic has never been seen. This means that all the single grains contained both organics and minerals, which means that the non-icy components are very well-mixed at the intimate level up to a relatively small scale.

MIDAS, the Micro-Imaging Dust Analysis System (Riedler et al. 2007), used atomic-force microscopy techniques to characterize grains from nanometers to micron sizes which appear as hierarchical agglomerates of fractal and compact particles (Mannel et al. 2016; Bentley et al. 2016). We refer the interested reader to Dust chapter (Fulle)-add reference for a more detailed discussion about dust grain properties. 


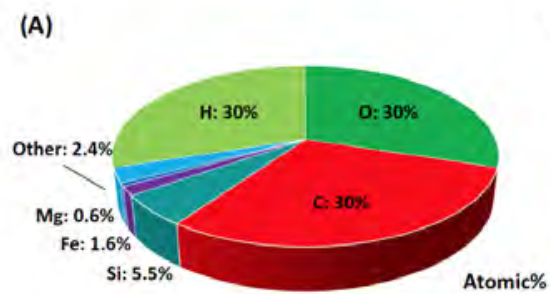

(B)

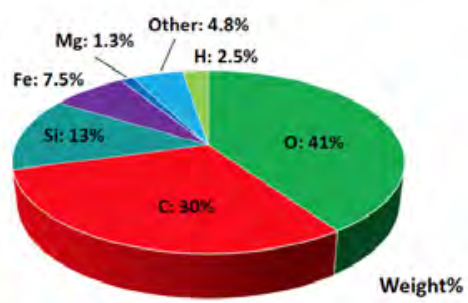

(c)

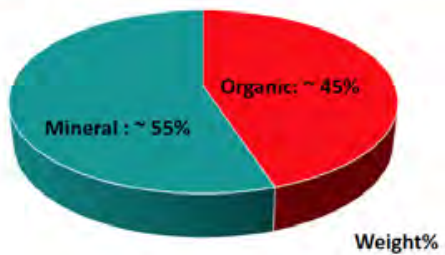

Fig. 6 Averaged composition of 67P/CG's dust particles as deduced from COSIMA measurements: panel a) by atomic fraction; panel b) by atomic mass fraction. Panel c) is the mineral and organic content estimated in mass fraction. Figure from Bardyn et al. (2017).

\section{Compositional Endmembers}

Following the 'dirty snowball' model of Whipple (1950) in which the cometary nuclei are described as a mixture of ices, CHON (carbon, hydrogen, oxygen, and nitrogen) organic material and rocky particles, in the following sections we review the current knowledge of these endmembers in the context of the aforementioned Rosetta's results.

\subsection{Volatiles/Ices}

So far, only two ice species have been identified on the surfaces of cometari nuclei by means of infrared spectroscopy: crystalline water ice and carbon dioxide ice. Water and carbon dioxide ices have been detected by Rosetta/VIRTIS-M on the surface of $67 \mathrm{P} / \mathrm{CG}$ during the pre-perihelion time. Deep Impact/HRI has observed water ice deposits on $9 \mathrm{P} /$ Tempel 1 . A summary of the properties of the ices is given in Table 4 .

During the pre-perihelion phase, crystalline water ice has been spectroscopically identified at near infrared wavelengths in three distinct modalities on $67 \mathrm{P} / \mathrm{CG}$ nucleus:

1. On the active areas of Hapi region where water ice changes its abundance with local time and illumination conditions, condensing during the night hours and sublimating during daytime (de Sanctis et al. 2015). During each rotation, when the surface is illuminated by the Sun, the water ice sublimates mainly from the inner layers reached by the propagation of the thermal wave. As soon as the same surface goes into shadow (or moves into the night side) surface temperature rapidly drops. Since Hapi is a region 
with a gravitational minimum, the surface here is preferentially blanketed by a many meters-thick layer of dust (Keller et al. 2017). In these conditions a temperature inversion occurs between the colder surface layer and the interior which remains at higher temperature for a longer time. The entire process is driven by the illumination conditions by means of the duration of the shadow/night and daytime periods, and by the surface properties, e.g. surface thermal inertia and thermal skin depth. Because the shadow is cast onto Hapi alternating by $67 \mathrm{P} / \mathrm{CG}$ 's head and body at the time of the observation, and due to the short rotation period, equal to 12.4 hours (Mottola et al. 2014; Jorda et al. 2016), the sublimation and condensation process occurred two times at each rotation. As a consequence of this, very small water ice grains in intimate mixture with the dark terrain condense on the surface. The water ice particles have diameters of $1-3 \mu \mathrm{m}$ and abundances up to $14 \%$ for the areas close to the shadow line where the measured temperature is $165-170 \mathrm{~K}$ (see Fig. 7). The condensationsublimation process seems to be common among comets. It has been also proposed to explain the surge of outbursts observed on comet $9 \mathrm{P} /$ Tempel 1 from areas near sunrise (Prialnik et al. 2008).

2. On recent debris fields collapsed from two elevated structures in the Imhotep region where more fresh and pristine material is exposed (Filacchione et al. 2016a). These areas are named BAPs, i.e. Bright Area Patches (Fig. 8). The gravitational displacement of the surface caused by overhang falls and the disruption of elevated structures (Groussin et al. 2015a) allows the exposure of more pristine material from the interior. The best-modeling of the VIRTIS spectra of the BAPs (panel $g$ in Fig. 8) corresponds with a solution in which $1.2 \%$ of the pixel area is occupied by patches of water ice particles with a diameter around $2 \mathrm{~mm}$ while the remaining $98.8 \%$ of the pixel area consists of an intimate mixture of water ice $(3.4 \%, 56 \mu \mathrm{m}$ grain diameter) and average dark terrain (95.4\%). Therefore the average total amount of surface water ice detected on the BAPs corresponds to about $4.6 \%$ for a $2.5 \times 2.5 \mathrm{~m}$ pixel footprint. The measured BAPs' surface temperature $(\mathrm{T}<160-180 \mathrm{~K})$ is about $20-25 \mathrm{~K}$ colder than in the surrounding areas but still warm enough to allow the presence of crystalline ice.

3. On eight bright spots located in the Khonsu, Imhotep, Anhur, Atum and Khepry regions where single or multiple grouped icy patches are observed (Barucci et al. 2016). Some of those areas were first detected on high resolution OSIRIS images (Pommerol et al. 2015) and form a plethora of small bright spots, or much larger individual or twin bright patches spanning from few meters to about $60 \mathrm{~m}$ in size. The spots are characterized by high albedo and blue visible colors in striking contrast with the dark-red color of the average terrain. OSIRIS images and visible spectra are shown in Fig. 9 for one of the eight spots discussed by Barucci et al. (2016). The spots are preferentially located in various morphological terrains within the equatorial regions, including freshly exposed cliffs, alcoves, flat terraces, layers, accumulation deposits, ancient outgassing conduits and rocky terrains. In general these spots appear on consolidated and dust-free areas and in some 
Table 4 Infrared spectroscopic identification of ice species, abundances and distributions on the surfaces of cometary nuclei. Note: ${ }^{a)} \mathrm{A}=$ Areal mixing, $\mathrm{I}=$ Intimate mixing; ${ }^{b}$ ) from shadow line. Labels ${ }^{c},{ }^{d}, e$ indicate similar areas in Table 5 for comparison.

\begin{tabular}{|c|c|c|c|c|c|c|}
\hline Comet & Region & Dimensions & Ice & Abundance & Grain size $\left(\right.$ Mixing $\left.^{a}\right)$ ) & Reference \\
\hline $67 \mathrm{P} / \mathrm{CG}$ & Hapi & $\leq 100 \mathrm{~m}^{b)}$ & $\mathrm{H}_{2} \mathrm{O}$ (cryst.) & $1-14 \%$ & $1-3 \mu \mathrm{m}(\mathrm{I})$ & de Sanctis et al. (2015) \\
\hline $67 \mathrm{P} / \mathrm{CG}$ & Imhotep $^{c}$ & $100 \times 100 \mathrm{~m}$ & $\mathrm{H}_{2} \mathrm{O}$ (cryst.) & $6 \%$ & $33-72 \mu \mathrm{m}(\mathrm{I}), 1.4-2.6 \mathrm{~mm}(\mathrm{~A})$ & Filacchione et al. (2016a) \\
\hline $67 \mathrm{P} / \mathrm{CG}$ & Various $^{d}$ & $1-60 \mathrm{~m}$ & $\mathrm{H}_{2} \mathrm{O}$ (cryst.) & $0.3-4 \%$ & $10 \mu \mathrm{m}(\mathrm{I}), 6.5 \mathrm{~mm}(\mathrm{~A})$ & Barucci et al. (2016) \\
\hline $67 \mathrm{P} / \mathrm{CG}$ & Anhur ${ }^{e}$ & $60 \times 80 \mathrm{~m}$ & $\mathrm{CO}_{2}$ & $0.1 \%$ & $50 \mu \mathrm{m}(\mathrm{A})$ & Filacchione et al. (2016b) \\
\hline 9P/Tempel 1 & Various & $0.55 \mathrm{~km}^{2}$ & $\mathrm{H}_{2} \mathrm{O}$ & $3-6 \%$ & $30 \pm 20 \mu \mathrm{m}(\mathrm{I})$ & Sunshine et al. (2006) \\
\hline
\end{tabular}

cases correspond to the sources of active processes (outbursts). On many of them the surface water ice continued to be visible for weeks and months, while others are more variable and correlated with the diurnal variation (Raponi et al. 2016). Co-located infrared spectroscopy by VIRTIS shows very variable water ice grain properties from spot to spot but within the limits given by the two aforementioned cases: water ice areal abundances are ranging between 0.3 to $4 \%$ with the presence of both small $10 \mu \mathrm{m}$ grains in intimate mixing with the dark terrain or very large mm-sized grains in areal mixing. Additionally, another debris field (CF3) enriched in water ice has been detected in the OSIRIS images in Imhotep region and confirmed by the presence of the $2 \mu \mathrm{m}$ absorption band on infrared spectra (Oklay et al. 2017).

A summary of the infrared spectroscopic identification of water ice, abundances and distributions on the surface of $67 \mathrm{P} / \mathrm{CG}$ is given in Table 4). Using spectroscopy, visible photometry, and imagery many of those water ice-rich areas are observed for prolonged period of time during the entire duration of the Rosetta mission on OSIRIS images. The large clusters (BAP 1, 2 and CF1, $2,3)$ close to the cliffs survived on well-illuminated surface locations for about 10 months, and several boulders enriched in water ice were still existing after 1.5 years of the first detection (Oklay et al. 2017). The isolated water ice-rich area coded IF2 (Oklay et al. 2017), which survived the entire mission, was also spectrally confirmed using early IR spectra.

Despite carbon dioxide being the second most abundant gaseous species detected on cometary comae after water vapor (Bockelée-Morvan and Biver 2017), the presence in the form of ice on nuclei surfaces has been always elusive due to its high volatility. Before Rosetta, in fact, it has never been observed on cometary nuclei. So far, carbon dioxide ice has been detected by VIRTIS only in a $60 \times 80 \mathrm{~m}$ area in the Anhur region while it was exiting from a four year-long winter-night season (Filacchione et al. 2016b). The spectroscopic identification has been possible by means of the diagnostic $2.0 \mu \mathrm{m}$ triplet and the 2.6-2.75 $\mu \mathrm{m}$ bands (Fig. 10). This ice deposit underwent rapid sublimation, disappearing within about one month after its initial detection in March 212015 (Fig. 10). A heat balance calculation for this specific area shows that an erosion of a $9 \mathrm{~cm}$ thick layer of carbon dioxide ice, for a total of $56 \mathrm{~kg}$, 

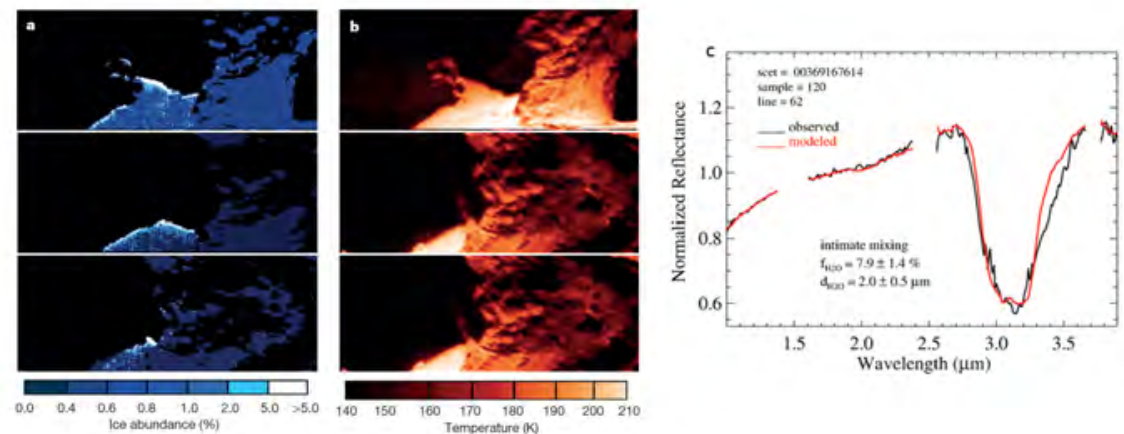

Fig. 7 Panel a): Ice abundance (by volume) maps on the Hapi active area; b): Temperature images; c): Best spectral fit to VIRTIS data corresponding to a mixture of average dark terrain and water ice grains. From de Sanctis et al. (2015).
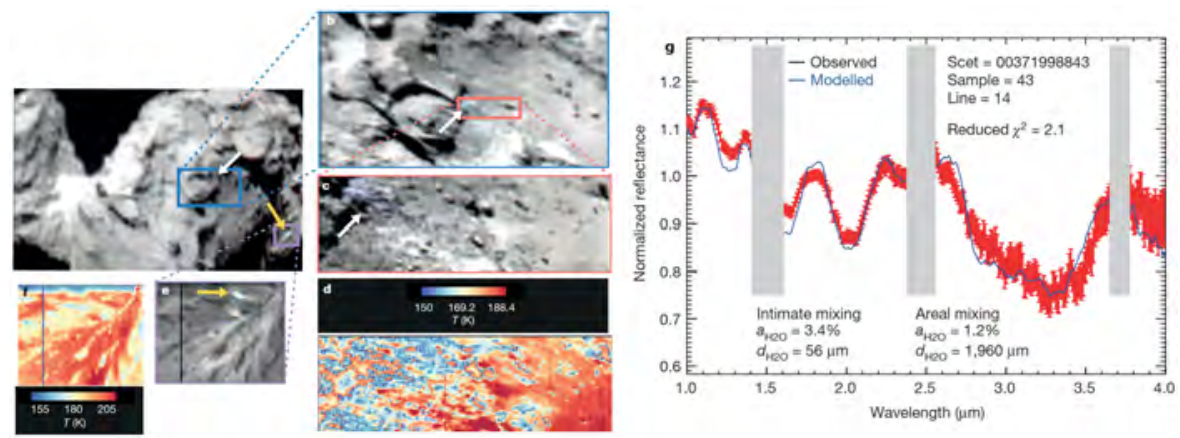

Fig. 8 Panel a): color image showing BAP1 and BAP2 (white and yellow arrows, respectively). b): Water-ice-rich waste terrain on BAP1 is visible (blue) on the right side of the circular elevated structure. c): Close-up image acquisition of BAP1 reveals the bluish color of the water-ice-rich unit. d): Temperature map showing the water-ice-rich terrain at $\mathrm{T}<$ 160 K. e): Hillside image showing BAP2. f): Temperature map showing the water-ice-rich terrain at $\mathrm{T}<180 \mathrm{~K}$. All color images are obtained from the $\mathrm{B}=1.3 \mu \mathrm{m}, \mathrm{G}=2.0 \mu \mathrm{m}$ and $\mathrm{R}=2.9 \mu \mathrm{m}$ channels. $\mathrm{g}$ ): BAP1 water-ice-rich VIRTIS spectrum (black curve with error bars in red) and best-fit synthetic model (blue curve). $a_{\mathrm{H}_{2} \mathrm{O}}$ is the percentage of crystalline water ice and $d_{\mathrm{H}_{2} \mathrm{O}}$ is the water-ice grain size. 'Scet' is the spacecraft time used to identify the observation; 'sample' and 'line' correspond to the position of the pixel on the image. The grayed-out spectral ranges are affected by instrumental order sorting filters. From Filacchione et al. (2016a).

has occurred. The ice patch was presumably formed after the comet's previous perihelion passage, in 2009, when the carbon dioxide outgassing from the nucleus' deeper layers condensed on the cold surface. The Anhur region is in fact located in the southern hemisphere which experienced a four year-long winter-night season during which the surface temperatures have dropped to sufficiently low values to allow the carbon dioxide to condense as ice. Moving towards perihelion, with the increase of the solar illumination, the carbon dioxide ice has rapidly disappeared. 

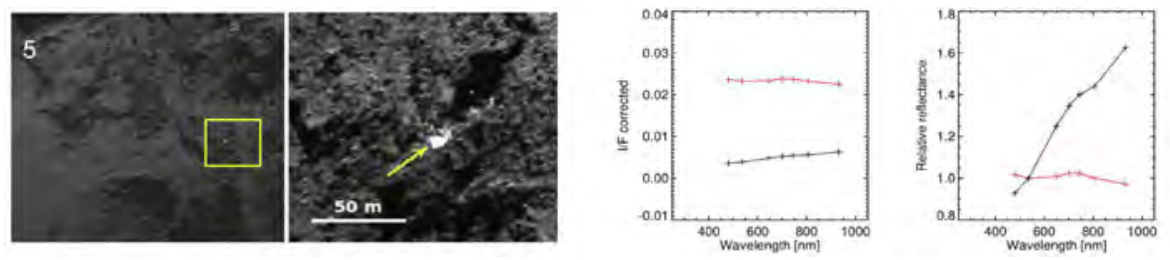

Fig. 9 Optical identification of a water ice bright spot in the Imhotep region by OSIRIS with F22 filter (at $649.2 \mathrm{~nm}$ ). First column: context image. Second column: zoomed image. Third column: I/F of the bright spots (red plot) shows higher reflectance than the surrounding non-icy area (black). Fourth column: relative reflectance (normalized to F23 filter at 535 $\mathrm{nm}$ ) of the bright spot (red) is spectrally flat while the surrounding area (black) is very red. From Barucci et al. (2016), spot\#5.
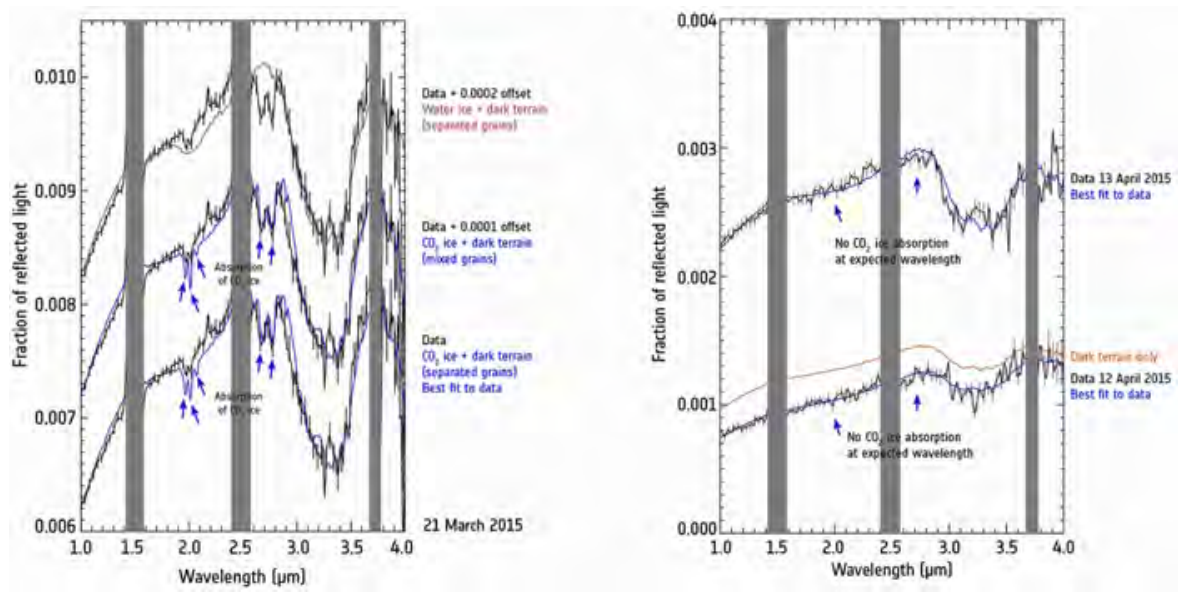

Fig. 10 Spectroscopic identification of transient $\mathrm{CO}_{2}$ ice in the Anhur region. Left panel: March 212015 spectra showing the detection of $\mathrm{CO}_{2}$ ice and spectral modeling results. Note that the modeling with water ice (top plot) fails to match the observed data. Right panel: the $\mathrm{CO}_{2}$ ice features are no more visible on April 12-13 2015 observations taken on the same area. The grayed-out spectral ranges are affected by instrumental order sorting filters From Filacchione et al. (2016b).

The OSIRIS camera has observed two unusually large patches of water ice in the southern regions of Anhur and Bes resulting in 20-30\% of water ice mixed with the dark material in a layer up to $30 \mathrm{~cm}$ thick (Fornasier et al. 2016). One of these patches has been located in the same area where the carbon dioxide ice sheet has been revealed by VIRTIS about one month before. Also the water ice patches have completely disappeared within about ten days after their initial detection. This indicates the presence of a dual layer, with superficial carbon dioxide ice overlayed above water ice, as result of the different condensation temperatures of the two species $\left(\mathrm{CO}_{2}\right.$ needs lower temperature than $\mathrm{H}_{2} \mathrm{O}$ to condense as ice) occurring during the winter-night season at aphelion. The double detection by VIRTIS and OSIRIS reveals the seasonal cycles of carbon dioxide and water ices, which unfolds during the 

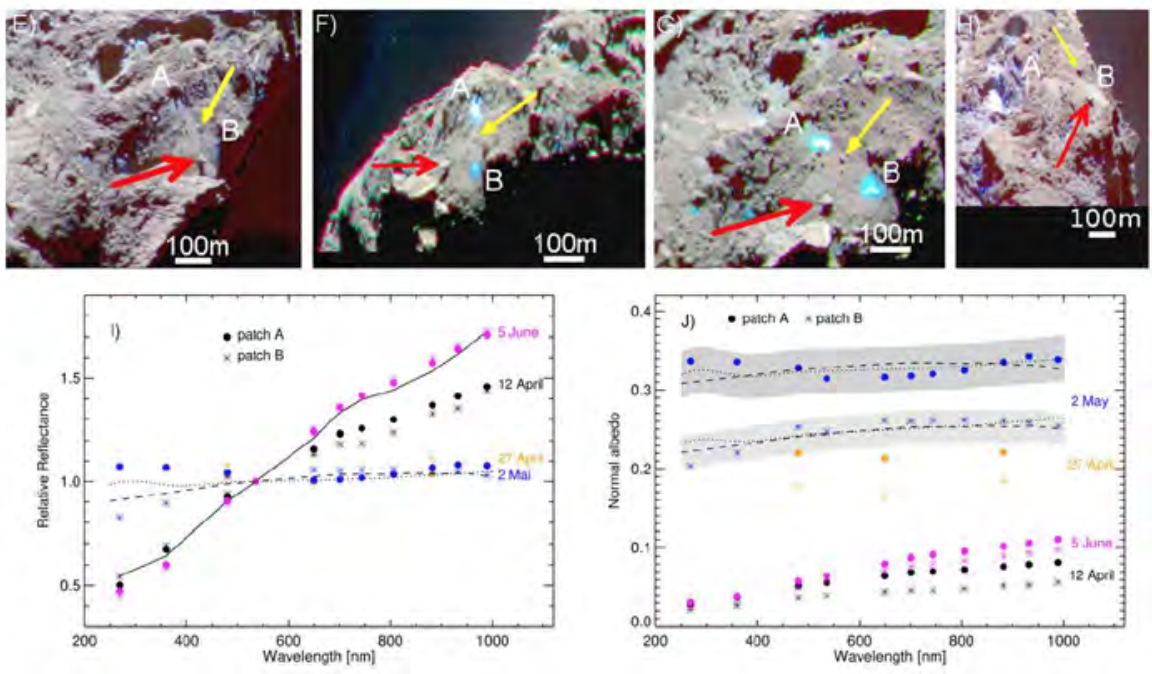

Fig. 11 Composite OSIRIS images (882 nm, $649 \mathrm{~nm}$ and $480 \mathrm{~nm}$ filters) showing the appearance of the bright patches in the Anhur/Bes regions (panels E, F, G, H). Red and Yellow arrows indicate two common boulders. The reflectance relative to $535 \mathrm{~nm}$ and the normal albedo are represented in the (I) and (J) panels: black line is the average spectrum of the nucleus from a region outside the bright patches; dashed and dotted lines show the best fit spectral models for the patches (in gray the associated uncertainty) as given by a linear mixture of the cometary dark terrain enriched with $21 \pm 3 \%$ of water ice (dashed line), or $23 \pm 3 \%$ of water ice (dotted line) for patch B, and with $29 \pm 3 \%$ of water ice (dashed line), or $32 \pm 3 \%$ of water frost (dotted line) for patch A. Simulations are performed by assuming a water ice grain size of $30 \mu \mathrm{m}$. From Fornasier et al. (2016).

6.5-year orbit of $67 \mathrm{P} / \mathrm{CG}$, as opposed to the daily cycle of water ice occurring on Hapi (de Sanctis et al. 2015).

One of the major advancements of the Rosetta observations is the retrieval of the distribution of the superficial crystalline water ice grains which appear distributed in three populations: 1) small micron-sized grains are frequent on the active areas where the rapidly changing diurnal variations (de Sanctis et al. 2015) do not allow the formation of larger grains. These grains can be constrained only by means of the $\mathrm{H}_{2} \mathrm{O}$ stretch band superimposed on the deep $3.2 \mu \mathrm{m}$ organic band and by the absence of the other diagnostic bands at 1.05, $1.25,1.5,1.65,2.05 \mu \mathrm{m}$ (see Fig. 7, panel c) which characterize larger grains; micron-sized grains are also candidates to constrain the average $1 \%$ amount of water ice visible on the dark dehydrated terrains (Capaccioni et al. 2015). 2 ) intermediate grains, e.g. tens of microns, appear preferentially in intimate mixing with the dark material in the water ice-rich patches (see Fig. 8, panel g). 3) large mm-size grains are built from the growth of secondary ice crystals from vapour diffusion in ice-rich colder layers and/or by ice grain sintering caused by thermal waves. Due to their dimensions, these grains are dispersed in areal mixing with the average dark terrain. 
Spectral modeling allows to quantitatively correlate the amount of water ice on the surface with VIRTIS comet spectral indicators (CSI) as introduced by Filacchione et al. (2016c). The CSI method is capable to infer the abundance of the water ice from the measured VIS-IR spectra as well as to reduce the data set dimension. The standard CSI are:

- $\mathrm{S}_{V I S}$ is the spectral slope in the VIS range, calculated by best fitting the reflectance in the $0.55-0.8 \mu \mathrm{m}$ range by a linear function after normalization to 1 at $0.55 \mu \mathrm{m}$;

$-\mathrm{S}_{I R}$ is the spectral slope in the IR range, calculated by best fitting the reflectance in the $1.0-2.35 \mu \mathrm{m}$ range by a linear function after normalization to 1 at $1.0 \mu \mathrm{m}$;

- BA is the band area of the absorption at $3.2 \mu \mathrm{m}$ computed after removal of the 2.7-3.6 $\mu \mathrm{m}$ continuum;

- $\mathrm{BC}$ is the band centre of the absorption at $3.2 \mu \mathrm{m}$ computed after continuum removal as the position of the minimum of a third-degree polynomial fit in the $2.7-3.6 \mu \mathrm{m}$ range.

The variability of these indicators as a function of the water ice abundance (up to $5 \%$ ) is shown in the left panel of Fig. 12. Concurrent spectral modeling in the visible and infrared ranges allows to study the visible spectral slope value as a function of the water ice abundance determined by infrared absorption bands once the mixing modality (areal or intimate) and dark terrain properties have been defined (Raponi et al. 2016). In Fig. 12 are shown the water ice superficial abundances for different mixing modalities. The models allow a quantitative derivation of the amount of surface water ice by the measurement of the visible color: a completely anhydrous surface has an average spectral slope of 2.2 $\mu \mathrm{m}^{-1}$. Slopes lower than $1.2 \mu \mathrm{m}^{-1}$ correspond to water ice abundance higher than $5 \%$ in intimate mixing or $1 \%$ in areal mixing at $95^{\circ}$ phase angle. To scale the result for different phase angles one should account for the phase function which produces slope variations of the order of $+0.007 \mu \mathrm{m}^{-1} \mathrm{deg}^{-1}$, according to Ciarniello et al. (2015).

Operating at visible wavelengths, OSIRIS is not capable like VIRTIS to detect the diagnostic absorption features of the water ice and therefore cannot derive its physical properties (abundance, grain size, temperature). However, regions enriched in water ice are easily detectable due to their blue color on RGB composites generated by using the images taken at NIR, visible, blue wavelengths. Conversely, OSIRIS images allow to observe the nucleus at much higher spatial resolution than VIRTIS and to better correlate the color variations with local morphology. On OSIRIS decorrelated-stretch color images is possible to derive the visible spectral slope which can be used as a proxy for the presence of water ice (Oklay et al. 2016a):

$$
\operatorname{slope}\left(\frac{\%}{100 n m}\right)=\frac{\left(R_{N I R}-R_{\text {green }}\right) \cdot 10.000}{\left(\lambda_{N I R}-\lambda_{\text {green }}\right) \cdot R_{\text {green }}}
$$



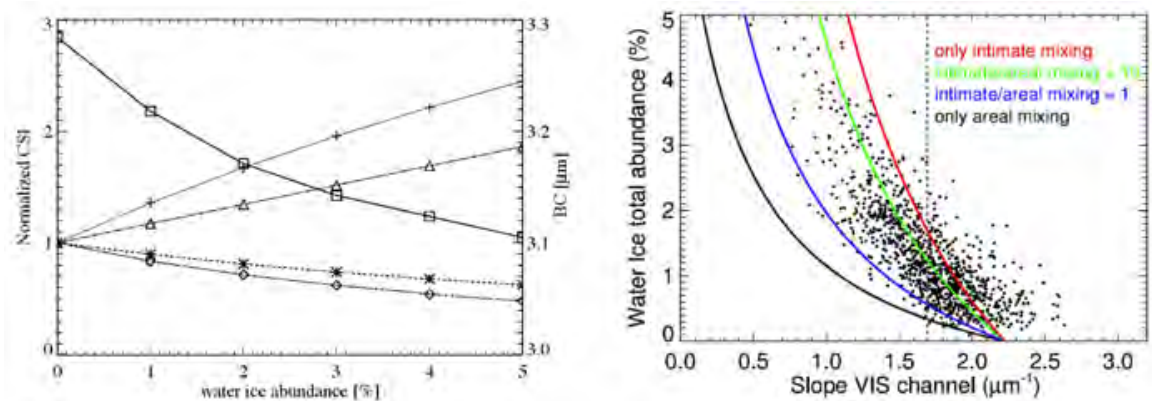

Fig. 12 Left panel: Simulated VIRTIS comet spectral indicators (CSI) normalized at their value computed on 67P/CG average dark terrain (shown in Fig. 2) as a function of water ice abundance: $\mathrm{S}_{V I S}$ (diamonds), $\mathrm{S}_{I R}$ (asterisks), $3.2 \mu \mathrm{m}$ BA (crosses) and single scattering albedo (triangles). The $3.2 \mu \mathrm{m} \mathrm{BC} \mathrm{(squares)} \mathrm{is} \mathrm{not} \mathrm{normalized,} \mathrm{and} \mathrm{its} \mathrm{scale} \mathrm{is} \mathrm{reported} \mathrm{on}$ the right axis. From Ciarniello et al. (2016). Right panel: theoretical abundance of water ice as a function of the slope in the VIS channel, as calculated by means of the Hapke (1993) radiative transfer model. The red and black lines correspond to water ice entirely in intimate or in areal mixture with the dark terrain, respectively. The blue and green lines correspond to the ratio between the amount of water ice in intimate and areal mixture equal to 1 and 10, respectively. Dots: water ice total abundance as a function of the measured slope in the VIRTIS VIS channel (for single acquisitions). Dashed grey line: average slope of the dots. The width of the dashed line is equal to the error on the average slope. From Raponi et al. (2016).

where $R(\lambda)$ are the radiance factors at a given filter wavelength $\lambda$. Oklay et al. (2016a) have identified three surface classes on $67 \mathrm{P} / \mathrm{CG}$ nucleus by means of OSIRIS spectral slopes values:

1. 8 to $13 \% / 100 \mathrm{~nm}$ corresponds to the surfaces where activity is observed: Hapi, active pits, alcoves, and bright water ice-rich features in Imhotep;

2. 13 to $15 \% / 100 \mathrm{~nm}$ characterizes either surfaces partially covered by material ejected from active spots or inactive areas peppered with small bright features;

3. $>15 \% / 100 \mathrm{~nm}$ is typical red color of the inactive surfaces where the dehydrated dust dominates.

In Fig. 13 is shown a sequence of color images and corresponding spectral slopes showing long-lasting (several months up to the entire mission) clusters and isolated icy features in Imhotep. All these regions enriched in water ice were existing on the surface when Rosetta reached the comet. The initial bluish color observed in 2014 on these features became much less evident in 2015 and finally disappeared in 2016 (top panel). However, the large isolated water icy feature (labeled IF) was existing on the surface since the first imaging to the last imaging of the area (Oklay et al. 2017). At the same time the spectral slopes from neutral become more and more red, similar to the non icy terrain, indicating that the ice fraction on the surface has sublimated (bottom panel). A further discussion about compositional changes caused by diurnal and seasonal effects is given in Section 4. 

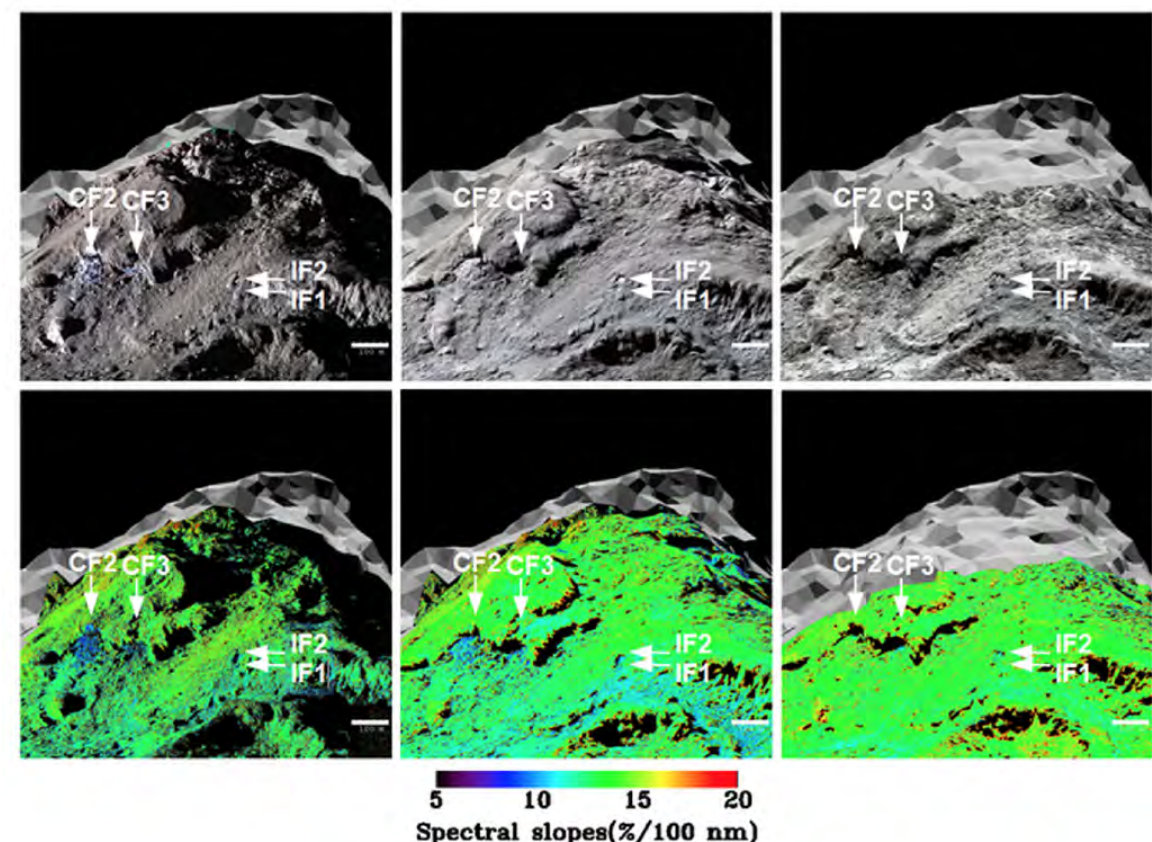

Fig. 13 Top panel: sequence of images showing several cluster features $(\mathrm{CF})$ and isolated features (IF) on three epochs of 2014, 2015 and 2016 (from left to right column). A $100 \mathrm{~m}$ scale-bar is shown in the right corner of each image. All images are projected onto a $3 \mathrm{D}$ shape model and displayed in a common frame to show the features in the same orientation. Images taken at 882.1 and $649.2 \mathrm{~nm}$ are used in the R and G channels, while 360.0 or 480.7 $\mathrm{nm}$ images are used for the B channel. Bottom panel: spectral slope images, showing the reduction of the ice on the surface. Retrieved water ice abundances for CF-IF features are given in Table 5. From Oklay et al. (2017).

The properties of the water ice rich areas on several locations as derived from OSIRIS images are reported in Table 5. The spectral modeling in the visible spectral range performed by Fornasier et al. (2016) and Oklay et al. (2017) is based on the same assumption of areal mixing between $30 \mu \mathrm{m}$ water ice grains and dark terrain. The thermal modeling performed in both studies gave more information about the water ice content, including the ice thickness estimations from several tens of centimeters up to several meters according to the lifetime of different water ice rich features. The locations for which retrievals from infrared observations are available are marked for comparison with Table 4. On average, water ice abundances derived from OSIRIS images are up to a factor 4 higher than those derived from VIRTIS data. This difference can be ascribed to three concurrent effects that need to be considered when comparing the results: 1) the spatial resolution between the two instruments is very different with OSIRIS NAC resolution about 7 times better than VIRTIS. As a consequence of this, OSIRIS can detect more pure areas within one VIRTIS pixel resulting in locally higher abundances; 2) the a-priori choice 
Table 5 Visible filters identification of water ice species, abundances and distributions on the surface of $67 \mathrm{P} / \mathrm{CG}$. Water ice abundance is computed assuming areal mixing and $30 \mu \mathrm{m}$ water ice grain size. Labels ${ }^{c},{ }^{d},{ }^{e}$ indicate similar areas in Table 4 for comparison.

\begin{tabular}{cccccc}
\hline \multicolumn{1}{c}{ Comet } & Region & Area size & Ice & Abundance & Reference \\
\hline $67 \mathrm{P} / \mathrm{CG}$ & Imhotep CF1 & $8373.8 \mathrm{~m}^{2}$ & $\mathrm{H}_{2} \mathrm{O}$ & 6 to $25 \%$ & Oklay et al. (2017) \\
$67 \mathrm{P} / \mathrm{CG}$ & Imhotep CF2 $^{c}$ & $14652.8 \mathrm{~m}^{2}$ & $\mathrm{H}_{2} \mathrm{O}$ & 6 to $20 \%$ & Oklay et al. (2017) \\
$67 \mathrm{P} / \mathrm{CG}$ & Imhotep CF3 & $4652.2 \mathrm{~m}^{2}$ & $\mathrm{H}_{2} \mathrm{O}$ & 15 to $10 \%$ & Oklay et al. (2017) \\
$67 \mathrm{P} / \mathrm{CG}$ & Imhotep IF1 & $126.5 \mathrm{~m}^{2}$ & $\mathrm{H}_{2} \mathrm{O}$ & $6 \%$ & Oklay et al. (2017) \\
$67 \mathrm{P} / \mathrm{CG}$ & Imhotep IF2 & $74.5 \mathrm{~m}^{2}$ & $\mathrm{H}_{2} \mathrm{O}$ & $48 \%$ & Oklay et al. (2017) \\
$67 \mathrm{P} / \mathrm{CG}$ & Anhur-Bes patch A & $\approx 1500 \mathrm{~m}^{2}$ & $\mathrm{H}_{2} \mathrm{O}$ & $21 \%$ (ice) or $23 \%$ (frost) & Fornasier et al. (2016) \\
$67 \mathrm{P} / \mathrm{CG}$ & Anhur-Bes patch B & $\approx 1500 \mathrm{~m}^{2}$ & $\mathrm{H}_{2} \mathrm{O}$ & $29 \%$ (ice) or $32 \%$ (frost) & Fornasier et al. (2016) \\
\hline
\end{tabular}

to use only areal mixing and fixed grain size to model OSIRIS data; 3) the different timing of OSIRIS and VIRTIS observations.

Apart from $67 \mathrm{P} / \mathrm{CG}$, water ice deposits have been observed on the surface of the 9P/Tempel 1 nucleus by Deep Impact (Sunshine et al. 2006) and identified by means of their blue colors at visible wavelengths and by absorption bands at 1.5, 2.0, 3.0 $\mu \mathrm{m}$ (Fig. 14). Spectral modeling indicates that the deposits are 3-6\% enriched in water ice with grain sizes of $30 \pm 20 \mu \mathrm{m}$. Nucleus morphology and illumination conditions limit the surface temperature between 285 and $295 \mathrm{~K}$ on the deposits, much colder than the maximum 330 $\mathrm{K}$ observed on the more illuminated areas. Moreover, the rapid appearance of large amounts of volatiles in the earliest ejecta after the impact of the projectile probe implies that water ice is quite near the surface (A'Hearn et al. 2005b). While detected on expelled chunks in the coma, water ice has not been directly detected by the EPOXI mission on the surface of 103P/Hartley 2 (A'Hearn et al. 2011). Also DeepSpace 1 has not found spectral evidence of absorptions due to water ice in the 1.3-2.6 $\mu \mathrm{m}$ spectral interval when observing the $9 \mathrm{P} /$ Borrelly nucleus with a spatial resolution of $160 \mathrm{~m}$ (Soderblom et al. 2002). 


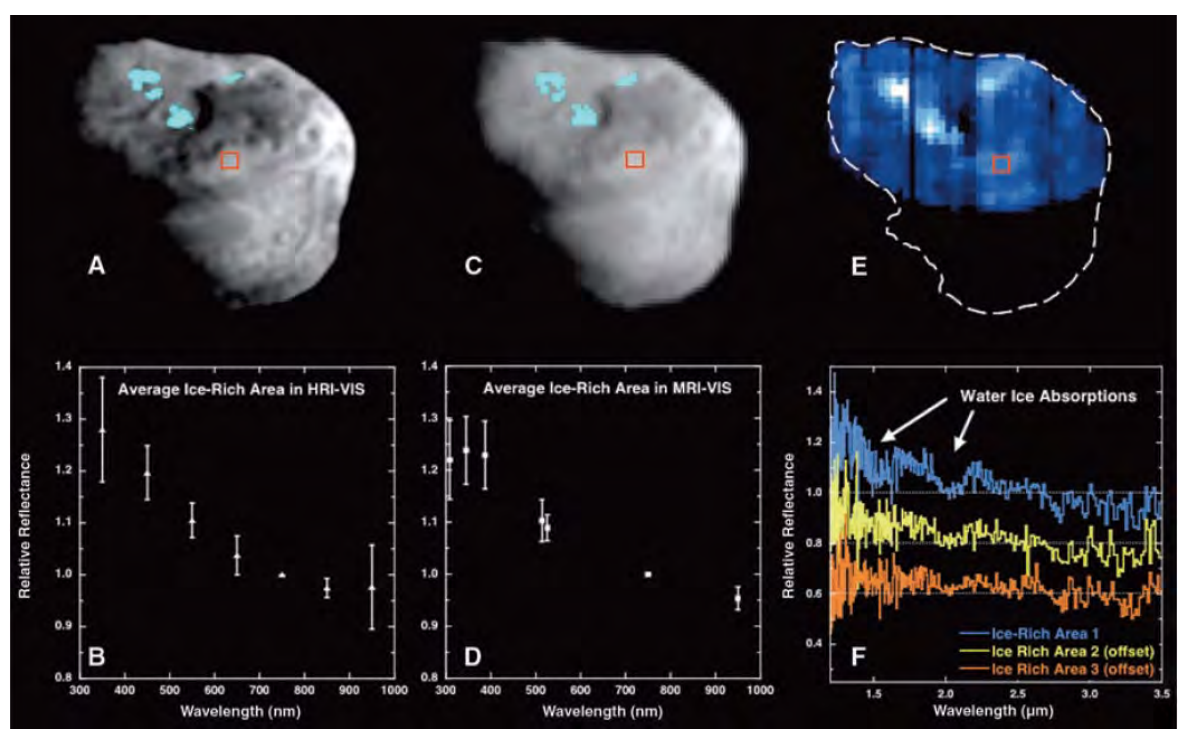

Fig. 14 Optical and spectral identification of ice-rich areas relative to non-ice regions on the 9P/Tempel 1 nucleus by Deep Impact. Panels A-B: HRI visible data and filters spectra at $16 \mathrm{~m} /$ pixel. Panels C-D: MRI visible data and filters spectra at $82 \mathrm{~m} /$ pixel. Panels E-F: strength of the $2.0 \mu \mathrm{m}$ water ice absorption and relative reflectance at $120 \mathrm{~m} /$ pixel. Note that the IR scan at the highest resolution only covers the upper half of the nucleus, as shown. The ice-rich areas are mapped in the visible images as combinations of high $450 \mathrm{~nm} / 750 \mathrm{~nm}$ relative reflectance $(387 \mathrm{~nm} / 750 \mathrm{~nm}$ for MRI) and low $950 \mathrm{~nm} / 750 \mathrm{~nm}$ relative reflectance. From Sunshine et al. (2006).

\subsection{Organic materials}

While cometary ice species are easily identifiable on VIS-IR reflectance data by means of their high albedo and numerous and well-known absorption bands, a much more challenging effort is to determine the composition of complex organic materials which can be grouped in the 'CHON' (Carbon, Hydrogen, Oxygen, Nitrogen) families (Whipple 1950; Clark et al. 1987). The emission features caused by the stretching and bending modes of organic (aliphatic and aromatic) compounds observed in the circumstellar envelope of evolved stars and in the interstellar medium (Kwok 2007) clearly indicate that plentiful $\mathrm{C}$ is available in the Universe (Pendleton and Allamandola 2002) and in the early solar system (Kerridge 1999). A large fraction of the carbon in the Universe is assembled in Polycyclic Aromatics (PAHs) resulting in the third most abundant molecular species after $\mathrm{H}_{2}$ and $\mathrm{CO}$ (Wooden et al. 2004). PAH were identified by means of their UV-visible (Moreels et al. 1994) and 3.2-3.6 $\mu \mathrm{m}$ infrared emissions (Bockelée-Morvan et al. 1995) for many cometary comae. In Pizzarello et al. (2006) is given a thorough review of the chemical properties of the organic materials found in meteorites and interplanetary dust particles (IDPs). 
Apart from their intrinsic low albedo, which implies lower signal, and red slopes at visible wavelengths, the majority of the organic materials in the 'CHON' inventory are characterized by vibrational modes carried by hydrocarbons, oxygen/nitrogen-bonds and acids chemical groups within the 3.0-3.6 $\mu \mathrm{m}$ spectral range (see Table 6 ).

Table 6 Diagnostic absorption bands of functional groups containing 'CHON' in the near infrared spectral range (Socrates 2001). Note: * Aliphatic compounds can be saturated, joined by single bonds (alkanes), or unsaturated, with double bonds (alkenes) or triple bonds (alkynes).

\begin{tabular}{|c|c|c|c|c|}
\hline Chemical Group & Functional Group & Vibration type & Absorption wavelength $(\mu \mathrm{m})$ & Intensity \\
\hline Alcohol & $\mathrm{O}-\mathrm{H}$ & stretch H-bonded & $2.78-3.12$ & strong-broad \\
\hline Alcohol & $\mathrm{O}-\mathrm{H}$ & stretch-free & $2-70-2.86$ & strong-sharp \\
\hline Alkane* & $\mathrm{C}-\mathrm{H}$ & stretch & $3.33-3.51$ & strong \\
\hline Alkene* & $=\mathrm{C}-\mathrm{H}$ & stretch & $3.23-3.32$ & medium \\
\hline Alkyne* & $\mathrm{C}-\mathrm{H}$ & stretch & 3.03 & strong-sharp \\
\hline Alkyne* & $-\mathrm{C} \equiv \mathrm{C}-$ & stretch & $4.42-4.76$ & variable \\
\hline Aliphatic hydrocarbon & $\mathrm{CH}_{2}$ & stretch & 3.42 (asym), 3.51 (sym.) & sharp \\
\hline Aliphatic hydrocarbon & $\mathrm{CH}_{3}$ & stretch & 3.38 (asym), 3.48 (sym.) & sharp \\
\hline Aromatic hydrocarbon & $\mathrm{C}-\mathrm{H}$ & stretch & $3.22-3.33$ & medium \\
\hline Amine & $\mathrm{N}-\mathrm{H}$ & stretch & $2.86-3.03$ & medium \\
\hline Nitrile & $\mathrm{C} \equiv \mathrm{N}$ & stretch & $4.35-4.55$ & medium \\
\hline IsoNitrile & $\mathrm{C} \equiv \mathrm{N}$ & stretch & $4.59-4.67$ & medium \\
\hline Carboxylic acid & $-\mathrm{COOH}$ & stretch & $3.03-4.00$ & strong-very broad \\
\hline Aldehyde & $=\mathrm{C}-\mathrm{H}$ & stretch & $3.63-3.68$ & medium \\
\hline Aldehyde & $=\mathrm{C}-\mathrm{H}$ & stretch & $3.51-3.55$ & medium \\
\hline Amide & $\mathrm{N}-\mathrm{H}$ & stretch & $2.85-3.22$ & medium \\
\hline
\end{tabular}

The wide $3.2 \mu \mathrm{m}$ band visible on the average spectral reflectance of $67 \mathrm{P} / \mathrm{CG}$ dark terrain (Fig. 2) has been attributed to a complex organic material with a variety of contributing species (Capaccioni et al. 2015). The broadness of the band may be explained by the contribution from carboxylic $\mathrm{O}-\mathrm{H}$ with plausible contributions from aliphatic and aromatic C-H, as well as alcoholic/phenolic O-H (Capaccioni et al. 2015; Quirico et al. 2016). The $3.2 \mu \mathrm{m}$ band appears distorted by two concurring effects, namely the presence of $\mathrm{OH}$ stretch which causes the broadening of absorption in the 2.7-3.0 $\mu \mathrm{m}$ range, and the surface thermal emission which influences the infrared spectral range starting from $3.5 \mu \mathrm{m}$ range (Filacchione et al. 2016c). For this reason the best VIRTIS data to study the $3.2 \mu \mathrm{m}$ band are those collected during Rosetta's prelanding phase when the surface was still relatively dehydrated and cold $(\mathrm{T}<230 \mathrm{~K})$. Approaching perihelion, the superficial water ice fraction increases (see discussion in Section 4) and the thermal emission becomes dominant with respect to the absorption bands exhibited by the reflectance spectra. In the following paragraphs we give a summary of the different organic materials which best-match the observed infrared spectral features.

The $\mathrm{C}-\mathrm{H}$ bonds in methylene $\left(\mathrm{CH}_{2}\right)$, methyl $\left(\mathrm{CH}_{3}\right)$ aliphatic groups and in aromatic hydrocarbons can be identified by means of their symmetric and 
antisymmetric stretch vibration modes (Table 6). Some of these features are compatible with the secondary absorptions shown in Fig. 2 - bottom panel (Raponi et al. 2018). Similar aliphatic features have been identified on other solar system objects, including Ceres (De Sanctis et al. 2017), Saturn's rings (Filacchione et al. 2014) and Iapetus (Cruikshank et al. 2014).

Within the instrument limitations (calibration residual at $4.6 \mu \mathrm{m}$ and removal of the thermal emission), VIRTIS data seems to indicate little to null contribution of the amine and nitrile groups (Capaccioni et al. 2015) confirming that $67 \mathrm{P} / \mathrm{CG}$ is depleted in $\mathrm{N}$ with respect to other comets. A similar indication is in agreement with ROSINA which has measured an average ratio of $\mathrm{N}_{2} / \mathrm{CO}=(5.70 \pm 0.66) \cdot 10^{-3}$ corresponding to a depletion by a factor of $\approx 25.4 \pm 8.9$ as compared to the protosolar value (Rubin et al. 2015). These data indicate that $67 \mathrm{P} / \mathrm{CG}$ must have formed at very low temperatures $(<30 \mathrm{~K})$ within the protosolar nebula resulting in a common origin with other Kuiper Belt objects.

Among the vast inventory of organic materials, coals, bitumens (Moroz et al. 1998; Quirico et al. 2016) and aliphatic-rich tholins (Quirico et al. 2008) share similar spectral features which make them a first class of analogs candidates for the identification of the hydrocarbon part of cometary organics. These compounds are characterized by a low reflectance and a neutral to red color at visible and near infrared wavelengths. Solid oil bitumens are complex macromolecular materials mostly consisting of polyaromatic and aliphatic hydrocarbons, that depending on their compositions and chemical structures are classified as asphaltites, kerites and anthraxolites (Moroz et al. (1998) and references therein). The fraction of kerogen relative to the fraction of solvent-soluble bitumen, carbon aromaticity, and $\mathrm{C} / \mathrm{H}$ ratio increase in this series from low-temperature asphaltites through kerites to the most thermally evolved high antraxolites (Moroz et al. (1998) and references therein). These changes are accompanied by a reduction of the spectral slope in the VNIR spectral range. High-kerites and low-anthraxolites show compositional and structural similarities to organic matter from CM2 and CI1 chondrites, while high-anthraxolites (shungites) resemble more carbonized organics in CV3 and CO3 chondrites (Moroz et al. 1998; de Bergh et al. 2008).

Tholins are synthesized by irradiation of simple C- and N-bearing compounds with solar UV radiation or energetic cosmic rays (Sagan and Khare 1979). The resulting compounds include amines, nitriles, and alkyne groups resulting in a prominent band around $3.2 \mu \mathrm{m}$ and various NIR overtone and combination bands. The VIS-NIR spectra of these polymer-like materials are characterized by a steep red slopes controlled by their carbon structure. Anhydrous tholins can be distinguished from ice tholins by the presence of the $\mathrm{C} \equiv \mathrm{N}$ stretches at 4.4-4.65 $\mu \mathrm{m}$ (Khare et al. 1994). In presence of methylene $\left(\mathrm{CH}_{2}\right)$ - and methyl $\left(\mathrm{CH}_{3}\right)$ - bonds, the aliphatic tholins are formed (Quirico et al. 2008). These are recognizable by means of their C-H stretches between 3.38-3.51 $\mu \mathrm{m}$ (see Fig. 15, left panel). The results of PTOLEMY and COSAC onboard Philae lander are compatible with the presence of polyoxymethylene (POM) chains in semi-volatile compounds (Wright et al. 2015; Goesmann 


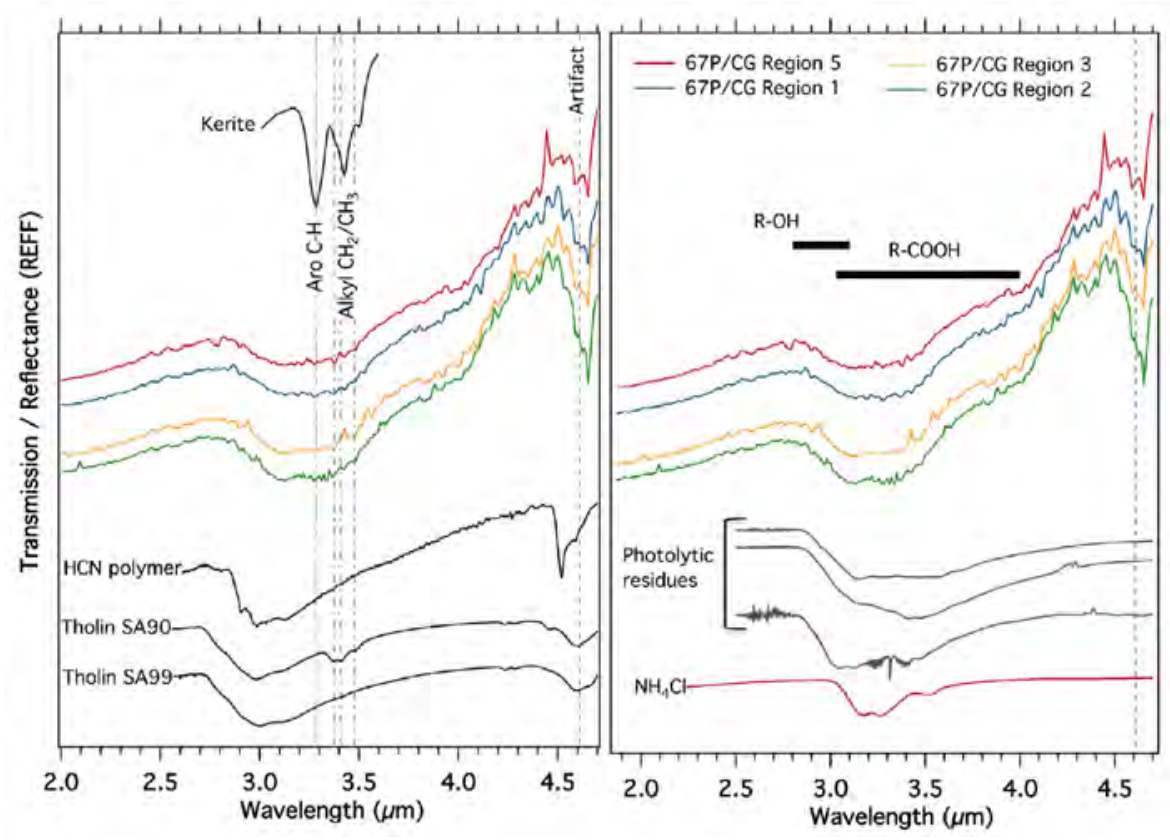

Fig. 15 Left panel: representative reflectance spectra of 67P/CG regions compared with reflectance spectra of low-anthraxolite (Moroz et al. 1998), transmission spectra of tholins (Quirico et al. 2008) and HCN polymer (Bonnet et al. 2015) (data with offset for clarity). The spectral shift in the position of the aliphatic modes in the low anthraxolite with respect to those of the tholin SA90 (vertical dash-dotted lines) is due to the nitrogen content. The dashed line indicates the position of the $4.6 \mu \mathrm{m}$ artifact on VIRTIS data which also fits the position of the OCN-anion in laboratory experiments. Right panel: further comparisons with transmission spectra of ammonium salt (from NIST database) and of photolytic residues produced under varying conditions (Muñoz Caro and Schutte 2003). From Quirico et al. (2016).

et al. 2015). The possible POM (long debated as a possible parent molecule of formaldehyde in comets) detection by PTOLEMY and COSAC is, however, a controversial issue. While the teams have interpreted their data as fragments of POM, later on Altwegg et al. (2017) concluded that a similar interpretation of the results is not unique because other $\mathrm{CHO}$-bearing molecules can be compatible with the measurements.

Phenolic and alcoholic OH groups (Pizzarello et al. 2006; Kolb and Liesch 2008) can contribute to the VIRTIS spectra of the 67P surface in the 2.7-3.1 $\mu \mathrm{m}$ spectral range (see Fig. 15, right panel).

Carboxylic Acids (R-COOH) are the main component in the soluble organic fraction in primitive meteorites, with several tens of carboxylic, dicarboxylic and hydroxylated acids identified so far (Sephton et al. 2002). Infrared spectra of these acids show a wide absorption in the 3.0-4.0 $\mu \mathrm{m}$ spectral range (see Fig. 15, right panel). Phenols and carboxylic acids can coexist in the same macromolecular structure, e.g., in solid bitumens and coals, but their contents 
are too low to show the intense absorption bands typical of the VIRTIS spectra. Quirico et al. (2016) suggested O-H in carboxylic acids as a highly plausible carrier of the broad absorption band in the VIRTIS spectra of the $67 \mathrm{P} / \mathrm{CG}$ nucleus surface.

Among amines-bearing compounds, HCN polymers (Bonnet et al. 2015) have some similarities with $67 \mathrm{P} / \mathrm{CG}$ spectra even if the high-abundance $\mathrm{N}$ species seems to be incompatible with the Rosina results (Altwegg et al. 2017). HCN polymers are characterized by the presence of an amine absorption band which extends from 2.7 to $3.7 \mu \mathrm{m}$ and is much broader than the $3.2 \mu \mathrm{m}$ band observed by VIRTIS towards shorter wavelengths (Fig. 15, left panel). Moreover, the strong nitrile absorption at $4.5 \mu \mathrm{m}$ shown in the polymer spectrum cannot be safely identified in VIRTIS data.

Other viable candidates are ammonium and cyanide salts. Ammonium salts contain the ammonium ion $\mathrm{NH}_{4}^{+}$which absorbs between 2.94 and $3.34 \mu \mathrm{m}$. In the residues formed by irradiation or heating of ice mixtures, the ammonium ion is often associated with the $\mathrm{OCH}^{-}$group (Quirico et al. 2016). The cyanide salts form by annealing $\mathrm{NH}_{3}+\mathrm{HCN}$ ices (Gerakines et al. 2004). Prolonged heating or irradiation of the ice mixtures by UV photons or energetic particles form refractory organic residues which include a variety of carboxylic acids and ammoniated salts, esters and amides (Muñoz Caro and Schutte 2003). The ammonium ion spectrum shown in Fig. 15, right panel, appears as a viable candidate, while photolytic residues may display a broad feature that encompasses the $3.2 \mu \mathrm{m}$ band.

Apart form 67P/CG, organic materials have been detected in infrared spectra of other comets. For 19P/Borrelly Soderblom et al. (2002) reported about the presence of a spectral band at $2.39 \mu \mathrm{m}$ about $0.02 \mu \mathrm{m}$ wide. The origin of the absorption feature is unknown but it could be compatible with various hydrocarbons such as polyoxymethylene. Infrared emission features at 3.3-3.4 $\mu \mathrm{m}$ of organics have been detected in the coma of 103P/Hartley 2 (A'Hearn et al. 2011) where are mainly associated with $\mathrm{CO}_{2}$-rich jets. A review of the organic species detected in $67 \mathrm{P} / \mathrm{CG}$ dust and in other comets is given in the Dust composition chapter (Engrand)-add reference.

\subsection{Inorganic refractories}

From the compositional analysis of 67P/CG dust grains (Bardyn et al. 2017) and from the inventory of mineral species detected on Stardust grains (Keller et al. 2006; Dobrică and Brearley 2011), interplanetary dust particles or IDPs (Engrand et al. 2016) and micrometeorites (Dobrică et al. 2011; Dobrică et al. 2012), we know that cometary inorganic refractories are dominated by a mixture of minerals including anhydrous Mg-rich silicates, Ni-bearing iron, Fe sulfides and glassy phases with embedded metals and sulphides or GEMS (Leroux et al. 2015). Other plausible refractory endmembers are amorphous and graphitic carbon present in the the interstellar medium dust particles (Papoular 2001). 

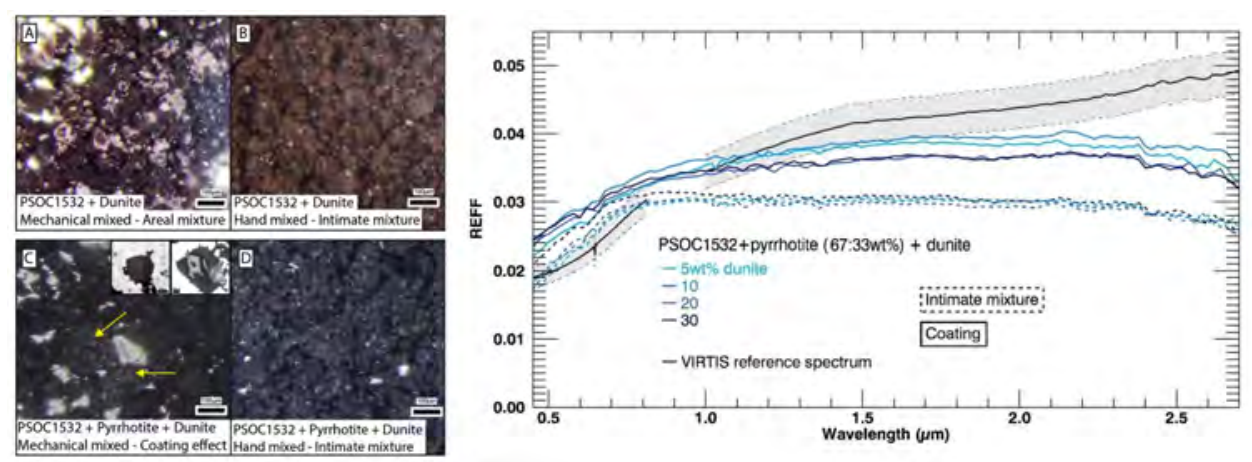

Fig. 16 Left: Optical binocular images of different mixtures sieved to grains $<25 \mu \mathrm{m}$ after a colloidal grinding with a planetary grinder. (A) Areal mixture of coal PSOC 1532 and dunite mixed with grinder MM200 without milling balls. (B) Intimate mixture of PSOC 1532 and dunite hand-mixed into a mortar with a pestle. (C) PSOC 1532, dunite and pyrrhotite are mixed with the grinder MM200 as sample A. Pyrrhotite coats unbroken aggregates of dunite and organics (yellow arrows). Boxes in the upper right corner show broken aggregates of PSOC 1532 and dunite. (D) Intimate mixture of PSOC 1532, dunite and pyrrhotite, hand mixed into a mortar. Right: Reflectance spectra of mechanically mixed ternary mixtures of coal PSOC 1532, pyrrhotite and dunite. This protocol preserves clumps of organics and silicate which are coated by pyrrhotite grains (solid lines). The resulting spectra are similar to the ones of the intimate mixtures (dashed lines) in the visible while they are redder and brighter in the infrared range. The fraction of dunite varies from $5 \mathrm{wt} \%$ to $30 \mathrm{wt} \%$ but does not lead to strong variations of the spectral shape. From Rousseau et al. (2018).

The presence of fine-grained opaques (including Fe-sulphides) is responsible for the reduction of the visible-near infrared albedo and of the reduced spectral contrast within the $3.2 \mu \mathrm{m}$ absorption band (Moroz et al. 2017). A thorough spectral investigation of cometary refractories analogs in the laboratory within the $0.45-2.7 \mu \mathrm{m}$ interval has shown that $67 \mathrm{P} / \mathrm{CG}$ spectral properties in this range can be reproduced by a mixture of coal, pyrrhotite and dunite grains (Rousseau et al. 2018). Noteworthy, the mixing state among these endmembers can drastically change the spectral properties of the sample (Fig. 16, left panel). This effect is mainly due to the coating of fine pyrrhotite particles occurring on the surfaces of larger clumps of coal and silicate grains. To date, the best spectral match to VIRTIS data in this range (Fig. 16, right panel) is achieved with a mixture of coal and pyrrhotite (in proportion $67: 33 \mathrm{wt} \%$ ) with a variable amount of dunite (between 5 to $30 \%$ ). The sample fails to completely reproduce correctly the visible-near infrared spectral slope but this could be compensated by adding few percent of H-rich organic material which typically introduce a reddening at visible-near infrared wavelengths.

The spectral properties of mixtures of organic material with opaque phases have been investigated by Moroz et al. (2017). Pyrrhotites and troilites are sulphides characterized by a decrease in reflectance with decreasing grain size, which is typical for opaque phases (Hunt et al. 1971). Mixtures containing sub-micron sulfides grains have the capability to drastically reduce the visible and near infrared albedo. Coarse size sulfides grains are much less effective in 
reducing the albedo than fine-grained ones. This could help in explaining the low albedo of $67 \mathrm{P} / \mathrm{CG}$ 's nucleus, as discussed in Section 2.1. The presence of a small amount of fine-grained opaque phase can effectively reduce the overall albedo of a bright material. In a similar way, the spectral reflectance of the ubiquitous dark terrain observed by VIRTIS on the surface of $67 \mathrm{P} / \mathrm{CG}$ could be explained by the presence of fine-grained opaques and organic refractories, while the presence of silicate is much less significant (Moroz et al. 2017; Rousseau et al. 2018). The analysis of reflectance spectra of kerite-troilite and kerite-pyrrhotite mixtures in different percentages made by Moroz et al. (2017) shows that Fe-sulfides intimately mixed with organic material significantly influence shapes and relative contrasts of absorption bands within the wide 3.2 $\mu \mathrm{m}$ band. The authors showed that the positions of individual aromatic $\mathrm{C}-\mathrm{H}$ and aliphatic $\mathrm{CH}_{2}$ and $\mathrm{CH}_{3}$ absorption bands coincide with the fine structure observed within the average spectrum of the 67P/CG's surface shown in Fig. 2 - bottom panel.

\subsection{Spectrophotometry of ice-containing cometary analogs}

It is commonly thought that while cometary nuclei are ice-rich in bulk, the low albedo of their surfaces is due to the presence of an optically thick desiccated layer, either a consequence of the sublimation of ice from the surface or rediposition of dry dust emitted by the cometary activity. Various laboratory experiments have reproduced the darkening of analogs for cometary matter, as the ice initially mixed with dark refractory dust sublimates, resulting in the formation and thickening of a porous sublimation lag (Oehler and Neukum 1991). The red spectral slope of these analogs also increases as the albedo decreases, resulting in the negative correlation between these parameters systematically observed at the surface of the nucleus of $67 \mathrm{P}$ (Pommerol et al. 2015; Poch et al. 2016b,a; Jost et al. 2017a).

However, many experiments show that it is actually possible to hide large amounts of water ice when intimately mixed with fine-grained dust which acts like a coating on larger grains. In these cases fine absorbing grains mixed with water ice have a darkening effect disproportional to their abundance. Measurements of the bidirectional visible reflectance of binary mixtures of calibrated water ice particles and reference lunar regolith simulant JSC1-AF (Figure 17) have shown that it is possible to mix up to $75 \%$ of ice by weight within the dust without increasing its reflectance notably, therefore making this ice hardly detectable for visible imagers (Yoldi et al. 2015). Similar measurements with dust analogs more relevant to cometary matter show even more pronounced effects, with as little as 2 wt. \% of fine-grained charcoal required to decrease the albedo of $70 \mu \mathrm{m}$ diameter ice particles to the value measured at the surface the nucleus of comet 67P (Jost et al. 2017b). Additional details about the choice of samples for cometary analogs and the set of measurements acquired are provided in Lab measurements Chapter (Pommerol)-add reference. 


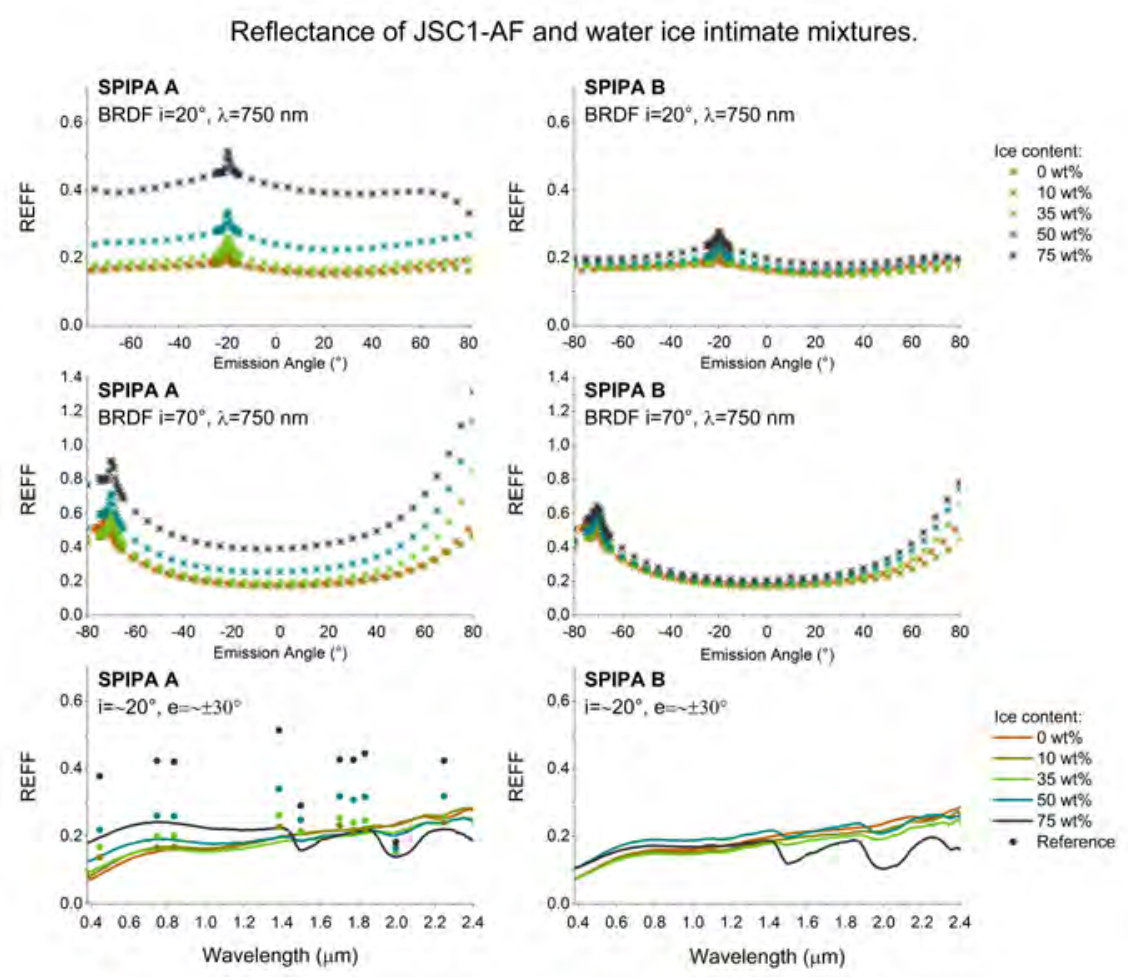

Fig. 17 Measured VIS $(750 \mathrm{~nm})$ phase curves (top: incidence $=20^{\circ}$ and middle: incidence $\left.=70^{\circ}\right)$ and VIS-NIR $(0.4-2.4 \mu \mathrm{m})$ reflectance spectra (bottom) of binary mixtures of the JSC1-AF simulant for fine lunar dust (McKay et al. 1993) with fine-grained ice (SPIPAA, left) and coarser-grained ice (SPIPA-B, right) in variable concentrations. The fine-grained ice (SPIPA-A) has a mean particle diameter of about $5 \mu \mathrm{m}$ whereas the coarser-grained ice (SPIPA-B) has a mean particle diameter of about $70 \mu \mathrm{m}$. These well-calibrated ice samples have been produced using dedicated Setups for the Production of Icy Planetary Analogs (SPIPA) developed at the University of Bern. From Yoldi et al. (2015).

The first consequence of these results is that the bright patches and regions observed at the surface of the nucleus must be very ice-rich if the ice is mixed intimately with the refractory dust. Depending on the size of the ice particles and both the size and composition of the dust particles, the measured reflectance factors of the bright patches that are several times higher than the average of the nucleus surface could indicate nearly pure ice. Alternative scenarios that would lead to lower inferred ice contents are areal mixtures at scales smaller than the resolution of OSIRIS NAC, i.e. centimeters to tens of centimeters, or the presence of frost at the surface of the dust grains. Both scenarios are plausible with ample evidence for frost deposition and sublimation at diurnal timescales (de Sanctis et al. 2015; Fornasier et al. 2016) and evidence for the formation of large particles of ice by re-condensation or sintering (Filacchione et al. 2016a). The second important implication of these 
experimental result is that the low albedo of the vast majority of the surface of the nucleus alone doesn't preclude the presence of large amounts of ice at the surface if it is intimately mixed with the dust, as expected for primordial ices that have condensed as layers around the surfaces of the dust grains. Therefore, the nucleus might be constituted of an ice-rich interior coated by a desiccated layer but punctuated by bright icy patches that form by re-condensation of sublimated water vapour and/or sintering of the ice and segregation from the dust.

The infrared spectral range contains more sensitive and diagnostic features for the presence and properties of water ice. Recent experiments by Yoldi et al. (2015) have been conducted to verify if the masking of the ice by dark dust seen in the visible spectral range is also efficient in the infrared. Binary mixtures between water ice and lunar regolith simulant (Figure 17) show that the spectral signatures of water ice can be identified for lower ice contents, of about $1 / 3$ by weight and possibly less. These infrared spectral signatures are thus significantly more sensitive to the presence of water ice than the visible albedo in the case of intimate mixtures. It still seems possible, however, to resolve at least 10 or $20 \mathrm{wt}$. \% of ice in the regolith depending on the properties of the ice and dust components. Unfortunately, the $3 \mu \mathrm{m}$ region, the most sensitive to the presence of water, was not investigated by Yoldi et al. (2015).

The intensity of the infrared signatures has been used to estimate both the ice content and the size of the ice particles by inverting the Hapke (1993) spectro-photometric model (see Lab measurements Chapter (Pommerol)-add reference). However, this leads to contradicting implications between relatively low amounts of ice (a few wt. \%) inferred from the infrared spectral features and much higher water ice contents required to explain the bright features in the visible range in the hypothesized case of purely intimate mixtures. This possibly means that the mode of association between ice and dust is generally not dominated by intimate mixtures at the grain scale and that recondensation and sintering leading to segregation of the ice and the dust are active in the surface layers of the nucleus probed by optical remote-sensing. New controlled experiments using more realistic low-albedo cometary dust analogs and reflectance measurements spanning both the visible and infrared spectral ranges up to $4 \mu \mathrm{m}$ need to be performed to better understand the amount and state of water ice compatible with Rosetta observations of $67 \mathrm{P} / \mathrm{CG}$ 's nucleus surface.

\section{Compositional changes driven by seasonal cycle and activity}

By orbiting in the vicinity of $67 \mathrm{P} / \mathrm{CG}$ for more than two years around the perihelion passage, from July 2014 to September 2016, Rosetta's remote sensing instruments had the opportunity to observe the nucleus with unprecedented spatial and temporal resolutions allowing to trace morphologic and compositional changes occurring on the surface at different heliocentric distances and local times. Thanks to these characteristics it was possible to follow the 
compositional variations caused by activity and seasonal cycles for different regions of the nucleus. $67 \mathrm{P} / \mathrm{CG}$ surface composition changes are driven by the following mechanisms:

1. Erosion of the surface due to the sublimation of water ice and other volatile species in the subsurface layers. This is the case for the roundish features formed in the Imhotep flat area in June-July 2015 (Groussin et al. 2015b) as a consequence of the deflating of the surface. The largest of these features developed with a lateral velocity of the order of $5.610^{-5}-8.1 \cdot 10^{-5} \mathrm{~m} / \mathrm{s}$ reaching diameters of $\approx 140-220 \mathrm{~m}$ with rims of about $5 \mathrm{~m}$ height (Fig. 18). The features' rim contours appear distinctively neutral to blue colored compared to the rest of surface where the visible spectral slope is $16 \%$ per $100 \mathrm{~nm}$. However, no unusual activity was observed during the formation or evolution of these large round features.

2. Localized activity in cliffs, fractures, pits, bright features areas appears correlated with the sources of dust jets (Vincent et al. 2016a). The jet activity was stable between successive nucleus rotations and is tuned by the local illumination conditions (Vincent et al. 2016b). As discussed in Section 3.1, the areas of local activity are enriched in water ice and are recognizable by means of their higher albedo and more neutral (8-13\%/100 $\mathrm{nm}$ ) visible spectral slope (Oklay et al. 2016a). This class encompasses the diurnal condensation and sublimation cycle of the water ice in Hapi discussed in Section 3.1.

3. Collapse of elevated structures, overhangs and cliffs resulting in the mechanical disruption of old terrains (Groussin et al. 2015a; Pommerol et al. 2015; Pajola et al. 2017) with consequent appearance of bright water icerich material in the exposed walls and nearby debris fields (Filacchione et al. 2016a; Vincent et al. 2016a; Oklay et al. 2016b, 2017).

4. Transfer and redeposition of the dust driven by the activity and local topography (Thomas et al. 2015; Keller et al. 2017; Hu et al. 2017). The material eroded and ejected from the south hemisphere is partially transferred to the northern regions during southern summer season (at perihelion). According to Lai et al. (2016), Hapi gains up to $0.4 \mathrm{~m}$ while Wosret loses up to $1.8 \mathrm{~m}$ of dust mantle per orbit. Some models indicate that about $20 \%$ of the eroded material in the south is deposited on the north hemisphere and that this airfall material is wet (Keller et al. 2017). This water ice rich airfall material was reported by Oklay et al. (2016b)

All these phenomena, occurring at different spatial and temporal scales, are affecting the surface composition: while the surface's disruption mechanisms give access to subsurface volatiles, and nocturnal condensation are able to enrich the outer layers with icy species, the transfer and consequent deposition of dust is responsible for the observed spatial homogeneity of the ubiquitous dark terrain composed of organic material and mineral dust grains (Capaccioni et al. 2015; Filacchione et al. 2016c; Ciarniello et al. 2016). However, the amount of water ice bound to dust grains is variable, depending on seasonal/diurnal cycle and local morphology. The major spectral changes were observed when 

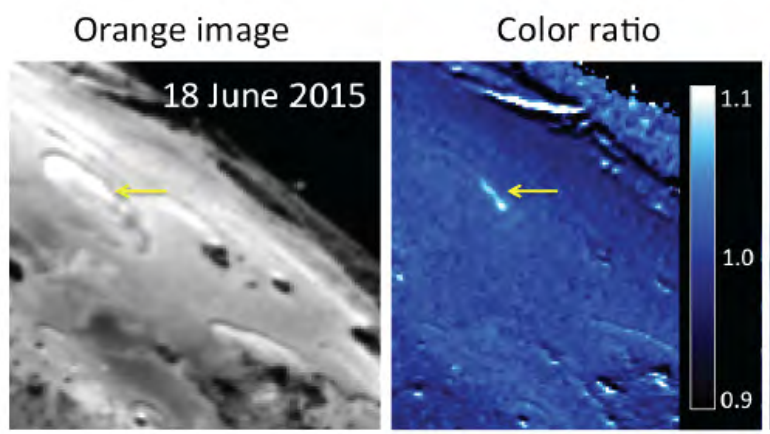

\section{Color composite}
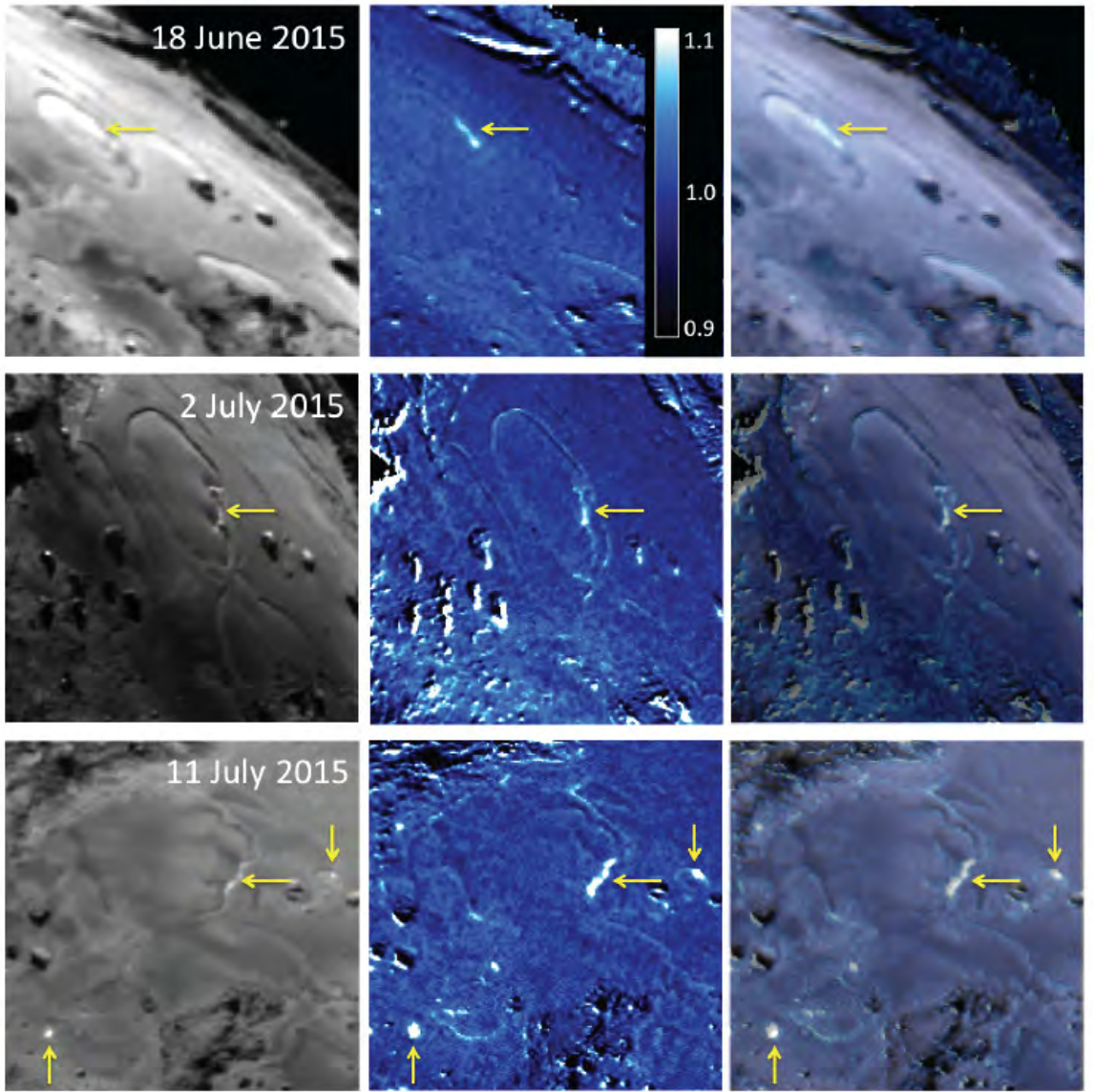

Fig. 18 The evolution of the roundish features developed in a flat area of the Imhotep. Blue $(481 \mathrm{~nm})$ over orange $(649 \mathrm{~nm})$ or red $(701 \mathrm{~nm})$ color ratios of the evolving region on 18 June 2015 (upper row), 2 July 2015 (middle row), and 11 July 2015 (lower row). The first column shows a context image of the region, the second column shows the color ratio (blue-to-orange for 18 June and 2 July, blue-to-red for 11 July), and the third column shows a color-composite image made of the first two columns. The yellow arrows indicate where erosion features started with a material bluer than average (value above 1 in the color ratio). The images were acquired by OSIRIS/NAC. From Groussin et al. (2015b).

67P/CG was near perihelion. At this time VIRTIS has measured an increase of the average albedo (up to $30 \%$ on average), the progressive bluening and flattening of the visible slope, the increase of the $3.2 \mu \mathrm{m}$ absorption band area caused by the $\mathrm{OH}$ absorption (Fig. 19) with the resulting shift of the band center towards shorter wavelengths (Filacchione et al. 2016c; Ciarniello et al. 2016). In the visible spectral range, also OSIRIS observed a decrease of the spectral slopes around the perihelion passage (Fornasier et al. 2016). All these 
effects are the consequence of the exposure of more icy and pristine terrains caused by the removal of the surface dust.

Spectral analysis conducted by Longobardo et al. (2017) shows that the 3.2 $\mu \mathrm{m}$ band depth is independent from phase angle but the band centre is slightly shifting towards longer wavelengths when the incidence angle increases. This effect is probably due to the exposure of water ice fraction on the surface by weak cometary activity at increasing temperatures. The fact that the $3.2 \mu \mathrm{m}$ band depth is uncorrelated to phase angle marks a substantial difference with the usual photometric responses of common materials which instead show an increase of the band depth at increasing phase angle. A similar effect is the consequence of the predominance of the multiple scattering on the band wings with respect to the single scattering on the band center occurring at high phases (Hapke 1993). This spectral behavior is interpreted by Longobardo et al. (2017) as the result of high abundance of fine-grained opaque species able to suppress not only the band itself, but also its dependence from the viewing geometry or by a different phase reddening able to change the band depth properties with phase.

The temporal evolution of three large water ice rich areas, BAP1-2 (Filacchione et al. 2016a) and SPOT6 (Barucci et al. 2016), is analyzed by Raponi et al. (2016) on IR spectra along a period of time of about 180 days during which the heliocentric distance was decreasing from 3.6 to $2.2 \mathrm{AU}$. The three regions show similar life cycles: the patches increase their dimensions and surface ice abundance, reach a maximum and then rapidly decrease until, eventually, the ice completely disappears from the surface. Since these three areas are located very close to the equator they share similar thermal history and evolution. However, the local topography drives the timing of the maximum dimension and water ice abundance. A similar trend is interpreted by means of the exposure of deeper water ice-rich layers which is consistent with the local morphology of these areas where overhang falls or landslides have caused the exposure of fresh material. After the initial exposure of the ice, the local activity increases removing more and more surface dust thank to the ice sublimation giving a positive feedback on the exposure itself. The process continues while the nucleus approaches the Sun and it reaches a turning point when the sublimation rate prevails on the exposure rate, until the complete sublimation of the patch occurs (Raponi et al. 2016).

\section{Conclusions}

We have reviewed the principal results achieved by in situ and remote sensing payloads aboard the Rosetta orbiter and Philae lander aiming to determine the composition of comet $67 \mathrm{P} / \mathrm{CG}$ and, where possible, to compare these results with data of other known comets. The determination of surface composition is a difficult task given the cometary active environment and the rough surface morphology. Moreover, the measurements were limited by the constraints given by Rosetta's orbit and Philae's not-nominal landing. In general the assessment 


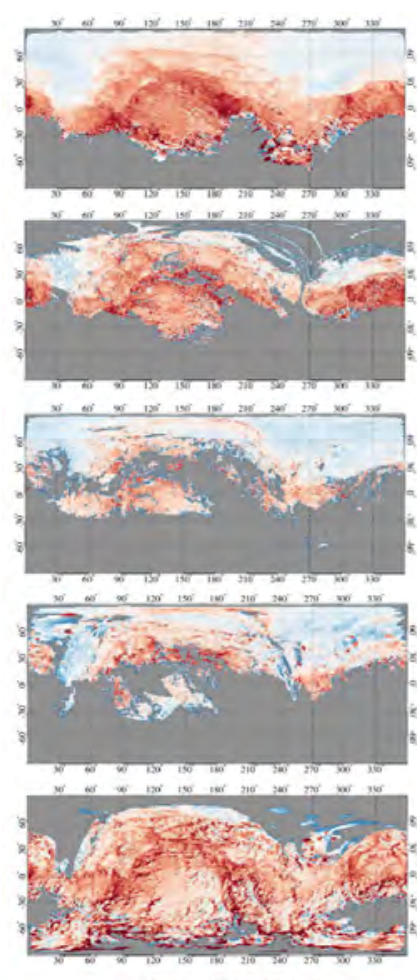

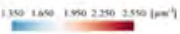
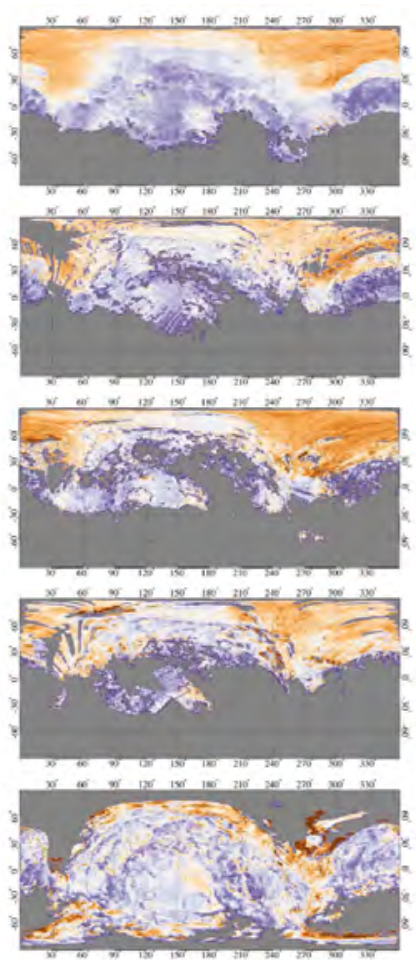

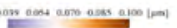
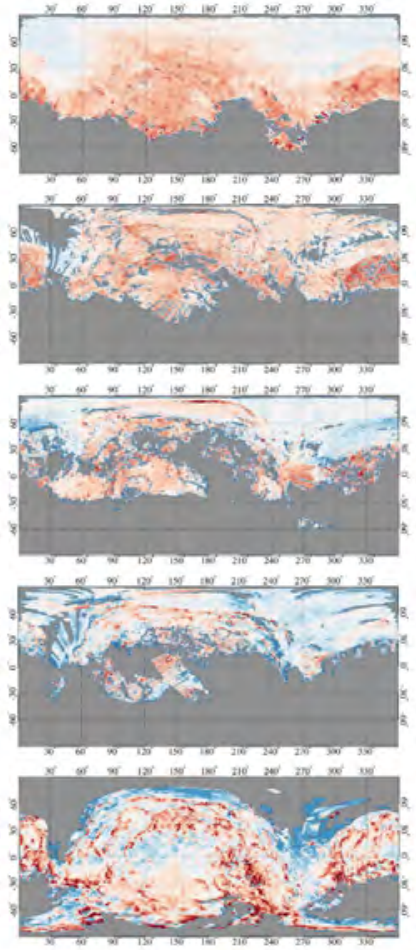

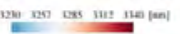

Fig. 19 Temporal evolution of $67 \mathrm{P} / \mathrm{CG}$ composition maps by VIRTIS. Left column: visible spectral slope. Center: $3.2 \mu \mathrm{m}$ band area. Right: $3.2 \mu \mathrm{m}$ band center. From top to bottom are shown maps built from data acquired during MTP006 period (2014 Aug 8-2014 Sept 2, $\mathrm{r}_{h}=3.62-3.44 \mathrm{AU}$ ), MTP007-MTP008 (2014 Sept 2-2014 Oct 24, $\mathrm{r}_{h}=3.44-3.12 \mathrm{AU}$ ) MTP009-MTP010 (2014 Oct 24-2014 Dec 19, $\mathrm{r}_{h}=3.11-2.75$ AU), MTP011-MTP012 (2014 Dec 19-2015 Feb 10, $\mathrm{r}_{h}=2.73-2.35$ AU) and MTP014-MTP015 (2015 Mar 10-2015 May 5, $\left.\mathrm{r}_{h}=2.13-1.72 \mathrm{AU}\right)$. For each MTP period the surface coverage changes according to VIRTIS observation schedule along the Rosetta's orbital phases. All data are photometrically corrected and mapped with a resolution of $0.5 \times 0.5^{\circ}$. Figure from Ciarniello et al. (2016).

of the volatile species, e.g. water and carbon dioxide, is more obvious than for the other materials: in gaseous phases they have been measured by mass spectrometers (Hässig et al. 2015), infrared spectrometer (Bockelée-Morvan et al. 2015; Fink et al. 2016) and microwave instruments (Biver et al. 2015; Lee et al. 2015); in solid phase at infrared wavelengths (de Sanctis et al. 2015; Filacchione et al. 2016a,b) with further evidence from the visible (Fornasier et al. 2016; Barucci et al. 2016; Oklay et al. 2017). The non-volatile fraction, which includes both mineral and organic materials, is much more difficult to characterize. While an infrared spectroscopic identification of the organic material (Capaccioni et al. 2015) present on the 67P/CG surface is still far from being fully achieved for the reasons previously described in Section 3, 
we can certainly assess that among the materials we have reviewed the most probable endmembers are included.

The nucleus particles consist of an assemblage of various organic components, minerals and water ice. The suggested organic compounds contain $\mathrm{COOH}$ and $\mathrm{OH}$-groups and a refractory macromolecular material bearing aliphatic $\left(\mathrm{CH}_{2}\right.$ and $\left.\mathrm{CH}_{3}\right)$ and polycyclic aromatic hydrocarbons which are the most plausible organic materials able to contribute to the reflectance spectra of $67 \mathrm{P} / \mathrm{CG}$ 's nucleus. The organic material appears mixed with minerals, including silicates, Fe-sulfides (pyrrhotite and/or troilite) and possibly ammoniated salt.

In the field of visible and infrared spectroscopy, the availability of optical constants measured on laboratory analogs is of the utmost importance. Spectral modeling efforts are in fact currently limited by the availability of these data which are known for only a relatively small number of the compounds that are likely to be present on the $67 \mathrm{P} / \mathrm{CG}$ 's nucleus surface. We must be aware that apart of composition also grain size distribution, mixing modalities among different endmembers and thermal evolution play fundamental roles in the interpretation of remotely-sensed data. Due to unexpected landing conditions of Philae, in-situ compositional studies could not be completed as planned. Therefore, a future sample return mission is strongly envisaged for the characterization of cometary nucleus composition.

Acknowledgements We gratefully thank the MIARD project team at ISSI, Bern, Switzerland led by Professor Nicolas Thomas from the University of Bern's Space Research and Planetology division who has invited us to write this review. G. F. M. C. and A. R. acknowledge financial support from ASI, Italian Space Agency. L. M. acknowledges the DFG (Deutsche Forschungsgemeinschaft) grant MO 3007/1-1. D. K. acknowledges DFG-grant KA $3757 / 2-1$

\section{References}

M.F. A'Hearn, M.J.S. Belton, A. Delamere, W.H. Blume, Deep Impact: A Large-Scale Active Experiment on a Cometary Nucleus. Space Science Reviews 117, 1-21 (2005a). doi:10.1007/s11214-005-3387-3

M.F. A'Hearn, M.J.S. Belton, W.A. Delamere, J. Kissel, K.P. Klaasen, L.A. McFadden, K.J. Meech, H.J. Melosh, P.H. Schultz, J.M. Sunshine, P.C. Thomas, J. Veverka, D.K. Yeomans, M.W. Baca, I. Busko, C.J. Crockett, S.M. Collins, M. Desnoyer, C.A. Eberhardy, C.M. Ernst, T.L. Farnham, L. Feaga, O. Groussin, D. Hampton, S.I. Ipatov, J.-Y. Li, D. Lindler, C.M. Lisse, N. Mastrodemos, W.M. Owen, J.E. Richardson, D.D. Wellnitz, R.L. White, Deep Impact: Excavating Comet Tempel 1. Science 310, 258-264 (2005b). doi:10.1126/science.1118923

M.F. A'Hearn, M.J.S. Belton, W.A. Delamere, L.M. Feaga, D. Hampton, J. Kissel, K.P. Klaasen, L.A. McFadden, K.J. Meech, H.J. Melosh, P.H. Schultz, J.M. Sunshine, P.C. Thomas, J. Veverka, D.D. Wellnitz, D.K. Yeomans, S. Besse, D. Bodewits, T.J. Bowling, B.T. Carcich, S.M. Collins, T.L. Farnham, O. Groussin, B. Hermalyn, M.S. Kelley, M.S. Kelley, J.-Y. Li, D.J. Lindler, C.M. Lisse, S.A. McLaughlin, F. Merlin, S. Protopapa, J.E. Richardson, J.L. Williams, EPOXI at Comet Hartley 2. Science 332, 1396 (2011). doi:10.1126/science.1204054 
K. Altwegg, H. Balsiger, J.J. Berthelier, A. Bieler, U. Calmonte, S.A. Fuselier, F. Goesmann, S. Gasc, T.I. Gombosi, L. Le Roy, J. de Keyser, A. Morse, M. Rubin, M. Schuhmann, M.G.G.T. Taylor, C.-Y. Tzou, I. Wright, Organics in comet 67P - a first comparative analysis of mass spectra from ROSINA-DFMS, COSAC and Ptolemy. Monthly Notices of the Royal Astronomical Society 469, 130-141 (2017). doi:10.1093/mnras/stx1415

A.-T. Auger, O. Groussin, L. Jorda, S. Bouley, R. Gaskell, P.L. Lamy, C. Capanna, N. Thomas, A. Pommerol, H. Sierks, C. Barbieri, R. Rodrigo, D. Koschny, H. Rickman, H.U. Keller, J. Agarwal, M.F. A'Hearn, M.A. Barucci, J.-L. Bertaux, I. Bertini, G. Cremonese, V. Da Deppo, B. Davidsson, S. Debei, M. De Cecco, M.R. El-Maarry, S. Fornasier, M. Fulle, P.J. Gutiérrez, C. Güttler, S. Hviid, W.-H. Ip, J. Knollenberg, J.R. Kramm, E. Kührt, M. Küppers, F. La Forgia, L.M. Lara, M. Lazzarin, J.J. Lopez Moreno, S. Marchi, F. Marzari, M. Massironi, H. Michalik, G. Naletto, N. Oklay, M. Pajola, L. Sabau, C. Tubiana, J.-B. Vincent, K.-P. Wenzel, Geomorphology of the Imhotep region on comet $67 \mathrm{P} /$ Churyumov-Gerasimenko from OSIRIS observations. Astron. Astrophys. 583, 35 (2015). doi:10.1051/0004-6361/201525947

H. Balsiger, K. Altwegg, P. Bochsler, P. Eberhardt, J. Fischer, S. Graf, A. Jäckel, E. Kopp, U. Langer, M. Mildner, J. Müller, T. Riesen, M. Rubin, S. Scherer, P. Wurz, S. Wüthrich, E. Arijs, S. Delanoye, J. de Keyser, E. Neefs, D. Nevejans, H. Rème, C. Aoustin, C. Mazelle, J.-L. Médale, J.A. Sauvaud, J.-J. Berthelier, J.-L. Bertaux, L. Duvet, J.-M. Illiano, S.A. Fuselier, A.G. Ghielmetti, T. Magoncelli, E.G. Shelley, A. Korth, K. Heerlein, H. Lauche, S. Livi, A. Loose, U. Mall, B. Wilken, F. Gliem, B. Fiethe, T.I. Gombosi, B. Block, G.R. Carignan, L.A. Fisk, J.H. Waite, D.T. Young, H. Wollnik, Rosina Rosetta Orbiter Spectrometer for Ion and Neutral Analysis. Space Science Reviews 128, 745-801 (2007). doi:10.1007/s11214-006-8335-3

A. Bardyn, D. Baklouti, H. Cottin, N. Fray, C. Briois, J. Paquette, O. Stenzel, C. Engrand, H. Fischer, K. Hornung, R. Isnard, Y. Langevin, H. Lehto, L. Le Roy, N. Ligier, S. Merouane, P. Modica, F.-R. Orthous-Daunay, J. Rynö, R. Schulz, J. Silén, L. Thirkell, K. Varmuza, B. Zaprudin, J. Kissel, M. Hilchenbach, Carbon-rich dust in comet $67 \mathrm{P} /$ Churyumov-Gerasimenko measured by COSIMA/Rosetta. Monthly Notices of the Royal Astronomical Society 469, 712-722 (2017). doi:10.1093/mnras/stx2640

M.A. Barucci, G. Filacchione, S. Fornasier, A. Raponi, J.D.P. Deshapriya, F. Tosi, C. Feller, M. Ciarniello, H. Sierks, F. Capaccioni, A. Pommerol, M. Massironi, N. Oklay, F. Merlin, J.-B. Vincent, M. Fulchignoni, A. Guilbert-Lepoutre, D. Perna, M.T. Capria, P.H. Hasselmann, B. Rousseau, C. Barbieri, D. Bockelée-Morvan, P.L. Lamy, C. De Sanctis, R. Rodrigo, S. Erard, D. Koschny, C. Leyrat, H. Rickman, P. Drossart, H.U. Keller, M.F. A'Hearn, G. Arnold, J.-L. Bertaux, I. Bertini, P. Cerroni, G. Cremonese, V. Da Deppo, B.J.R. Davidsson, M.R. El-Maarry, S. Fonti, M. Fulle, O. Groussin, C. Güttler, S.F. Hviid, W. Ip, L. Jorda, D. Kappel, J. Knollenberg, J.-R. Kramm, E. Kührt, M. Küppers, L. Lara, M. Lazzarin, J.J. Lopez Moreno, F. Mancarella, F. Marzari, S. Mottola, G. Naletto, M. Pajola, E. Palomba, E. Quirico, B. Schmitt, N. Thomas, C. Tubiana, Detection of exposed $\mathrm{H}_{2} \mathrm{O}$ ice on the nucleus of comet $67 \mathrm{P} /$ Churyumov-Gerasimenko. as observed by Rosetta OSIRIS and VIRTIS instruments. Astron. Astrophys. 595, 102 (2016). doi:10.1051/0004-6361/201628764

J. Benkhoff, Numerical Simulations of the Gas Flux at the surface of a 2060 Chiron, in Amer ican Astronomical Society Meeting Abstracts. Bulletin of the American Astronomical Society, vol. 27,1995 , p. 1338

M.S. Bentley, R. Schmied, T. Mannel, K. Torkar, H. Jeszenszky, J. Romstedt, A.-C. Levasseur-Regourd, I. Weber, E.K. Jessberger, P. Ehrenfreund, C. Koeberl, O. Havnes, Aggregate dust particles at comet $67 \mathrm{P} /$ Churyumov-Gerasimenko. Nature 537, 73-75 (2016). doi:10.1038/nature19091

J.-P. Bibring, H. Rosenbauer, H. Boehnhardt, S. Ulamec, J. Biele, S. Espinasse, B. Feuerbacher, P. Gaudon, P. Hemmerich, P. Kletzkine, D. Moura, R. Mugnuolo, G. Nietner, B. Pätz, R. Roll, H. Scheuerle, K. Szegö, K. Wittmann, The Rosetta Lander (Philae) Investigations. Space Science Reviews 128, 205-220 (2007). doi:10.1007/s11214-006-9138-2

J.-P. Bibring, Y. Langevin, J. Carter, P. Eng, B. Gondet, L. Jorda, S. Le Mouélic, S. Mottola, C. Pilorget, F. Poulet, M. Vincendon, 67P/Churyumov-Gerasimenko surface properties as derived from CIVA panoramic images. Science 349(2) (2015) doi:10.1126/science.aab0671 
J. Biele, S. Ulamec, M. Maibaum, R. Roll, L. Witte, E. Jurado, P. Muñoz, W. Arnold, H.-U. Auster, C. Casas, C. Faber, C. Fantinati, F. Finke, H.-H. Fischer, K. Geurts, C. Güttler, P. Heinisch, A. Herique, S. Hviid, G. Kargl, M. Knapmeyer, J. Knollenberg, W. Kofman, N. Kömle, E. Kührt, V. Lommatsch, S. Mottola, R. Pardo de Santayana, E. Remetean, F. Scholten, K.J. Seidensticker, H. Sierks, T. Spohn, The landing(s) of Philae and inferences about comet surface mechanical properties. Science 349(1) (2015). doi:10.1126/science.aaa9816

A. Bieler, K. Altwegg, H. Balsiger, J.-J. Berthelier, U. Calmonte, M. Combi, J. De Keyser, B. Fiethe, N. Fougere, S. Fuselier, S. Gasc, T. Gombosi, K. Hansen, M. Hässig, Z Huang, A. Jäckel, X. Jia, L. Le Roy, U.A. Mall, H. Rème, M. Rubin, V. Tenishev, G. Tóth, C.-Y. Tzou, P. Wurz, Comparison of 3D kinetic and hydrodynamic models to ROSINA-COPS measurements of the neutral coma of $67 \mathrm{P} /$ Churyumov-Gerasimenko. Astron. Astrophys. 583, 7 (2015). doi:10.1051/0004-6361/201526178

N. Biver, M. Hofstadter, S. Gulkis, D. Bockelée-Morvan, M. Choukroun, E. Lellouch, F.P. Schloerb, L. Rezac, W.H. Ip, C. Jarchow, P. Hartogh, S. Lee, P. von Allmen, J. Crovisier, C. Leyrat, P. Encrenaz, Distribution of water around the nucleus of comet 67P/Churyumov-Gerasimenko at 3.4 AU from the Sun as seen by the MIRO instrument on Rosetta. Astron. Astrophys. 583, 3 (2015). doi:10.1051/0004-6361/201526094

D. Bockelée-Morvan, N. Biver, The composition of cometary ices. Philosophical Transactions of the Royal Society of London Series A 375, 20160252 (2017). doi:10.1098/rsta.2016.0252

D. Bockelée-Morvan, T.Y. Brooke, J. Crovisier, On the origin of the 3.2 to 3.6-micron emission features in comets. Icarus 116, 18-39 (1995). doi:10.1006/icar.1995.1111

D. Bockelée-Morvan, V. Debout, S. Erard, C. Leyrat, F. Capaccioni, G. Filacchione, N. Fougere, P. Drossart, G. Arnold, M. Combi, B. Schmitt, J. Crovisier, M.-C. de Sanctis, T. Encrenaz, E. Kührt, E. Palomba, F.W. Taylor, F. Tosi, G. Piccioni, U. Fink, G. Tozzi, A. Barucci, N. Biver, M.-T. Capria, M. Combes, W. Ip, M. Blecka, F. Henry, S. Jacquinod, J.-M. Reess, A. Semery, D. Tiphene, First observations of $\mathrm{H}_{2} \mathrm{O}$ and $\mathrm{CO}_{2}$ vapor in comet 67P/Churyumov-Gerasimenko made by VIRTIS onboard Rosetta. Astron. Astrophys. 583, 6 (2015). doi:10.1051/0004-6361/201526303

D. Bockelée-Morvan, J. Crovisier, S. Erard, F. Capaccioni, C. Leyrat, G. Filacchione, P. Drossart, T. Encrenaz, N. Biver, M.-C. de Sanctis, B. Schmitt, E. Kührt, M.-T. Capria, M. Combes, M. Combi, N. Fougere, G. Arnold, U. Fink, W. Ip, A. Migliorini, G. Piccioni, G. Tozzi, Evolution of $\mathrm{CO}_{2}, \mathrm{CH}_{4}$, and OCS abundances relative to $\mathrm{H}_{2} \mathrm{O}$ in the coma of comet $67 \mathrm{P}$ around perihelion from Rosetta/VIRTIS-H observations. Monthly Notices of the Royal Astronomical Society 462, 170-183 (2016). doi:10.1093/mnras/stw2428

H. Boehnhardt, J.-P. Bibring, I. Apathy, H.U. Auster, A. Ercoli Finzi, F. Goesmann, G. Klingelhöfer, M. Knapmeyer, W. Kofman, H. Krüger, S. Mottola, W. Schmidt, K. Seidensticker, T. Spohn, I. Wright, The Philae lander mission and science overview. Philosophical Transactions of the Royal Society of London Series A 375, 20160248 (2017). doi:10.1098/rsta.2016.0248

J.-Y. Bonnet, E. Quirico, A. Buch, R. Thissen, C. Szopa, N. Carrasco, G. Cernogora, N. Fray, H. Cottin, L. Le Roy, G. Montagnac, E. Dartois, R. Brunetto, C. Engrand, J. Duprat, Formation of analogs of cometary nitrogen-rich refractory organics from thermal degradation of tholin and HCN polymer. Icarus 250, 53-63 (2015). doi:10.1016/j.icarus.2014.11.006

D.E. Brownlee, P. Tsou, J.D. Anderson, M.S. Hanner, R.L. Newburn, Z. Sekanina, B.C. Clark, F. Hörz, M.E. Zolensky, J. Kissel, J.A.M. McDonnell, S.A. Sandford, A.J. Tuzzolino, Stardust: Comet and interstellar dust sample return mission. Journal of Geophysical Research (Planets) 108, 8111 (2003). doi:10.1029/2003JE002087

B.J. Buratti, M.D. Hicks, L.A. Soderblom, D. Britt, J. Oberst, J.K. Hillier, Deep Space 1 photometry of the nucleus of Comet 19P/Borrelly. Icarus 167, 16-29 (2004). doi:10.1016/j.icarus.2003.05.002

F. Capaccioni, A. Coradini, G. Filacchione, S. Erard, G. Arnold, P. Drossart, M.C. De Sanctis, D. Bockelee-Morvan, M.T. Capria, F. Tosi, C. Leyrat, B. Schmitt, E. Quirico, P. Cerroni, V. Mennella, A. Raponi, M. Ciarniello, T. McCord, L. Moroz, E. Palomba, E. Ammannito, M.A. Barucci, G. Bellucci, J. Benkhoff, J.P. Bibring, A. Blanco, M. Blecka, R. Carlson, U. Carsenty, L. Colangeli, M. Combes, M. Combi, J. Crovisier, T. Encrenaz, 
C. Federico, U. Fink, S. Fonti, W.H. Ip, P. Irwin, R. Jaumann, E. Kuehrt, Y. Langevin, G. Magni, S. Mottola, V. Orofino, P. Palumbo, G. Piccioni, U. Schade, F. Taylor, D. Tiphene, G.P. Tozzi, P. Beck, N. Biver, L. Bonal, J.-P. Combe, D. Despan, E. Flamini, S. Fornasier, A. Frigeri, D. Grassi, M. Gudipati, A. Longobardo, K. Markus, F. Merlin, R. Orosei, G. Rinaldi, K. Stephan, M. Cartacci, A. Cicchetti, S. Giuppi, Y. Hello, F. Henry, S. Jacquinod, R. Noschese, G. Peter, R. Politi, J.M. Reess, A. Semery, The organic-rich surface of comet $67 \mathrm{P} /$ Churyumov-Gerasimenko as seen by VIRTIS/Rosetta. Science 347(1), 0628 (2015). doi:10.1126/science.aaa0628

M. Ciarniello, F. Capaccioni, G. Filacchione, A. Raponi, F. Tosi, M.C. De Sanctis, M.T. Capria, S. Erard, D. Bockelee-Morvan, C. Leyrat, G. Arnold, A. Barucci, P. Beck, G. Bellucci, S. Fornasier, A. Longobardo, S. Mottola, E. Palomba, E. Quirico, B. Schmitt, Photometric properties of comet $67 \mathrm{P} /$ Churyumov-Gerasimenko from VIRTIS-M onboard Rosetta. Astron. Astrophys. 583, 31 (2015). doi:10.1051/0004-6361/201526307

M. Ciarniello, A. Raponi, F. Capaccioni, G. Filacchione, F. Tosi, M.C. De Sanctis, D. Kappel, B. Rousseau, G. Arnold, M.T. Capria, M.A. Barucci, E. Quirico, A. Longobardo, E. Kuehrt, S. Mottola, S. Erard, D. Bockelée-Morvan, C. Leyrat, A. Migliorini, A. Zinzi, E. Palomba, B. Schmitt, G. Piccioni, P. Cerroni, W.-H. Ip, G. Rinaldi, M. Salatti, The global surface composition of $67 \mathrm{P} /$ Churyumov-Gerasimenko nucleus by Rosetta/VIRTIS. II) Diurnal and seasonal variability. Monthly Notices of the Royal Astronomical Society 462, 443-458 (2016). doi:10.1093/mnras/stw3177

B.C. Clark, L.W. Mason, J. Kissel, Systematics of the CHON and Other Light Element Particle Populations in Comet p/ Halley. Astron. Astrophys. 187, 779 (1987)

L. Colangeli, J.J. Lopez-Moreno, P. Palumbo, J. Rodriguez, M. Cosi, V. Della Corte, F. Esposito, M. Fulle, M. Herranz, J.M. Jeronimo, A. Lopez-Jimenez, E.M. Epifani, R. Morales, F. Moreno, E. Palomba, A. Rotundi, The Grain Impact Analyser and Dust Accumulator (GIADA) Experiment for the Rosetta Mission: Design, Performances and First Results. Space Science Reviews 128, 803-821 (2007). doi:10.1007/s11214-006-90385

A. Coradini, F. Capaccioni, P. Drossart, G. Arnold, E. Ammannito, F. Angrilli, A. Barucci, G. Bellucci, J. Benkhoff, G. Bianchini, J.P. Bibring, M. Blecka, D. Bockelee-Morvan, M.T. Capria, R. Carlson, U. Carsenty, P. Cerroni, L. Colangeli, M. Combes, M. Combi, J. Crovisier, M.C. De Sanctis, E.T. Encrenaz, S. Erard, C. Federico, G. Filacchione, U. Fink, S. Fonti, V. Formisano, W.H. Ip, R. Jaumann, E. Kuehrt, Y. Langevin, G. Magni, T. McCord, V. Mennella, S. Mottola, G. Neukum, P. Palumbo, G. Piccioni, H. Rauer, B. Saggin, B. Schmitt, D. Tiphene, G. Tozzi, Virtis: An Imaging Spectrometer for the Rosetta Mission. Space Science Reviews 128, 529-559 (2007). doi:10.1007/s11214-0069127-5

D.P. Cruikshank, C.M. Dalle Ore, R.N. Clark, Y.J. Pendleton, Aromatic and aliphatic organic materials on Iapetus: Analysis of Cassini VIMS data. Icarus 233, 306-315 (2014). doi:10.1016/j.icarus.2014.02.011

A.A. de Almeida, W.F. Huebner, J. Benkhoff, D.C. Boice, P.D. Singh, The Three Sources of Gas in the Comae of Comets, in Revista Mexicana de Astronomia y Astrofisica Conference Series, ed. by E. Falco, J.A. Fernandez, R.F. Ferrero Revista Mexicana de Astronomia y Astrofisica Conference Series, vol. 4, 1996, p. 110

C. de Bergh, B. Schmitt, L.V. Moroz, E. Quirico, D.P. Cruikshank, Laboratory Data on Ices, Refractory Carbonaceous Materials, and Minerals Relevant to Transneptunian Objects and Centaurs, ed. by M.A. Barucci, H. Boehnhardt, D.P. Cruikshank, A. Morbidelli, R. Dotson 2008, pp. 483-506

D. de Niem, E. Kührt, S. Hviid, B. Davidsson, Low velocity collisions of porous planetesimals in the early solar system. Icarus 301, 196-218 (2018). doi:10.1016/j.icarus.2017.09.024

M.C. de Sanctis, M.T. Capria, A. Coradini, Thermal evolution model of $67 \mathrm{P} /$ ChuryumovGerasimenko, the new Rosetta target. Astron. Astrophys. 444, 605-614 (2005). doi:10.1051/0004-6361:20053036

M.C. de Sanctis, F. Capaccioni, M. Ciarniello, G. Filacchione, M. Formisano, S. Mottola, A. Raponi, F. Tosi, D. Bockelée-Morvan, S. Erard, C. Leyrat, B. Schmitt, E. Ammannito, G. Arnold, M.A. Barucci, M. Combi, M.T. Capria, P. Cerroni, W.-H. Ip, E. Kuehrt, T.B. McCord, E. Palomba, P. Beck, E. Quirico, VIRTIS Team, G. Piccioni, G. Bellucci, M. Fulchignoni, R. Jaumann, K. Stephan, A. Longobardo, V. Mennella, A. Migliorini, J. 
Benkhoff, J.P. Bibring, A. Blanco, M. Blecka, R. Carlson, U. Carsenty, L. Colangeli, M. Combes, J. Crovisier, P. Drossart, T. Encrenaz, C. Federico, U. Fink, S. Fonti, P. Irwin, Y. Langevin, G. Magni, L. Moroz, V. Orofino, U. Schade, F. Taylor, D. Tiphene, G.P. Tozzi, N. Biver, L. Bonal, J.-P. Combe, D. Despan, E. Flamini, S. Fornasier, A. Frigeri, D. Grassi, M.S. Gudipati, F. Mancarella, K. Markus, F. Merlin, R. Orosei, G. Rinaldi, M. Cartacci, A. Cicchetti, S. Giuppi, Y. Hello, F. Henry, S. Jacquinod, J.M. Rees, R. Noschese, R. Politi, G. Peter, The diurnal cycle of water ice on comet $67 \mathrm{P} / \mathrm{Churyumov}$ Gerasimenko. Nature 525, 500-503 (2015). doi:10.1038/nature14869

M.C. De Sanctis, E. Ammannito, H.Y. McSween, A. Raponi, S. Marchi, F. Capaccioni, M.T. Capria, F.G. Carrozzo, M. Ciarniello, S. Fonte, M. Formisano, A. Frigeri, M. Giardino, A. Longobardo, G. Magni, L.A. McFadden, E. Palomba, C.M. Pieters, F. Tosi, F. Zambon, C.A. Raymond, C.T. Russell, Localized aliphatic organic material on the surface of Ceres. Science 355, 719-722 (2017). doi:10.1126/science.aaj2305

V. Della Corte, A. Rotundi, M. Fulle, E. Gruen, P. Weissman, R. Sordini, M. Ferrari, S. Ivanovski, F. Lucarelli, M. Accolla, V. Zakharov, E. Mazzotta Epifani, J.J. LopezMoreno, J. Rodriguez, L. Colangeli, P. Palumbo, E. Bussoletti, J.F. Crifo, F. Esposito, S.F. Green, P.L. Lamy, J.A.M. McDonnell, V. Mennella, A. Molina, R. Morales, F. Moreno, J.L. Ortiz, E. Palomba, J.M. Perrin, F.J.M. Rietmeijer, R. Rodrigo, J.C. Zarnecki, M. Cosi, F. Giovane, B. Gustafson, M.L. Herranz, J.M. Jeronimo, M.R. Leese, A.C. Lopez-Jimenez, N. Altobelli, GIADA: shining a light on the monitoring of the comet dust production from the nucleus of $67 \mathrm{P} /$ Churyumov-Gerasimenko. Astronomy and Astrophysics 583, 13 (2015). doi:10.1051/0004-6361/201526208

N. Dello Russo, R.J. Vervack, H.A. Weaver, N. Biver, D. Bockelée-Morvan, J. Crovisier, C.M. Lisse, Compositional homogeneity in the fragmented comet $73 \mathrm{P} /$ SchwassmannWachmann 3. Nature 448, 172-175 (2007). doi:10.1038/nature05908

A.H. Delsemme, The Cometary Connection with Prebiotic Chemistry. Origins of Life 14, 51-60 (1984). doi:10.1007/BF00933639

J.D.P. Deshapriya, M.A. Barucci, S. Fornasier, C. Feller, P.H. Hasselmann, H. Sierks, M.R. El-Maarry, M. Pajola, C. Barbieri, P.L. Lamy, R. Rodrigo, D. Koschny, H. Rickman, J. Agarwal, M.F. A'Hearn, J.-L. Bertaux, I. Bertini, S. Boudreault, G. Cremonese, V. Da Deppo, B.J.R. Davidsson, S. Debei, J. Deller, M. De Cecco, M. Fulle, A. Gicquel, O. Groussin, P.J. Gutierrez, C. Güttler, M. Hofmann, S.F. Hviid, W. Ip, L. Jorda, H.U. Keller, J. Knollenberg, R. Kramm, E. Kührt, M. Küppers, L. Lara, M. Lazzarin, J.J. Lopez Moreno, F. Marzari, S. Mottola, G. Naletto, N. Oklay, D. Perna, A. Pommerol, N. Thomas, C. Tubiana, J.-B. Vincent, Spectrophotometry of the Khonsu region on the comet $67 \mathrm{P} /$ Churyumov-Gerasimenko using OSIRIS instrument images. Monthly Notices of the Royal Astronomical Society 462, 274-286 (2016). doi:10.1093/mnras/stw2530

E. Dobrică, C. Engrand, H. Leroux, J.-N. Rouzaud, J. Duprat, Transmission Electron Microscopy of CONCORDIA UltraCarbonaceous Antarctic MicroMeteorites (UCAMMs): Mineralogical properties. Geochimica et Cosmochimica Acta 76, 68-82 (2012). doi:10.1016/j.gca.2011.10.025

E. Dobrică, A.J. Brearley, Crystalline Silicates in Comet 81P/Wild 2 from the Stardust Track 81. Meteoritics and Planetary Science Supplement 74, 5413 (2011)

E. Dobrică, C. Engrand, E. Quirico, G. Montagnac, J. Duprat, Raman characterization of carbonaceous matter in CONCORDIA Antarctic micrometeorites. Meteoritics and Planetary Science 46, 1363-1375 (2011). doi:10.1111/j.1945-5100.2011.01235.x

M.R. El-Maarry, N. Thomas, L. Giacomini, M. Massironi, M. Pajola, R. Marschall, A. Gracia-Berná, H. Sierks, C. Barbieri, P.L. Lamy, R. Rodrigo, H. Rickman, D. Koschny, H.U. Keller, J. Agarwal, M.F. A'Hearn, A.-T. Auger, M.A. Barucci, J.-L. Bertaux, I. Bertini, S. Besse, D. Bodewits, G. Cremonese, V. Da Deppo, B. Davidsson, M. De Cecco, S. Debei, C. Güttler, S. Fornasier, M. Fulle, O. Groussin, P.J. Gutierrez, S.F. Hviid, W.H. Ip, L. Jorda, J. Knollenberg, G. Kovacs, J.-R. Kramm, E. Kührt, M. Küppers, F. La Forgia, L.M. Lara, M. Lazzarin, J.J. Lopez Moreno, S. Marchi, F. Marzari, H. Michalik, G. Naletto, N. Oklay, A. Pommerol, F. Preusker, F. Scholten, C. Tubiana, J.-B. Vincent, Regional surface morphology of comet $67 \mathrm{p} /$ churyumov-gerasimenko from rosetta/osiris images. Astron. Astrophys. 583, 26 (2015). doi:10.1051/0004-6361/201525723

C. Engrand, J. Duprat, E. Dartois, K. Benzerara, H. Leroux, D. Baklouti, A. Bardyn, C. Briois, H. Cottin, H. Fischer, N. Fray, M. Godard, M. Hilchenbach, Y. Langevin, J. 
Paquette, J. Rynö, R. Schulz, J. Silén, O. Stenzel, L. Thirkell, Cosima Team, Variations in cometary dust composition from Giotto to Rosetta, clues to their formation mechanisms. Monthly Notices of the Royal Astronomical Society 462, 323-330 (2016). doi:10.1093/mnras/stw2844

S. Espinasse, J. Klinger, C. Ritz, B. Schmitt, Modeling of the thermal behavior and of the chemical differentiation of cometary nuclei. Icarus 92, 350-365 (1991). doi:10.1016/00191035(91)90058-2

L.M. Feaga, M.F. A'Hearn, J.M. Sunshine, O. Groussin, T.L. Farnham, Asymmetries in the distribution of $\mathrm{H}_{2} \mathrm{O}$ and $\mathrm{CO}_{2}$ in the inner coma of Comet $9 \mathrm{P} /$ Tempel 1 as observed by Deep Impact. Icarus 191, 134-145 (2007). doi:10.1016/j.icarus.2007.04.038

G. Filacchione, M. Ciarniello, F. Capaccioni, R.N. Clark, P.D. Nicholson, M.M. Hedman, J.N. Cuzzi, D.P. Cruikshank, C.M. Dalle Ore, R.H. Brown, P. Cerroni, N. Altobelli, L.J. Spilker, Cassini-VIMS observations of Saturn's main rings: I. Spectral properties and temperature radial profiles variability with phase angle and elevation. Icarus 241, 45-65 (2014). doi:10.1016/j.icarus.2014.06.001

G. Filacchione, M.C. de Sanctis, F. Capaccioni, A. Raponi, F. Tosi, M. Ciarniello, P. Cerroni, G. Piccioni, M.T. Capria, E. Palomba, G. Bellucci, S. Erard, D. Bockelee-Morvan, C. Leyrat, G. Arnold, M.A. Barucci, M. Fulchignoni, B. Schmitt, E. Quirico, R. Jaumann, K. Stephan, A. Longobardo, V. Mennella, A. Migliorini, E. Ammannito, J. Benkhoff, J.P. Bibring, A. Blanco, M.I. Blecka, R. Carlson, U. Carsenty, L. Colangeli, M. Combes, M. Combi, J. Crovisier, P. Drossart, T. Encrenaz, C. Federico, U. Fink, S. Fonti, W.H. Ip, P. Irwin, E. Kuehrt, Y. Langevin, G. Magni, T. McCord, L. Moroz, S. Mottola, V. Orofino, U. Schade, F. Taylor, D. Tiphene, G.P. Tozzi, P. Beck, N. Biver, L. Bonal, J.-P. Combe, D. Despan, E. Flamini, M. Formisano, S. Fornasier, A. Frigeri, D. Grassi, M.S. Gudipati, D. Kappel, F. Mancarella, K. Markus, F. Merlin, R. Orosei, G. Rinaldi, M. Cartacci, A. Cicchetti, S. Giuppi, Y. Hello, F. Henry, S. Jacquinod, J.M. Reess, R. Noschese, R. Politi, G. Peter, Exposed water ice on the nucleus of comet $67 \mathrm{P} /$ Churyumov-Gerasimenko. Nature 529, 368-372 (2016a). doi:10.1038/nature16190

G. Filacchione, A. Raponi, F. Capaccioni, M. Ciarniello, F. Tosi, M.T. Capria, M.C. De Sanctis, A. Migliorini, G. Piccioni, P. Cerroni, M.A. Barucci, S. Fornasier, B. Schmitt, E. Quirico, S. Erard, D. Bockelee-Morvan, C. Leyrat, G. Arnold, V. Mennella, E. Ammannito, G. Bellucci, J. Benkhoff, J.P. Bibring, A. Blanco, M.I. Blecka, R. Carlson, U. Carsenty, L. Colangeli, M. Combes, M. Combi, J. Crovisier, P. Drossart, T. Encrenaz, C. Federico, U. Fink, S. Fonti, M. Fulchignoni, W.-H. Ip, P. Irwin, R. Jaumann, E. Kuehrt, Y. Langevin, G. Magni, T. McCord, L. Moroz, S. Mottola, E. Palomba, U. Schade, K. Stephan, F. Taylor, D. Tiphene, G.P. Tozzi, P. Beck, N. Biver, L. Bonal, J.-P. Combe, D. Despan, E. Flamini, M. Formisano, A. Frigeri, D. Grassi, M.S. Gudipati, D. Kappel, A. Longobardo, F. Mancarella, K. Markus, F. Merlin, R. Orosei, G. Rinaldi, M. Cartacci, A. Cicchetti, Y. Hello, F. Henry, S. Jacquinod, J.M. Reess, R. Noschese, R. Politi, G. Peter, Seasonal exposure of carbon dioxide ice on the nucleus of comet $67 \mathrm{P} / \mathrm{Churyumov-}$ Gerasimenko. Science 354, 1563-1566 (2016b). doi:10.1126/science.aag3161

G. Filacchione, F. Capaccioni, M. Ciarniello, A. Raponi, F. Tosi, M.C. De Sanctis, S. Erard, D.B. Morvan, C. Leyrat, G. Arnold, B. Schmitt, E. Quirico, G. Piccioni, A. Migliorini, M.T. Capria, E. Palomba, P. Cerroni, A. Longobardo, A. Barucci, S. Fornasier, R.W. Carlson, R. Jaumann, K. Stephan, L.V. Moroz, D. Kappel, B. Rousseau, S. Fonti, F. Mancarella, D. Despan, M. Faure, The global surface composition of $67 \mathrm{P} / \mathrm{CG}$ nucleus by Rosetta/VIRTIS. (I) Prelanding mission phase. Icarus 274, 334-349 (2016c). doi:10.1016/j.icarus.2016.02.055

U. Fink, L. Doose, G. Rinaldi, A. Bieler, F. Capaccioni, D. Bockelée-Morvan, G. Filacchione, S. Erard, C. Leyrat, M. Blecka, M.T. Capria, M. Combi, J. Crovisier, M.C. De Sanctis, N. Fougere, F. Taylor, A. Migliorini, G. Piccioni, Investigation into the disparate origin of $\mathrm{CO}_{2}$ and $\mathrm{H}_{2} \mathrm{O}$ outgassing for Comet 67/P. Icarus 277, 78-97 (2016). doi:10.1016/j.icarus.2016.04.040

S. Fornasier, P.H. Hasselmann, M.A. Barucci, C. Feller, S. Besse, C. Leyrat, L. Lara, P.J. Gutierrez, N. Oklay, C. Tubiana, F. Scholten, H. Sierks, C. Barbieri, P.L. Lamy, R. Rodrigo, D. Koschny, H. Rickman, H.U. Keller, J. Agarwal, M.F. A'Hearn, J.-L. Bertaux, I. Bertini, G. Cremonese, V. Da Deppo, B. Davidsson, S. Debei, M. De Cecco, M. Fulle, O. Groussin, C. Güttler, S.F. Hviid, W. Ip, L. Jorda, J. Knollenberg, G. Ko- 
vacs, R. Kramm, E. Kührt, M. Küppers, F. La Forgia, M. Lazzarin, J.J. Lopez Moreno, F. Marzari, K.-D. Matz, H. Michalik, F. Moreno, S. Mottola, G. Naletto, M. Pajola, A. Pommerol, F. Preusker, X. Shi, C. Snodgrass, N. Thomas, J.-B. Vincent, Spectrophotometric properties of the nucleus of comet $67 \mathrm{P} /$ Churyumov-Gerasimenko from the OSIRIS instrument onboard the ROSETTA spacecraft. Astron. Astrophys. 583, 30 (2015). doi:10.1051/0004-6361/201525901

S. Fornasier, S. Mottola, H.U. Keller, M.A. Barucci, B. Davidsson, C. Feller, J.D.P. Deshapriya, H. Sierks, C. Barbieri, P.L. Lamy, R. Rodrigo, D. Koschny, H. Rickman, M. A'Hearn, J. Agarwal, J.-L. Bertaux, I. Bertini, S. Besse, G. Cremonese, V. Da Deppo, S. Debei, M. De Cecco, J. Deller, M.R. El-Maarry, M. Fulle, O. Groussin, P.J. Gutierrez, C. Güttler, M. Hofmann, S.F. Hviid, W.-H. Ip, L. Jorda, J. Knollenberg, G. Kovacs, R. Kramm, E. Kührt, M. Küppers, M.L. Lara, M. Lazzarin, J.J.L. Moreno, F. Marzari, M. Massironi, G. Naletto, N. Oklay, M. Pajola, A. Pommerol, F. Preusker, F. Scholten, X. Shi, N. Thomas, I. Toth, C. Tubiana, J.-B. Vincent, Rosetta's comet $67 \mathrm{p} /$ churyumovgerasimenko sheds its dusty mantle to reveal its icy nature. Science 354, 1566-1570 (2016). doi:10.1126/science.aag2671

N. Fougere, K. Altwegg, J.-J. Berthelier, A. Bieler, D. Bockelée-Morvan, U. Calmonte, F. Capaccioni, M.R. Combi, J. De Keyser, V. Debout, S. Erard, B. Fiethe, G. Filacchione, U. Fink, S.A. Fuselier, T.I. Gombosi, K.C. Hansen, M. Hässig, Z. Huang, L. Le Roy, C. Leyrat, A. Migliorini, G. Piccioni, G. Rinaldi, M. Rubin, Y. Shou, V. Tenishev, G. Toth, C.-Y. Tzou, Direct Simulation Monte Carlo modelling of the major species in the coma of comet $67 \mathrm{P} /$ Churyumov-Gerasimenko. Monthly Notices of the Royal Astronomical Society 462, 156-169 (2016). doi:10.1093/mnras/stw2388

N. Fray, B. Schmitt, Sublimation of ices of astrophysical interest: A bibliographic review. Planetary and Space Science 57, 2053-2080 (2009). doi:10.1016/j.pss.2009.09.011

M. Fulle, F. Marzari, V. Della Corte, S. Fornasier, H. Sierks, A. Rotundi, C. Barbieri, P.L. Lamy, R. Rodrigo, D. Koschny, H. Rickman, H.U. Keller, J.J. López-Moreno, M. Accolla, J. Agarwal, M.F. A’Hearn, N. Altobelli, M.A. Barucci, J.-L. Bertaux, I. Bertini, D. Bodewits, E. Bussoletti, L. Colangeli, M. Cosi, G. Cremonese, J.-F. Crifo, V. Da Deppo, B. Davidsson, S. Debei, M. De Cecco, F. Esposito, M. Ferrari, F. Giovane, B. Gustafson, S.F. Green, O. Groussin, E. Grün, P. Gutierrez, C. Güttler, M.L. Herranz, S.F. Hviid, W. Ip, S.L. Ivanovski, J.M. Jerónimo, L. Jorda, J. Knollenberg, R. Kramm, E. Kührt, M. Küppers, L. Lara, M. Lazzarin, M.R. Leese, A.C. López-Jiménez, F. Lucarelli, E. Mazzotta Epifani, J.A.M. McDonnell, V. Mennella, A. Molina, R. Morales, F. Moreno, S. Mottola, G. Naletto, N. Oklay, J.L. Ortiz, E. Palomba, P. Palumbo, J.-M. Perrin, F.J.M. Rietmeijer, J. Rodríguez, R. Sordini, N. Thomas, C. Tubiana, J.-B. Vincent, P. Weissman, K.-P. Wenzel, V. Zakharov, J.C. Zarnecki, Evolution of the Dust Size Distribution of Comet 67P/Churyumov-Gerasimenko from 2.2 au to Perihelion. Astrophysical Journal 821, 19 (2016a). doi:10.3847/0004-637X/821/1/19

M. Fulle, N. Altobelli, B. Buratti, M. Choukroun, M. Fulchignoni, E. Grün, M.G.G.T. Taylor, P. Weissman, Unexpected and significant findings in comet $67 \mathrm{P} /$ ChuryumovGerasimenko: an interdisciplinary view. Monthly Notices of the Royal Astronomical Society 462, 2-8 (2016b). doi:10.1093/mnras/stw1663

P.A. Gerakines, M.H. Moore, R.L. Hudson, Ultraviolet photolysis and proton irradiation of astrophysical ice analogs containing hydrogen cyanide. Icarus 170, 202-213 (2004). doi:10.1016/j.icarus.2004.02.005

K.-H. Glassmeier, H. Boehnhardt, D. Koschny, E. Kührt, I. Richter, The Rosetta Mission: Flying Towards the Origin of the Solar System. Space Science Reviews 128, 1-21 (2007). doi:10.1007/s11214-006-9140-8

F. Goesmann, H. Rosenbauer, R. Roll, C. Szopa, F. Raulin, R. Sternberg, G. Israel, U. Meierhenrich, W. Thiemann, G. Munoz-Caro, Cosac, The Cometary Sampling and Composition Experiment on Philae. Space Science Reviews 128, 257-280 (2007). doi:10.1007/s11214-006-9000-6

F. Goesmann, H. Rosenbauer, J.H. Bredehöft, M. Cabane, P. Ehrenfreund, T. Gautier, C. Giri, H. Krüger, L. Le Roy, A.J. MacDermott, S. McKenna-Lawlor, U.J. Meierhenrich, G.M.M. Caro, F. Raulin, R. Roll, A. Steele, H. Steininger, R. Sternberg, C. Szopa, W. Thiemann, S. Ulamec, Organic compounds on comet $67 \mathrm{P} /$ Churyumov-Gerasimenko revealed by COSAC mass spectrometry. Science $\mathbf{3 4 9}(2)$ 
(2015). doi:10.1126/science.aab0689

R. Gomes, H.F. Levison, K. Tsiganis, A. Morbidelli, Origin of the cataclysmic Late Heavy Bombardment period of the terrestrial planets. Nature 435, 466-469 (2005). doi:10.1038/nature03676

O. Groussin, L. Jorda, A.-T. Auger, E. Kührt, R. Gaskell, C. Capanna, F. Scholten, F. Preusker, P. Lamy, S. Hviid, J. Knollenberg, U. Keller, C. Huettig, H. Sierks, C. Barbieri, R. Rodrigo, D. Koschny, H. Rickman, M.F. A'Hearn, J. Agarwal, M.A. Barucci, J.-L. Bertaux, I. Bertini, S. Boudreault, G. Cremonese, V. Da Deppo, B. Davidsson, S. Debei, M. De Cecco, M.R. El-Maarry, S. Fornasier, M. Fulle, P.J. Gutiérrez, C. Güttler, W.-H. Ip, J.-R. Kramm, M. Küppers, M. Lazzarin, L.M. Lara, J.J. Lopez Moreno, S. Marchi, F. Marzari, M. Massironi, H. Michalik, G. Naletto, N. Oklay, A. Pommerol, M. Pajola, N. Thomas, I. Toth, C. Tubiana, J.-B. Vincent, Gravitational slopes, geomorphology, and material strengths of the nucleus of comet $67 \mathrm{P} /$ Churyumov-Gerasimenko from OSIRIS observations. Astron. Astrophys. 583, 32 (2015a). doi:10.1051/0004-6361/201526379

O. Groussin, H. Sierks, C. Barbieri, P. Lamy, R. Rodrigo, D. Koschny, H. Rickman, H.U. Keller, M.F. A'Hearn, A.-T. Auger, M.A. Barucci, J.-L. Bertaux, I. Bertini, S. Besse, G. Cremonese, V. Da Deppo, B. Davidsson, S. Debei, M. De Cecco, M.R. El-Maarry, S. Fornasier, M. Fulle, P.J. Gutiérrez, C. Güttler, S. Hviid, W.-H. Ip, L. Jorda, J. Knollenberg, G. Kovacs, J.R. Kramm, E. Kührt, M. Küppers, L.M. Lara, M. Lazzarin, J.J. Lopez Moreno, S. Lowry, S. Marchi, F. Marzari, M. Massironi, S. Mottola, G. Naletto, N. Oklay, M. Pajola, A. Pommerol, N. Thomas, I. Toth, C. Tubiana, J.-B. Vincent, Temporal morphological changes in the Imhotep region of comet $67 \mathrm{P} /$ Churyumov-Gerasimenko. Astron. Astrophys. 583, 36 (2015b). doi:10.1051/0004-6361/201527020

S. Gulkis, M. Frerking, J. Crovisier, G. Beaudin, P. Hartogh, P. Encrenaz, T. Koch, C. Kahn, Y. Salinas, R. Nowicki, R. Irigoyen, M. Janssen, P. Stek, M. Hofstadter, M. Allen, C. Backus, L. Kamp, C. Jarchow, E. Steinmetz, A. Deschamps, J. Krieg, M. Gheudin, D. Bockelée-Morvan, N. Biver, T. Encrenaz, D. Despois, W. Ip, E. Lellouch, I. Mann, D. Muhleman, H. Rauer, P. Schloerb, T. Spilker, MIRO: Microwave Instrument for Rosetta Orbiter. Space Science Reviews 128, 561-597 (2007). doi:10.1007/s11214-006-9032-y

B. Hapke, Theory of reflectance and emittance spectroscopy 1993

P.H. Hasselmann, M.A. Barucci, S. Fornasier, C. Feller, J.D.P. Deshapriya, M. Fulchignoni, B. Jost, H. Sierks, C. Barbieri, P.L. Lamy, R. Rodrigo, D. Koschny, H. Rickman, M. A'Hearn, J.-L. Bertaux, I. Bertini, G. Cremonese, V. Da Deppo, B. Davidsson, S. Debei, M. De Cecco, J. Deller, M. Fulle, R.W. Gaskell, O. Groussin, P.J. Gutierrez, C. Güttler, M. Hofmann, S.F. Hviid, W.-H. Ip, L. Jorda, H.U. Keller, J. Knollenberg, G. Kovacs, R. Kramm, E. Kührt, M. Küppers, M.L. Lara, M. Lazzarin, J.J. LopezMoreno, F. Marzari, S. Mottola, G. Naletto, N. Oklay, A. Pommerol, N. Thomas, C. Tubiana, J.-B. Vincent, The opposition effect of $67 \mathrm{P} /$ Churyumov-Gerasimenko on postperihelion Rosetta images. Monthly Notices of the Royal Astronomical Society 469 , 550-567 (2017). doi:10.1093/mnras/stx1834

M. Hässig, K. Altwegg, H. Balsiger, A. Bar-Nun, J.J. Berthelier, A. Bieler, P. Bochsler, C. Briois, U. Calmonte, M. Combi, J. De Keyser, P. Eberhardt, B. Fiethe, S.A. Fuselier, M. Galand, S. Gasc, T.I. Gombosi, K.C. Hansen, A. Jäckel, H.U. Keller, E. Kopp, A. Korth, E. Kührt, L. Le Roy, U. Mall, B. Marty, O. Mousis, E. Neefs, T. Owen, H. Rème, M. Rubin, T. Sémon, C. Tornow, C.-Y. Tzou, J.H. Waite, P. Wurz, Time variability and heterogeneity in the coma of 67P/Churyumov-Gerasimenko. Science 347(1), 0276 (2015). doi:10.1126/science.aaa0276

M. Hoang, K. Altwegg, H. Balsiger, A. Beth, A. Bieler, U. Calmonte, M.R. Combi, J. De Keyser, B. Fiethe, N. Fougere, S.A. Fuselier, A. Galli, P. Garnier, S. Gasc, T. Gombosi, K.C. Hansen, A. Jäckel, A. Korth, J. Lasue, L. Le Roy, U. Mall, H. Rème, M. Rubin, T. Sémon, D. Toublanc, C.-Y. Tzou, J.H. Waite, P. Wurz, The heterogeneous coma of comet $67 \mathrm{P} /$ Churyumov-Gerasimenko as seen by ROSINA: $\mathrm{H} 2 \mathrm{O}, \mathrm{CO} 2$, and $\mathrm{CO}$ from September 2014 to February 2016. Astron. Astrophys. 600, 77 (2017). doi:10.1051/0004$6361 / 201629900$

X. Hu, X. Shi, H. Sierks, M. Fulle, J. Blum, H.U. Keller, E. Kührt, B. Davidsson, C. Güttler, B. Gundlach, M. Pajola, D. Bodewits, J.-B. Vincent, N. Oklay, M. Massironi, S. Fornasier, C. Tubiana, O. Groussin, S. Boudreault, S. Höfner, S. Mottola C. Barbieri, P.L. Lamy, R. Rodrigo, D. Koschny, H. Rickman, M. A'Hearn, J. Agarwal, 
M.A. Barucci, J.-L. Bertaux, I. Bertini, G. Cremonese, V. Da Deppo, S. Debei, M. De Cecco, J. Deller, M.R. El-Maarry, A. Gicquel, P. Gutierrez-Marques, P.J. Gutiérrez, M. Hofmann, S.F. Hviid, W.-H. Ip, L. Jorda, J. Knollenberg, G. Kovacs, J.-R. Kramm, M. Küppers, L.M. Lara, M. Lazzarin, J.J. Lopez-Moreno, F. Marzari, G. Naletto, N. Thomas, Seasonal erosion and restoration of the dust cover on comet $67 \mathrm{P} / \mathrm{Churyumov-}$ Gerasimenko as observed by OSIRIS onboard Rosetta. Astron. Astrophys. 604, 114 (2017). doi:10.1051/0004-6361/201629910

W.F. Huebner, Origins of Cometary Materials. Space Science Reviews 138, 5-25 (2008). doi:10.1007/s11214-007-9299-7

W.F. Huebner, J. Benkhoff, From Coma Abundances to Nucleus Composition. Space Science Reviews 90, 117-130 (1999). doi:10.1023/A:1005289829692

W.F. Huebner, J. Benkhoff, M.-T. Capria, A. Coradini, C. De Sanctis, R. Orosei, D. Prialnik (eds.), Heat and Gas Diffusion in Comet Nuclei, in Heat and Gas Diffusion in Comet Nuclei, by Walter F. Huebner, Johannes Benkhoff, Maria-Theresa Capria, Angioletta Coradini, Christina De Sanctis, Roberto Orosei, and Dina Prialnik. SR-004, June, 2006. ISBN 1608-280X. Published for The International Space Science Institute, Bern, Switzerland, by ESA Publications Division, Noordwijk, The Netherlands, 2006. 2006

D.W. Hughes, The size, mass, mass loss and age of Halley's comet. Monthly Notices of the Royal Astronomical Society 213, 103-109 (1985). doi:10.1093/mnras/213.1.103

G.R. Hunt, J.W. Salisbury, C.J. Lenhoff, Visible and near-infrared spectra of minerals and rocks - iv. sulphides and sulphates. Modern Geology 3, 1-14 (1971)

L. Jorda, R. Gaskell, C. Capanna, S. Hviid, P. Lamy, J. Ďurech, G. Faury, O. Groussin, P. Gutiérrez, C. Jackman, S.J. Keihm, H.U. Keller, J. Knollenberg, E. Kührt, S. Marchi, S. Mottola, E. Palmer, F.P. Schloerb, H. Sierks, J.-B. Vincent, M.F. A'Hearn, C. Barbieri, R. Rodrigo, D. Koschny, H. Rickman, M.A. Barucci, J.L. Bertaux, I. Bertini, G. Cremonese, V. Da Deppo, B. Davidsson, S. Debei, M. De Cecco, S. Fornasier, M. Fulle, C. Güttler, W.-H. Ip, J.R. Kramm, M. Küppers, L.M. Lara, M. Lazzarin, J.J. Lopez Moreno, F. Marzari, G. Naletto, N. Oklay, N. Thomas, C. Tubiana, K.-P. Wenzel, The global shape, density and rotation of Comet 67P/ChuryumovGerasimenko from preperihelion Rosetta/OSIRIS observations. Icarus 277, 257-278 (2016). doi:10.1016/j.icarus.2016.05.002

B. Jost, A. Pommerol, O. Poch, Z. Yoldi, S. Fornasier, P.H. Hasselmann, C. Feller, N. Carrasco, C. Szopa, N. Thomas, Bidirectional reflectance and VIS-NIR spectroscopy of cometary analogues under simulated space conditions. Planetary and Space Science 145, 14-27 (2017a). doi:10.1016/j.pss.2017.07.009

B. Jost, A. Pommerol, O. Poch, Y. Brouet, S. Fornasier, N. Carrasco, C. Szopa, N. Thomas, Bidirectional reflectance of laboratory cometary analogues to interpret the spectrophotometric properties of the nucleus of comet $67 \mathrm{P} /$ Churyumov-Gerasimenko. Planetary and Space Science 148, 1-11 (2017b). doi:10.1016/j.pss.2017.09.009

H.U. Keller, The nucleus of Comet Halley, in Diversity and Similarity of Comets, ed. by E.J. Rolfe, B. Battrick ESA Special Publication, vol. 278, 1987

H.U. Keller, C. Barbieri, P. Lamy, H. Rickman, R. Rodrigo, K.-P. Wenzel, H. Sierks, M.F. A'Hearn, F. Angrilli, M. Angulo, M.E. Bailey, P. Barthol, M.A. Barucci, J.-L. Bertaux, G. Bianchini, J.-L. Boit, V. Brown, J.A. Burns, I. Büttner, J.M. Castro, G. Cremonese, W. Curdt, V. da Deppo, S. Debei, M. de Cecco, K. Dohlen, S. Fornasier, M. Fulle, D. Germerott, F. Gliem, G.P. Guizzo, S.F. Hviid, W.-H. Ip, L. Jorda, D. Koschny, J.R. Kramm, E. Kührt, M. Küppers, L.M. Lara, A. Llebaria, A. López, A. López-Jimenez, J. López-Moreno, R. Meller, H. Michalik, M.D. Michelena, R. Müller, G. Naletto, A. Origné, G. Parzianello, M. Pertile, C. Quintana, R. Ragazzoni, P. Ramous, K.-U. Reiche, M. Reina, J. Rodríguez, G. Rousset, L. Sabau, A. Sanz, J.-P. Sivan, K. Stöckner, J. Tabero, U. Telljohann, N. Thomas, V. Timon, G. Tomasch, T. Wittrock, M. Zaccariotto, OSIRIS The Scientific Camera System Onboard Rosetta. Space Science Reviews 128, 433-506 (2007). doi:10.1007/s11214-006-9128-4

H.U. Keller, S. Mottola, B. Davidsson, S.E. Schröder, Y. Skorov, E. Kührt, O. Groussin, M. Pajola, S.F. Hviid, F. Preusker, F. Scholten, M.F. A'Hearn, H. Sierks, C. Barbieri, P. Lamy, R. Rodrigo, D. Koschny, H. Rickman, M.A. Barucci, J.-L. Bertaux, I. Bertini, G. Cremonese, V. Da Deppo, S. Debei, M. De Cecco, S. Fornasier, M. Fulle, P.J. Gutiérrez, W.-H. Ip, L. Jorda, J. Knollenberg, J.R. Kramm, M. Küppers, L.M. Lara, M. Lazzarin, 
J.J. Lopez Moreno, F. Marzari, H. Michalik, G. Naletto, L. Sabau, N. Thomas, J.B. Vincent, K.-P. Wenzel, J. Agarwal, C. Güttler, N. Oklay, C. Tubiana, Insolation, erosion, and morphology of comet $67 \mathrm{P} /$ Churyumov-Gerasimenko. Astron. Astrophys. 583, 34 (2015). doi:10.1051/0004-6361/201525964

H.U. Keller, S. Mottola, S.F. Hviid, J. Agarwal, E. Kührt, Y. Skorov, K. Otto, J.-B. Vincent, N. Oklay, S.E. Schröder, B. Davidsson, M. Pajola, X. Shi, D. Bodewits, I. Toth, F. Preusker, F. Scholten, H. Sierks, C. Barbieri, P. Lamy, R. Rodrigo, D. Koschny, H. Rickman, M.F. A'Hearn, M.A. Barucci, J.-L. Bertaux, I. Bertini, G. Cremonese, V. Da Deppo, S. Debei, M. De Cecco, J. Deller, S. Fornasier, M. Fulle, O. Groussin, P.J. Gutiérrez, C. Güttler, M. Hofmann, W.-H. Ip, L. Jorda, J. Knollenberg, J.R. Kramm, M. Küppers, L.-M. Lara, M. Lazzarin, J.J. Lopez-Moreno, F. Marzari, G. Naletto, C. Tubiana, N. Thomas, Seasonal mass transfer on the nucleus of comet $67 \mathrm{P} /$ ChuyumovGerasimenko. Monthly Notices of the Royal Astronomical Society 469, 357-371 (2017). doi:10.1093/mnras/stx1726

L.P. Keller, S. Bajt, G.A. Baratta, J. Borg, J.P. Bradley, D.E. Brownlee, H. Busemann, J.R. Brucato, M. Burchell, L. Colangeli, L. D'Hendecourt, Z. Djouadi, G. Ferrini, G. Flynn, I.A. Franchi, M. Fries, M.M. Grady, G.A. Graham, F. Grossemy, A. Kearsley, G. Matrajt, K. Nakamura-Messenger, V. Mennella, L. Nittler, M.E. Palumbo, F.J. Stadermann, P. Tsou, A. Rotundi, S.A. Sandford, C. Snead, A. Steele, D. Wooden, M. Zolensky, Infrared Spectroscopy of Comet 81P/Wild 2 Samples Returned by Stardust. Science 314, 1728 (2006). doi:10.1126/science.1135796

J.F. Kerridge, Formation and Processing of Organics in the Early Solar System. Space Science Reviews 90, 275-288 (1999). doi:10.1023/A:1005222804192

B.N. Khare, C. Sagan, W.R. Thompson, E.T. Arakawa, C. Meisse, P.S. Tuminello, Optical properties of poly-HCN and their astronomical applications. Canadian Journal of Chemistry 72, 678-694 (1994)

J. Kissel, K. Altwegg, B.C. Clark, L. Colangeli, H. Cottin, S. Czempiel, J. Eibl, C. Engrand, H.M. Fehringer, B. Feuerbacher, M. Fomenkova, A. Glasmachers, J.M. Greenberg, E. Grün, G. Haerendel, H. Henkel, M. Hilchenbach, H. von Hoerner, H. Höfner, K. Hornung, E.K. Jessberger, A. Koch, H. Krüger, Y. Langevin, P. Parigger, F. Raulin, F. Rüdenauer, J. Rynö, E.R. Schmid, R. Schulz, J. Silén, W. Steiger, T. Stephan, L. Thirkell, R. Thomas, K. Torkar, N.G. Utterback, K. Varmuza, K.P. Wanczek, W. Werther, H. Zscheeg, Cosima High Resolution Time-of-Flight Secondary Ion Mass Spectrometer for the Analysis of Cometary Dust Particles onboard Rosetta. Space Science Reviews 128, 823-867 (2007). doi:10.1007/s11214-006-9083-0

V.M. Kolb, P.J. Liesch, Astrobiological relevance of phenols and their silicates, in Proceedings of the SPIE, Instruments, Methods, and Missions for Astrobiology XI, vol. 7097, 2008, p. 709706. doi:10.1117/12.792665

H. Krüger, F. Goesmann, C. Giri, I. Wright, A. Morse, J.H. Bredehöft, S. Ulamec, B. Cozzoni, P. Ehrenfreund, T. Gautier, S. McKenna-Lawlor, F. Raulin, H. Steininger, C. Szopa, Decay of COSAC and Ptolemy mass spectra at comet $67 \mathrm{P} /$ ChuryumovGerasimenko. Astron. Astrophys. 600, 56 (2017). doi:10.1051/0004-6361/201630286

S. Kwok, Enrichment of the solar system by organic compounds delivered from evolved stars. Advances in Space Research 40, 1613-1619 (2007). doi:10.1016/j.asr.2007.05.016

F. La Forgia, L. Giacomini, M. Lazzarin, M. Massironi, N. Oklay, F. Scholten, M. Pajola, I. Bertini, G. Cremonese, C. Barbieri, G. Naletto, E. Simioni, F. Preusker, N. Thomas, H. Sierks, P. Lamy, R. Rodrigo, D. Koschny, H. Rickman, H.U. Keller, J. Agarwal, A.-T. Auger, M.F. A'Hearn, M.A. Barucci, J.-L. Bertaux, S. Besse, D. Bodewits, V. Da Deppo, B. Davidsson, S. Debei, M. De Cecco, M.R. El-Maarry, F. Ferri, S. Fornasier, M. Fulle, O. Groussin, P.J. Gutiérrez, C. Güttler, I. Hall, S.F. Hviid, W.-H. Ip, L. Jorda, J. Knollenberg, J.R. Kramm, E. Kührt, M. Küppers, L.-M. Lara, J.J. Lopez Moreno, S. Magrin, F. Marzari, H. Michalik, S. Mottola, A. Pommerol, C. Tubiana, J.-B. Vincent, Geomorphology and spectrophotometry of Philae's landing site on comet 67P/Churyumov-Gerasimenko. Astron. Astrophys. 583, 41 (2015). doi:10.1051/0004$6361 / 201525983$

I.-L. Lai, W.-H. Ip, C.-C. Su, J.-S. Wu, J.-C. Lee, Z.-Y. Lin, Y. Liao, N. Thomas, H. Sierks, C. Barbieri, P. Lamy, R. Rodrigo, D. Koschny, H. Rickman, H.U. Keller, J. Agarwal, M.F. A'Hearn, M.A. Barucci, J.-L. Bertaux, I. Bertini, S. Boudreault, G. Cremonese, 
V. Da Deppo, B. Davidsson, S. Debei, M. De Cecco, J. Deller, S. Fornasier, M. Fulle, O. Groussin, P.J. Gutiérrez, C. Güttler, M. Hofmann, S.F. Hviid, L. Jorda, J. Knollenberg, G. Kovacs, J.-R. Kramm, E. Kührt, M. Küppers, L.M. Lara, M. Lazzarin, J.J. Lopez Moreno, F. Marzari, G. Naletto, N. Oklay, X. Shi, C. Tubiana, J.-B. Vincent, Gas outflow and dust transport of comet $67 \mathrm{P} /$ Churyumov-Gerasimenko. Monthly Notices of the Royal Astronomical Society 462, 533-546 (2016). doi:10.1093/mnras/stx332

P.L. Lamy, I. Toth, H.A. Weaver, L. Jorda, M. Kaasalainen, P.J. Gutiérrez, Hubble Space Telescope observations of the nucleus and inner coma of comet $67 \mathrm{P} /$ ChuryumovGerasimenko. Astron. Astrophys. 458, 669-678 (2006). doi:10.1051/0004-6361:20065253

Y. Langevin, M. Hilchenbach, N. Ligier, S. Merouane, K. Hornung, C. Engrand, R. Schulz, J. Kissel, J. Rynö, P. Eng, Typology of dust particles collected by the COSIMA mass spectrometer in the inner coma of 67P/Churyumov Gerasimenko. Icarus 271, 76-97 (2016). doi:10.1016/j.icarus.2016.01.027

L. Le Roy, K. Altwegg, H. Balsiger, J.-J. Berthelier, A. Bieler, C. Briois, U. Calmonte, M.R. Combi, J. De Keyser, F. Dhooghe, B. Fiethe, S.A. Fuselier, S. Gasc, T.I. Gombosi, M. Hässig, A. Jäckel, M. Rubin, C.-Y. Tzou, Inventory of the volatiles on comet 67P/Churyumov-Gerasimenko from Rosetta/ROSINA. Astron. Astrophys. 583 1 (2015). doi:10.1051/0004-6361/201526450

S. Lee, P. von Allmen, M. Allen, G. Beaudin, N. Biver, D. Bockelée-Morvan, M. Choukroun, J. Crovisier, P. Encrenaz, M. Frerking, S. Gulkis, P. Hartogh, M. Hofstadter, W.-H. Ip, M. Janssen, C. Jarchow, S. Keihm, E. Lellouch, C. Leyrat, L. Rezac, F.P. Schloerb, T. Spilker, B. Gaskell, L. Jorda, H.U. Keller, H. Sierks, Spatial and diurnal variation of water outgassing on comet $67 \mathrm{P} /$ Churyumov-Gerasimenko observed from Rosetta/MIRO in August 2014. Astron. Astrophys. 583, 5 (2015). doi:10.1051/0004-6361/201526155

H. Leroux, P. Cuvillier, B. Zanda, R.H. Hewins, GEMS-like material in the matrix of the Paris meteorite and the early stages of alteration of CM chondrites. Geochimica et Cosmochimica Acta 170, 247-265 (2015). doi:10.1016/j.gca.2015.09.019

J.-Y. Li, M.F. A'Hearn, M.J.S. Belton, C.J. Crockett, T.L. Farnham, C.M. Lisse, L.A. McFadden, K.J. Meech, J.M. Sunshine, P.C. Thomas, J. Veverka, Deep Impact photometry of Comet 9P/Tempel 1. Icarus 187, 41-55 (2007a). doi:10.1016/j.icarus.2006.09.018

J.-Y. Li, M.F. A'Hearn, L.A. McFadden, M.J.S. Belton, Photometric analysis and diskresolved thermal modeling of Comet 19P/Borrelly from Deep Space 1 data. Icarus 188, 195-211 (2007b). doi:10.1016/j.icarus.2006.11.015

J.-Y. Li, M.F. A'Hearn, T.L. Farnham, L.A. McFadden, Photometric analysis of the nucleus of Comet 81P/Wild 2 from Stardust images. Icarus 204, 209-226 (2009). doi:10.1016/j.icarus.2009.06.002

J.-Y. Li, S. Besse, M.F. A'Hearn, M.J.S. Belton, D. Bodewits, T.L. Farnham, K.P. Klaasen, C.M. Lisse, K.J. Meech, J.M. Sunshine, P.C. Thomas, Photometric properties of the nucleus of Comet 103P/Hartley 2. Icarus 222, 559-570 (2013). doi:10.1016/j.icarus.2012.11.001

A. Longobardo, E. Palomba, F. Capaccioni, M. Ciarniello, F. Tosi, S. Mottola, L.V. Moroz, G. Filacchione, A. Raponi, E. Quirico, A. Zinzi, M.T. Capria, D. Bockelee-Morvan, S. Erard, C. Leyrat, G. Rinaldi, F. Dirri, Photometric behaviour of $67 \mathrm{P} /$ ChuryumovGerasimenko and analysis of its pre-perihelion diurnal variations. Monthly Notices of the Royal Astronomical Society 469, 346-356 (2017). doi:10.1093/mnras/stx1803

S.C. Lowry, A. Fitzsimmons, S. Collander-Brown, CCD photometry of distant comets. III. Ensemble properties of Jupiter-family comets. Astron. Astrophys. 397, 329-343 (2003). doi:10.1051/0004-6361:20021486

A. Lucchetti, G. Cremonese, L. Jorda, F. Poulet, J.-P. Bibring, M. Pajola, F. La Forgia, M. Massironi, M.R. El-Maarry, N. Oklay, H. Sierks, C. Barbieri, P. Lamy, R. Rodrigo, D. Koschny, H. Rickman, H.U. Keller, J. Agarwal, M.F. A'Hearn, M.A. Barucci, J.-L. Bertaux, I. Bertini, V. Da Deppo, B. Davidsson, S. Debei, M. De Cecco, S. Fornasier, M. Fulle, O. Groussin, P.J. Gutierrez, C. Güttler, S.F. Hviid, W.-H. Ip, J. Knollenberg, J.-R. Kramm, E. Kührt, M. Küppers, L.M. Lara, M. Lazzarin, J.J. Lopez Moreno, F. Marzari, S. Mottola, G. Naletto, F. Preusker, F. Scholten, N. Thomas, C. Tubiana, J.-B. Vincent, Characterization of the Abydos region through OSIRIS high-resolution images in support of CIVA measurements. Astron. Astrophys. 585, 1 (2016). doi:10.1051/0004$6361 / 201527330$ 
A. Lucchetti, M. Pajola, S. Fornasier, S. Mottola, L. Penasa, L. Jorda, G. Cremonese, C. Feller, P.H. Hasselmann, M. Massironi, S. Ferrari, G. Naletto, N. Oklay, H. Sierks, C. Barbieri, P.L. Lamy, R. Rodrigo, D. Koschny, H. Rickman, H.U. Keller, J. Agarwal, M.F. A'Hearn, M.A. Barucci, J.L. Bertaux, I. Bertini, S. Boudreault, V. Da Deppo, B. Davidsson, S. Debei, M. De Cecco, J. Deller, M. Fulle, O. Groussin, P.J. Gutierrez, C. Güttler, M. Hoffman, S.F. Hviid, W.H. Ip, J. Knollenberg, J.R. Kramm, E. Kührt, M. Küppers, L.M. Lara, M. Lazzarin, F. La Forgia, L.Z. Lin, J.J. Lopez Moreno, F. Marzari, F. Preusker, F. Scholten, X. Shi, N. Thomas, C. Tubiana, J.B. Vincent, Geomorphological and spectrophotometric analysis of Seth's circular niches on comet 67P/Churyumov-Gerasimenko using OSIRIS images. Monthly Notices of the Royal Astronomical Society 469, 238-251 (2017). doi:10.1093/mnras/stx1590

A. Luspay-Kuti, M. Hässig, S.A. Fuselier, K.E. Mandt, K. Altwegg, H. Balsiger, S. Gasc, A. Jäckel, L. Le Roy, M. Rubin, C.-Y. Tzou, P. Wurz, O. Mousis, F. Dhooghe, J.J. Berthelier, B. Fiethe, T.I. Gombosi, U. Mall, Composition-dependent outgassing of comet 67P/Churyumov-Gerasimenko from ROSINA/DFMS. Implications for nucleus heterogeneity? Astron. Astrophys. 583, 4 (2015). doi:10.1051/0004-6361/201526205

A. Luspay-Kuti, O. Mousis, M. Hässig, S.A. Fuselier, J.I. Lunine, B. Marty, K.E. Mandt, P. Wurz, M. Rubin, The presence of clathrates in comet $67 \mathrm{P} /$ Churyumov-Gerasimenko. Science Advances 2, 1501781 (2016). doi:10.1126/sciadv.1501781

T. Mannel, M.S. Bentley, R. Schmied, H. Jeszenszky, A.C. Levasseur-Regourd, J. Romstedt, K. Torkar, Fractal cometary dust - a window into the early Solar system. Monthly Notices of the Royal Astronomical Society 462, 304-311 (2016). doi:10.1093/mnras/stw2898

U. Marboeuf, B. Schmitt, How to link the relative abundances of gas species in coma of comets to their initial chemical composition? Icarus 242, 225-248 (2014). doi:10.1016/j.icarus.2014.07.001

N. Masoumzadeh, N. Oklay, L. Kolokolova, H. Sierks, S. Fornasier, M.A. Barucci, J.-B. Vincent, C. Tubiana, C. Güttler, F. Preusker, F. Scholten, S. Mottola, P.H. Hasselmann, C. Feller, C. Barbieri, P.L. Lamy, R. Rodrigo, D. Koschny, H. Rickman, M.F. A'Hearn, J.-L. Bertaux, I. Bertini, G. Cremonese, V. Da Deppo, B.J.R. Davidsson, S. Debei, M. De Cecco, M. Fulle, A. Gicquel, O. Groussin, P.J. Gutiérrez, I. Hall, M. Hofmann, S.F. Hviid, W.-H. Ip, L. Jorda, H.U. Keller, J. Knollenberg, G. Kovacs, J.-R. Kramm, E. Kührt, M. Küppers, L.M. Lara, M. Lazzarin, J.J. Lopez Moreno, F. Marzari, G. Naletto, X. Shi, N. Thomas, Opposition effect on comet $67 \mathrm{P} /$ Churyumov-Gerasimenko using Rosetta-OSIRIS images. Astron. Astrophys. 599, 11 (2017). doi:10.1051/0004$6361 / 201629734$

J. Mayo Greenberg, C.X. Mendoza-Gómez, The seeding of life by comets. Advances in Space Research 12, 169-180 (1992). doi:10.1016/0273-1177(92)90170-3

D.S. McKay, J.L. Carter, W.W. Boles, C.C. Allen, J.H. Allton, JSC-1: A new lunar regolith simulant, in Lunar and Planetary Science Conference. Lunar and Planetary Inst. Technical Report, vol. 24, 1993

G. Moreels, J. Clairemidi, P. Hermine, P. Brechignac, P. Rousselot, Detection of a polycyclic aromatic molecule in comet P/Halley. Astron. Astrophys. 282, 643-656 (1994)

L.V. Moroz, G. Arnold, A.V. Korochantsev, R. Wäsch, Natural Solid Bitumens as Possible Analogs for Cometary and Asteroid Organics:. 1. Reflectance Spectroscopy of Pure Bitumens. Icarus 134, 253-268 (1998). doi:10.1006/icar.1998.5955

L.V. Moroz, K. Markus, G. Arnold, D. Henkel, D. Kappel, U. Schade, M. Ciarniello, B Rousseau, E. Quirico, B. Schmitt, F. Capaccioni, D. Bockelee-Morvan, G. Filacchione, S. Erard, C. Leyrat, A. Longobardo, Laboratory spectral reflectance studies aimed at providing clues to composition of refractory phases of comet 67P/CG's nucleus. European Planetary Science Congress 11, 2017-266 (2017)

S. Mottola, S. Lowry, C. Snodgrass, P.L. Lamy, I. Toth, A. Rożek, H. Sierks, M.F. A'Hearn F. Angrilli, C. Barbieri, M.A. Barucci, J.-L. Bertaux, G. Cremonese, V. Da Deppo, B. Davidsson, M. De Cecco, S. Debei, S. Fornasier, M. Fulle, O. Groussin, P. Gutiérrez, S.F. Hviid, W. Ip, L. Jorda, H.U. Keller, J. Knollenberg, D. Koschny, R. Kramm, E. Kührt, M. Küppers, L. Lara, M. Lazzarin, J.J. Lopez Moreno, F. Marzari, H. Michalik, G. Naletto, H. Rickman, R. Rodrigo, L. Sabau, N. Thomas, K.-P. Wenzel, J. Agarwal, I. Bertini, F. Ferri, C. Güttler, S. Magrin, N. Oklay, C. Tubiana, J.-B. Vincent, 
The rotation state of $67 \mathrm{P} /$ Churyumov-Gerasimenko from approach observations with the OSIRIS cameras on Rosetta. Astron. Astrophys. 569, 2 (2014). doi:10.1051/0004$6361 / 201424590$

S. Mottola, G. Arnold, H.-G. Grothues, R. Jaumann, H. Michaelis, G. Neukum, J.-P. Bibring, S.E. Schröder, M. Hamm, K.A. Otto, I. Pelivan, G. Proffe, F. Scholten, D. Tirsch, M. Kreslavsky, E. Remetean, F. Souvannavong, B. Dolives, The structure of the regolith on 67P/Churyumov-Gerasimenko from ROLIS descent imaging. Science 349(2) (2015). doi:10.1126/science.aab0232

O. Mousis, A. Guilbert-Lepoutre, B. Brugger, L. Jorda, J.S. Kargel, A. Bouquet, A.-T. Auger, P. Lamy, P. Vernazza, N. Thomas, H. Sierks, Pits Formation from Volatile Outgassing on 67P/Churyumov-Gerasimenko. Astrophysical Journal, Letters 814, 5 (2015). doi:10.1088/2041-8205/814/1/L5

G.M. Muñoz Caro, W.A. Schutte, UV-photoprocessing of interstellar ice analogs: New infrared spectroscopic results. Astron. Astrophys. 412, 121-132 (2003). doi:10.1051/00046361:20031408

M.J. Mumma, S.B. Charnley, The Chemical Composition of Comets - Emerging Taxonomies and Natal Heritage. Annu. Rev. Astro. Astrophys. 49, 471-524 (2011). doi:10.1146/annurev-astro-081309-130811

R.M. Nelson, M.D. Rayman, H.A. Weaver, The Deep Space 1 encounter with Comet 19P/Borrelly. Icarus 167, 1-3 (2004). doi:10.1016/j.icarus.2003.10.008

A. Oehler, G. Neukum, Visible and near IR albedo measurements of ice/dust mixtures. Geophys. Res. Lett. 18, 253-256 (1991). doi:10.1029/91GL00174

N. Oklay, J.M. Sunshine, M. Pajola, A. Pommerol, J.-B. Vincent, S. Mottola, H. Sierks, S. Fornasier, M.A. Barucci, F. Preusker, F. Scholten, L.M. Lara, C. Barbieri, P.L. Lamy, R. Rodrigo, D. Koschny, H. Rickman, M.F. A'Hearn, J.-L. Bertaux, I. Bertini, D. Bodewits, G. Cremonese, V. Da Deppo, B.J.R. Davidsson, S. Debei, M. De Cecco, J. Deller, M. Fulle, A. Gicquel, O. Groussin, P.J. Gutiérrez, C. Güttler, I. Hall, M. Hofmann, S.F. Hviid, W.-H. Ip, L. Jorda, H.U. Keller, J. Knollenberg, G. Kovacs, J.-R. Kramm, E. Kührt, M. Küppers, M. Lazzarin, Z.-Y. Lin, J.J. Lopez Moreno, F. Marzari, G. Naletto, X. Shi, N. Thomas, C. Tubiana, Comparative study of water ice exposures on cometary nuclei using multispectral imaging data. Monthly Notices of the Royal Astronomical Society 462, 394-414 (2016a). doi:10.1093/mnras/stw2918

N. Oklay, J.-B. Vincent, S. Fornasier, M. Pajola, S. Besse, B.J.R. Davidsson, L.M. Lara S. Mottola, G. Naletto, H. Sierks, A.M. Barucci, F. Scholten, F. Preusker, A. Pommerol, N. Masoumzadeh, M. Lazzarin, C. Barbieri, P.L. Lamy, R. Rodrigo, D. Koschny, H. Rickman, M.F. A'Hearn, J.-L. Bertaux, I. Bertini, D. Bodewits, G. Cremonese, V. Da Deppo, S. Debei, M. De Cecco, M. Fulle, O. Groussin, P.J. Gutiérrez, C. Güttler, I. Hall, M. Hofmann, S.F. Hviid, W.-H. Ip, L. Jorda, H.U. Keller, J. Knollenberg, G. Kovacs, J.-R. Kramm, E. Kührt, M. Küppers, Z.-Y. Lin, J.J. Lopez Moreno, F. Marzari, F. Moreno, X. Shi, N. Thomas, I. Toth, C. Tubiana, Variegation of comet 67P/Churyumov-Gerasimenko in regions showing activity. Astron. Astrophys. 586, 80 (2016b). doi:10.1051/0004-6361/201527369

N. Oklay, S. Mottola, J.-B. Vincent, M. Pajola, S. Fornasier, S.F. Hviid, D. Kappel, E. Kührt, H.U. Keller, M.A. Barucci, C. Feller, F. Preusker, F. Scholten, I. Hall, H. Sierks, C. Barbieri, P.L. Lamy, R. Rodrigo, D. Koschny, H. Rickman, M.F. A'Hearn, J.-L. Bertaux, I. Bertini, D. Bodewits, G. Cremonese, V. Da Deppo, B.J.R. Davidsson, S. Debei, M. De Cecco, J. Deller, J.D.P. Deshapriya, M. Fulle, A. Gicquel, O. Groussin, P.J. Gutiérrez, C. Güttler, P.H. Hasselmann, M. Hofmann, W.-H. Ip, L. Jorda, J. Knollenberg, G. Kovacs, J.-R. Kramm, M. Küppers, L.M. Lara, M. Lazzarin, Z.-Y. Lin, J.J.L. Moreno, A. Lucchetti, F. Marzari, N. Masoumzadeh, G. Naletto, A. Pommerol, X. Shi, N. Thomas, C. Tubiana, Long-term survival of surface water ice on comet $67 \mathrm{P}$. Monthly Notices of the Royal Astronomical Society 469, 582-597 (2017). doi:10.1093/mnras/stx2298

M. Pajola, S. Höfner, J.B. Vincent, N. Oklay, F. Scholten, F. Preusker, S. Mottola, G. Naletto, S. Fornasier, S. Lowry, C. Feller, P.H. Hasselmann, C. Güttler, C. Tubiana, H. Sierks, C. Barbieri, P. Lamy, R. Rodrigo, D. Koschny, H. Rickman, H.U. Keller, J. Agarwal, M.F. A'Hearn, M.A. Barucci, J.-L. Bertaux, I. Bertini, S. Besse, S. Boudreault, G. Cremonese, V. da Deppo, B. Davidsson, S. Debei, M. de Cecco, J. Deller, J.D.P. Deshapriya, M.R. El-Maarry, S. Ferrari, F. Ferri, M. Fulle, O. Groussin, P. Gutierrez, 
M. Hofmann, S.F. Hviid, W.-H. Ip, L. Jorda, J. Knollenberg, G. Kovacs, J.R. Kramm, E. Kührt, M. Küppers, L.M. Lara, Z.-Y. Lin, M. Lazzarin, A. Lucchetti, J.J. Lopez Moreno, F. Marzari, M. Massironi, H. Michalik, L. Penasa, A. Pommerol, E. Simioni, N. Thomas, I. Toth, E. Baratti, The pristine interior of comet $67 \mathrm{P}$ revealed by the combined Aswan outburst and cliff collapse. Nature Astronomy 1, 0092 (2017). doi:10.1038/s41550-0170092

R. Papoular, The use of kerogen data in understanding the properties and evolution of interstellar carbonaceous dust. Astron. Astrophys. 378, 597-607 (2001). doi:10.1051/00046361:20011224

Y.J. Pendleton, L.J. Allamandola, The Organic Refractory Material in the Diffuse Interstellar Medium: Mid-Infrared Spectroscopic Constraints. The Astrophysical Journal Supplement Series 138, 75-98 (2002). doi:10.1086/322999

D. Perna, M. Fulchignoni, M.A. Barucci, S. Fornasier, C. Feller, J.D.P. Deshapriya, P.H. Hasselmann, H. Sierks, C. Barbieri, P.L. Lamy, R. Rodrigo, D. Koschny, H. Rickman, M. A'Hearn, J.-L. Bertaux, I. Bertini, G. Cremonese, V. Da Deppo, B. Davidsson, S. Debei, J. Deller, M. De Cecco, M.R. El-Maarry, M. Fulle, O. Groussin, P.J. Gutierrez, C. Güttler, M. Hofmann, S.F. Hviid, W.-H. Ip, L. Jorda, H.U. Keller, J. Knollenberg, R. Kramm, E. Kührt, M. Küppers, L.M. Lara, M. Lazzarin, J.J. Lopez Moreno, F. Marzari, G. Naletto, N. Oklay, N. Thomas, C. Tubiana, J.-B. Vincent, Multivariate statistical analysis of OSIRIS/Rosetta spectrophotometric data of comet 67P/ChuryumovGerasimenko. Astron. Astrophys. 600, 115 (2017). doi:10.1051/0004-6361/201630015

S. Pizzarello, G.W. Cooper, G.J. Flynn, The Nature and Distribution of the Organic Material in Carbonaceous Chondrites and Interplanetary Dust Particles, ed. by D.S. Lauretta, H.Y. McSween 2006, pp. 625-651

O. Poch, A. Pommerol, B. Jost, N. Carrasco, C. Szopa, N. Thomas, Sublimation of icetholins mixtures: A morphological and spectro-photometric study. Icarus 266, 288-305 (2016a). doi:10.1016/j.icarus.2015.11.006

O. Poch, A. Pommerol, B. Jost, N. Carrasco, C. Szopa, N. Thomas, Sublimation of water ice mixed with silicates and tholins: Evolution of surface texture and reflectance spectra, with implications for comets. Icarus 267, 154-173 (2016b). doi:10.1016/j.icarus.2015.12.017

A. Pommerol, N. Thomas, M.R. El-Maarry, M. Pajola, O. Groussin, A.-T. Auger, N. Oklay, S. Fornasier, C. Feller, B. Davidsson, A. Gracia-Berná, B. Jost, R. Marschall, O. Poch, M.A. Barucci, J.-L. Bertaux, F. La Forgia, H.U. Keller, E. Kührt, S.C. Lowry, S. Mottola, G. Naletto, H. Sierks, C. Barbieri, P.L. Lamy, R. Rodrigo, D. Koschny, H. Rickman, J. Agarwal, M.F. A'Hearn, I. Bertini, S. Boudreault, G. Cremonese, V. Da Deppo, M. De Cecco, S. Debei, C. Güttler, M. Fulle, P.J. Gutierrez, S.F. Hviid, W.-H. Ip, L. Jorda, J. Knollenberg, G. Kovacs, J.-R. Kramm, E. Küppers, L. Lara, M. Lazzarin, J.L. Lopez Moreno, F. Marzari, H. Michalik, F. Preusker, F. Scholten, C. Tubiana, J.-B. Vincent, OSIRIS observations of meter-sized exposures of $\mathrm{H}_{2} \mathrm{O}$ ice at the surface of $67 \mathrm{P} /$ Churyumov-Gerasimenko and interpretation using laboratory experiments. Astron. Astrophys. 583, 25 (2015). doi:10.1051/0004-6361/201525977

F. Preusker, F. Scholten, K.-D. Matz, T. Roatsch, K. Willner, S.F. Hviid, J. Knollenberg, L. Jorda, P.J. Gutiérrez, E. Kührt, S. Mottola, M.F. A'Hearn, N. Thomas, H. Sierks, C. Barbieri, P. Lamy, R. Rodrigo, D. Koschny, H. Rickman, H.U. Keller, J. Agarwal, M.A. Barucci, J.-L. Bertaux, I. Bertini, G. Cremonese, V. Da Deppo, B. Davidsson, S. Debei, M. De Cecco, S. Fornasier, M. Fulle, O. Groussin, C. Güttler, W.-H. Ip, J.R. Kramm, M. Küppers, L.M. Lara, M. Lazzarin, J.J. Lopez Moreno, F. Marzari, H. Michalik, G. Naletto, N. Oklay, C. Tubiana, J.-B. Vincent, Shape model, reference system definition, and cartographic mapping standards for comet $67 \mathrm{P} /$ Churyumov-Gerasimenko - Stereophotogrammetric analysis of Rosetta/OSIRIS image data. Astron. Astrophys. 583, 33 (2015). doi:10.1051/0004-6361/201526349

D. Prialnik, M.F. A'Hearn, K.J. Meech, A mechanism for short-lived cometary outbursts at sunrise as observed by Deep Impact on 9P/Tempel 1. Monthly Notices of the Royal Astronomical Society 388, 20-23 (2008). doi:10.1111/j.1745-3933.2008.00491.x

E. Quirico, G. Montagnac, V. Lees, P.F. McMillan, C. Szopa, G. Cernogora, J.-N. Rouzaud, P. Simon, J.-M. Bernard, P. Coll, N. Fray, R.D. Minard, F. Raulin, B. Reynard, B. Schmitt, New experimental constraints on the composition and structure of tholins. 
Icarus 198, 218-231 (2008). doi:10.1016/j.icarus.2008.07.012

E. Quirico, L.V. Moroz, B. Schmitt, G. Arnold, M. Faure, P. Beck, L. Bonal, M. Ciarniello, F. Capaccioni, G. Filacchione, S. Erard, C. Leyrat, D. Bockelée-Morvan, A. Zinzi, E. Palomba, P. Drossart, F. Tosi, M.T. Capria, M.C. De Sanctis, A. Raponi, S. Fonti, F. Mancarella, V. Orofino, A. Barucci, M.I. Blecka, R. Carlson, D. Despan, A. Faure, S. Fornasier, M.S. Gudipati, A. Longobardo, K. Markus, V. Mennella, F. Merlin, G. Piccioni, B. Rousseau, F. Taylor, Refractory and semi-volatile organics at the surface of comet 67P/Churyumov-Gerasimenko: Insights from the VIRTIS/Rosetta imaging spectrometer. Icarus 272, 32-47 (2016). doi:10.1016/j.icarus.2016.02.028

A. Raponi, M. Ciarniello, F. Capaccioni, G. Filacchione, F. Tosi, M.C. De Sanctis, M.T. Capria, M.A. Barucci, A. Longobardo, E. Palomba, D. Kappel, G. Arnold, S. Mottola, B. Rousseau, E. Quirico, G. Rinaldi, S. Erard, D. Bockelee-Morvan, C. Leyrat, The temporal evolution of exposed water ice-rich areas on the surface of $67 \mathrm{P} /$ ChuryumovGerasimenko: spectral analysis. Monthly Notices of the Royal Astronomical Society 462, 476-490 (2016). doi:10.1093/mnras/stw3281

A. Raponi, M. Ciarniello, G. Filacchione, F. Capaccioni, M.C. De Sanctis, L.V. Moroz, V. Vinogradoff, F. Tosi, G. Arnold, E. Quirico, V. Mennella, P. Beck, C. Pilorget, A. Pommerol, S. Schroder, D. Kappel, I. Istiqomah, B. Rousseau, O. Poch, Organic features on the spectrum of 67P Churyumov-Gerasimenko from the improved calibration of VIRTIS-M-IR, in European Planetary Science Congress 2018, 16-21 September 2018, vol. EPSC2018-865, 2018

R. Reinhard, The Giotto mission to Halley's comet. Advances in Space Research 2, 97-107 (1982). doi:10.1016/0273-1177(82)90293-9

W. Riedler, K. Torkar, H. Jeszenszky, J. Romstedt, H.S.C. Alleyne, H. Arends, W. Barth, J.V.D. Biezen, B. Butler, P. Ehrenfreund, M. Fehringer, G. Fremuth, J. Gavira, O. Havnes, E.K. Jessberger, R. Kassing, W. Klöck, C. Koeberl, A.C. Levasseur-Regourd, M. Maurette, F. Rüdenauer, R. Schmidt, G. Stangl, M. Steller, I. Weber, MIDAS The Micro-Imaging Dust Analysis System for the Rosetta Mission. Space Science Reviews 128, 869-904 (2007). doi:10.1007/s11214-006-9040-y

A. Rotundi, H. Sierks, V. Della Corte, M. Fulle, P.J. Gutierrez, L. Lara, C. Barbieri, P.L. Lamy, R. Rodrigo, D. Koschny, H. Rickman, H.U. Keller, J.J. López-Moreno, M. Accolla, J. Agarwal, M.F. A'Hearn, N. Altobelli, F. Angrilli, M.A. Barucci, J.-L. Bertaux, I. Bertini, D. Bodewits, E. Bussoletti, L. Colangeli, M. Cosi, G. Cremonese, J.-F. Crifo, V. Da Deppo, B. Davidsson, S. Debei, M. De Cecco, F. Esposito, M. Ferrari, S. Fornasier, F. Giovane, B. Gustafson, S.F. Green, O. Groussin, E. Grün, C. Güttler, M.L. Herranz, S.F. Hviid, W. Ip, S. Ivanovski, J.M. Jerónimo, L. Jorda, J. Knollenberg, R. Kramm, E. Kührt, M. Küppers, M. Lazzarin, M.R. Leese, A.C. López-Jiménez, F. Lucarelli, S.C. Lowry, F. Marzari, E.M. Epifani, J.A.M. McDonnell, V. Mennella, H. Michalik, A. Molina, R. Morales, F. Moreno, S. Mottola, G. Naletto, N. Oklay, J.L. Ortiz, E. Palomba, P. Palumbo, J.-M. Perrin, J. Rodríguez, L. Sabau, C. Snodgrass, R. Sordini, N. Thomas, C. Tubiana, J.-B. Vincent, P. Weissman, K.-P. Wenzel, V. Zakharov, J.C. Zarnecki, Dust measurements in the coma of comet $67 \mathrm{P} /$ Churyumov-Gerasimenko inbound to the Sun. Science 347(1), 3905 (2015). doi:10.1126/science.aaa3905

B. Rousseau, S. Érard, P. Beck, É. Quirico, B. Schmitt, O. Brissaud, G. Montes-Hernandez, F. Capaccioni, G. Filacchione, D. Bockelée-Morvan, C. Leyrat, M. Ciarniello, A. Raponi, D. Kappel, G. Arnold, L.V. Moroz, E. Palomba, F. Tosi, Laboratory simulations of the Vis-NIR spectra of comet $67 \mathrm{P}$ using sub- $\mu \mathrm{m}$ sized cosmochemical analogues. Icarus $\mathbf{3 0 6}$, 306-318 (2018)

M. Rubin, N. Fougere, K. Altwegg, M.R. Combi, L. Le Roy, V.M. Tenishev, N. Thomas, Mass Transport around Comets and its Impact on the Seasonal Differences in Water Production Rates. Astrophys. J. 788, 168 (2014). doi:10.1088/0004-637X/788/2/168

M. Rubin, K. Altwegg, H. Balsiger, A. Bar-Nun, J.-J. Berthelier, A. Bieler, P. Bochsler, C. Briois, U. Calmonte, M. Combi, J. De Keyser, F. Dhooghe, P. Eberhardt, B. Fiethe, S.A. Fuselier, S. Gasc, T.I. Gombosi, K.C. Hansen, M. Hässig, A. Jäckel, E. Kopp, A. Korth, L. Le Roy, U. Mall, B. Marty, O. Mousis, T. Owen, H. Rème, T. Sémon, C.-Y. Tzou, J.H. Waite, P. Wurz, Molecular nitrogen in comet $67 \mathrm{P} /$ Churyumov-Gerasimenko indicates a low formation temperature. Science 348, 232-235 (2015). doi:10.1126/science.aaa6100 
C. Sagan, B.N. Khare, Tholins - Organic chemistry of interstellar grains and gas. Nature 277, 102-107 (1979). doi:10.1038/277102a0

R.Z. Sagdeev, G.A. Avanesov, Y.L. Ziman, V.I. Moroz, V.I. Tarnopolsky, B.S. Zhukov, V.A. Shamis, B. Smith, I. Toth, TV experiment of the Vega mission: Photometry of the nucleus and the inner coma, in ESA Proceedings of the 20th ESLAB Symposium on the Exploration of Halley's Comet. Volume 2: Dust and Nucleus p 317-326 (SEE N87-25908 19-90), vol. 2, 1986

S.E. Schröder, Y. Grynko, A. Pommerol, H.U. Keller, N. Thomas, T.L. Roush, Laboratory observations and simulations of phase reddening. Icarus 239, 201-216 (2014). doi:10.1016/j.icarus.2014.06.010

M.A. Sephton, I.P. Wright, I. Gilmour, J.W. de Leeuw, M.M. Grady, C.T. Pillinger, High molecular weight organic matter in martian meteorites. Planetary and Space Science 50, 711-716 (2002). doi:10.1016/S0032-0633(02)00053-3

H. Sierks, C. Barbieri, P.L. Lamy, R. Rodrigo, D. Koschny, H. Rickman, H.U. Keller, J. Agarwal, M.F. A'Hearn, F. Angrilli, A.-T. Auger, M.A. Barucci, J.-L. Bertaux, I. Bertini, S. Besse, D. Bodewits, C. Capanna, G. Cremonese, V. Da Deppo, B. Davidsson, S. Debei, M. De Cecco, F. Ferri, S. Fornasier, M. Fulle, R. Gaskell, L. Giacomini, O. Groussin, P. Gutierrez-Marques, P.J. Gutiérrez, C. Güttler, N. Hoekzema, S.F. Hviid, W.-H. Ip, L. Jorda, J. Knollenberg, G. Kovacs, J.R. Kramm, E. Kührt, M. Küppers, F. La Forgia, L.M. Lara, M. Lazzarin, C. Leyrat, J.J. Lopez Moreno, S. Magrin, S. Marchi, F. Marzari, M. Massironi, H. Michalik, R. Moissl, S. Mottola, G. Naletto, N. Oklay, M. Pajola, M. Pertile, F. Preusker, L. Sabau, F. Scholten, C. Snodgrass, N. Thomas, C. Tubiana, J.-B. Vincent, K.-P. Wenzel, M. Zaccariotto, M. Pätzold, On the nucleus structure and activity of comet 67P/Churyumov-Gerasimenko. Science 347(1), 1044 (2015). doi:10.1126/science.aaa1044

Y. Skorov, J. Blum, Dust release and tensile strength of the non-volatile layer of cometary nuclei. Icarus 221, 1-11 (2012). doi:10.1016/j.icarus.2012.01.012

G. Socrates, Infrared and Raman Characteristic Group Frequencies - Tables and Charts (John Wiley and Sons, LTD, 2001)

L.A. Soderblom, T.L. Becker, G. Bennett, D.C. Boice, D.T. Britt, R.H. Brown, B.J. Buratti, C. Isbell, B. Giese, T. Hare, M.D. Hicks, E. Howington-Kraus, R.L. Kirk, M. Lee, R.M. Nelson, J. Oberst, T.C. Owen, M.D. Rayman, B.R. Sandel, S.A. Stern, N. Thomas, R.V. Yelle, Observations of Comet 19P/Borrelly by the Miniature Integrated Camera and Spectrometer Aboard Deep Space 1. Science 296, 1087-1091 (2002). doi:10.1126/science.1069527

S.A. Stern, D.C. Slater, J. Scherrer, J. Stone, M. Versteeg, M.F. A'Hearn, J.L. Bertaux, P.D. Feldman, M.C. Festou, J.W. Parker, O.H.W. Siegmund, Alice: The rosetta Ultraviolet Imaging Spectrograph. Space Science Reviews 128, 507-527 (2007). doi:10.1007/s11214006-9035-8

J.M. Sunshine, M.F. A'Hearn, O. Groussin, J.-Y. Li, M.J.S. Belton, W.A. Delamere, J. Kissel, K.P. Klaasen, L.A. McFadden, K.J. Meech, H.J. Melosh, P.H. Schultz, P.C. Thomas, J. Veverka, D.K. Yeomans, I.C. Busko, M. Desnoyer, T.L. Farnham, L.M. Feaga, D.L. Hampton, D.J. Lindler, C.M. Lisse, D.D. Wellnitz, Exposed Water Ice Deposits on the Surface of Comet 9P/Tempel 1. Science 311, 1453-1455 (2006). doi:10.1126/science. 1123632

M.G.G.T. Taylor, N. Altobelli, B.J. Buratti, M. Choukroun, The Rosetta mission orbiter science overview: the comet phase. Philosophical Transactions of the Royal Society of London Series A 375, 20160262 (2017). doi:10.1098/rsta.2016.0262

N. Thomas, H.U. Keller, The colour of Comet P/Halley's nucleus and dust. Astron. Astrophys. 213, 487-494 (1989)

N. Thomas, H. Sierks, C. Barbieri, P.L. Lamy, R. Rodrigo, H. Rickman, D. Koschny, H.U. Keller, J. Agarwal, M.F. A'Hearn, F. Angrilli, A.-T. Auger, M.A. Barucci, J.-L. Bertaux, I. Bertini, S. Besse, D. Bodewits, G. Cremonese, V. Da Deppo, B. Davidsson, M. De Cecco, S. Debei, M.R. El-Maarry, F. Ferri, S. Fornasier, M. Fulle, L. Giacomini, O. Groussin, P.J. Gutierrez, C. Güttler, S.F. Hviid, W.-H. Ip, L. Jorda, J. Knollenberg, J.-R. Kramm, E. Kührt, M. Küppers, F. La Forgia, L.M. Lara, M. Lazzarin, J.J.L. Moreno, S. Magrin, S. Marchi, F. Marzari, M. Massironi, H. Michalik, R. Moissl, S. Mottola, G. Naletto, N. Oklay, M. Pajola, A. Pommerol, F. Preusker, 
L. Sabau, F. Scholten, C. Snodgrass, C. Tubiana, J.-B. Vincent, K.-P. Wenzel, The morphological diversity of comet $67 \mathrm{P} /$ Churyumov-Gerasimenko. Science 347(1), 0440 (2015). doi:10.1126/science.aaa0440

C. Tubiana, H. Böhnhardt, J. Agarwal, M. Drahus, L. Barrera, J.L. Ortiz, 67P/ChuryumovGerasimenko at large heliocentric distance. Astron. Astrophys. 527, 113 (2011). doi:10.1051/0004-6361/201016027

J.-B. Vincent, D. Bodewits, S. Besse, H. Sierks, C. Barbieri, P. Lamy, R. Rodrigo, D. Koschny, H. Rickman, H.U. Keller, J. Agarwal, M.F. A'Hearn, A.-T. Auger, M.A. Barucci, J.-L. Bertaux, I. Bertini, C. Capanna, G. Cremonese, V. da Deppo, B. Davidsson, S. Debei, M. de Cecco, M.R. El-Maarry, F. Ferri, S. Fornasier, M. Fulle, R. Gaskell, L. Giacomini, O. Groussin, A. Guilbert-Lepoutre, P. Gutierrez-Marques, P.J. Gutiérrez, C. Güttler, N. Hoekzema, S. Höfner, S.F. Hviid, W.-H. Ip, L. Jorda, J. Knollenberg, G. Kovacs, R. Kramm, E. Kührt, M. Küppers, F. La Forgia, L.M. Lara, M. Lazzarin, V. Lee, C. Leyrat, Z.-Y. Lin, J.J. Lopez Moreno, S. Lowry, S. Magrin, L. Maquet, S. Marchi, F. Marzari, M. Massironi, H. Michalik, R. Moissl, S. Mottola, G. Naletto, N. Oklay, M. Pajola, F. Preusker, F. Scholten, N. Thomas, I. Toth, C. Tubiana, Large heterogeneities in comet $67 \mathrm{P}$ as revealed by active pits from sinkhole collapse. Nature 523, 63-66 (2015). doi:10.1038/nature14564

J.-B. Vincent, N. Oklay, M. Pajola, S. Höfner, H. Sierks, X. Hu, C. Barbieri, P.L. Lamy, R. Rodrigo, D. Koschny, H. Rickman, H.U. Keller, M.F. A'Hearn, M.A. Barucci, J.-L. Bertaux, I. Bertini, S. Besse, D. Bodewits, G. Cremonese, V. Da Deppo, B. Davidsson, S. Debei, M. De Cecco, M.R. El-Maarry, S. Fornasier, M. Fulle, O. Groussin, P.J. Gutiérrez, P. Gutiérrez-Marquez, C. Güttler, M. Hofmann, S.F. Hviid, W.-H. Ip, L. Jorda, J. Knollenberg, G. Kovacs, J.-R. Kramm, E. Kührt, M. Küppers, L.M. Lara, M. Lazzarin, Z.-Y. Lin, J.J. Lopez Moreno, S. Lowry, F. Marzari, M. Massironi, F. Moreno, S. Mottola, G. Naletto, F. Preusker, F. Scholten, X. Shi, N. Thomas, I. Toth, C. Tubiana, Are fractured cliffs the source of cometary dust jets? Insights from OSIRIS/Rosetta at 67P/Churyumov-Gerasimenko. Astron. Astrophys. 587, 14 (2016a). doi:10.1051/0004$6361 / 201527159$

J.-B. Vincent, M.F. A'Hearn, Z.-Y. Lin, M.R. El-Maarry, M. Pajola, H. Sierks, C. Barbieri, P.L. Lamy, R. Rodrigo, D. Koschny, H. Rickman, H.U. Keller, J. Agarwal, M.A. Barucci, J.-L. Bertaux, I. Bertini, S. Besse, D. Bodewits, G. Cremonese, V. Da Deppo, B. Davidsson, S. Debei, M. De Cecco, J. Deller, S. Fornasier, M. Fulle, A. Gicquel, O. Groussin, P.J. Gutiérrez, P. Gutiérrez-Marquez, C. Güttler, S. Höfner, M. Hofmann, S.F. Hviid, W.-H. Ip, L. Jorda, J. Knollenberg, G. Kovacs, J.-R. Kramm, E. Kührt, M. Küppers, L.M. Lara, M. Lazzarin, J.J. Lopez Moreno, F. Marzari, M. Massironi, S. Mottola, G. Naletto, N. Oklay, F. Preusker, F. Scholten, X. Shi, N. Thomas, I. Toth, C. Tubiana, Summer fireworks on comet 67P. Monthly Notices of the Royal Astronomical Society 462, 184-194 (2016b). doi:10.1093/mnras/stw2409

F.L. Whipple, A comet model. I. The acceleration of Comet Encke. Astrophys. J. 111, 375-394 (1950). doi:10.1086/145272

D.H. Wooden, S.B. Charnley, P. Ehrenfreund, Composition and evolution of interstellar clouds, ed. by G.W. Kronk 2004, pp. 33-66

I.P. Wright, S.J. Barber, G.H. Morgan, A.D. Morse, S. Sheridan, D.J. Andrews, J. Maynard, D. Yau, S.T. Evans, M.R. Leese, J.C. Zarnecki, B.J. Kent, N.R. Waltham, M.S. Whalley, S. Heys, D.L. Drummond, R.L. Edeson, E.C. Sawyer, R.F. Turner, C.T Pillinger, Ptolemy an Instrument to Measure Stable Isotopic Ratios of Key Volatiles on a Cometary Nucleus. Space Science Reviews 128, 363-381 (2007). doi:10.1007/s11214006-9001-5

I.P. Wright, S. Sheridan, S.J. Barber, G.H. Morgan, D.J. Andrews, A.D. Morse, CHObearing organic compounds at the surface of $67 \mathrm{P} / \mathrm{Churyumov}-$ Gerasimenko revealed by Ptolemy. Science 349(2) (2015). doi:10.1126/science.aab0673

I.P. Wright, S. Sheridan, G.H. Morgan, S.J. Barber, A.D. Morse, On the attempts to measure water (and other volatiles) directly at the surface of a comet. Philosophical Transactions of the Royal Society of London Series A 375, 20150385 (2017). doi:10.1098/rsta.2015.0385

Z. Yoldi, A. Pommerol, B. Jost, O. Poch, J. Gouman, N. Thomas, VIS-NIR reflectance of water ice/regolith analogue mixtures and implications for the detectability of 
ice mixed within planetary regoliths. Geophys. Res. Lett. 42, 6205-6212 (2015) doi:10.1002/2015GL064780 